\title{
Measuring Neptunium Concentration Using Optical Spectrometry for the Plutonium-238 Supply Program
}

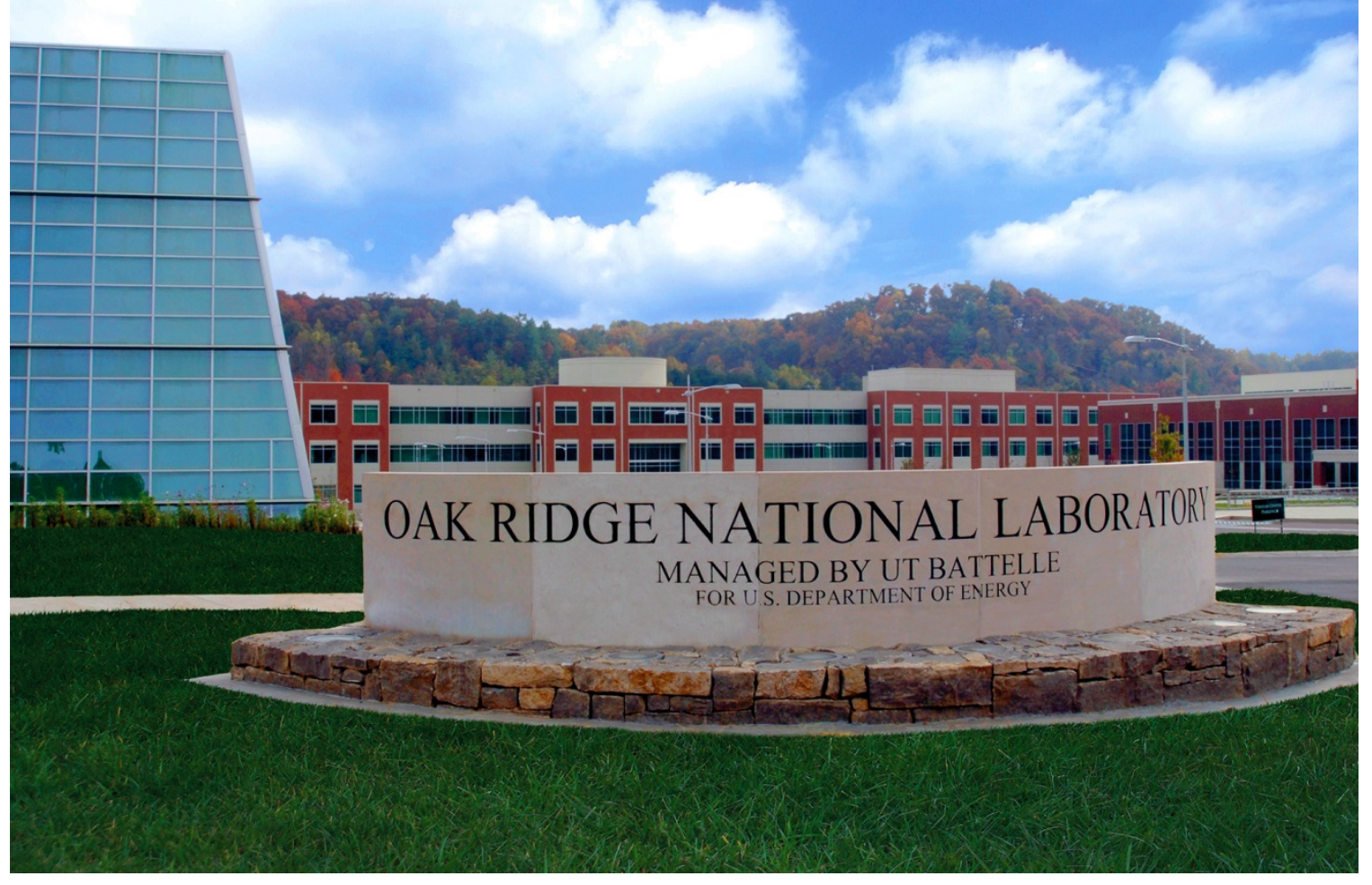

Luke R. Sadergaski

Kaara K. Patton

Gretchen K. Toney

David W. DePaoli

Lætitia H. Delmau

September 2021 


\title{
DOCUMENT AVAILABILITY
}

Reports produced after January 1, 1996, are generally available free via US Department of Energy (DOE) SciTech Connect.

Website www.osti.gov

Reports produced before January 1, 1996, may be purchased by members of the public from the following source:

\author{
National Technical Information Service \\ 5285 Port Royal Road \\ Springfield, VA 22161 \\ Telephone 703-605-6000 (1-800-553-6847) \\ TDD 703-487-4639 \\ Fax 703-605-6900 \\ E-mail info@ntis.gov \\ Website http://classic.ntis.gov/
}

Reports are available to DOE employees, DOE contractors, Energy Technology Data Exchange representatives, and International Nuclear Information System representatives from the following source:

Office of Scientific and Technical Information

PO Box 62

Oak Ridge, TN 37831

Telephone 865-576-8401

Fax 865-576-5728

E-mail reports@osti.gov

Website http://www.osti.gov/

This report was prepared as an account of work sponsored by an agency of the United States Government. Neither the United States Government nor any agency thereof, nor any of their employees, makes any warranty, express or implied, or assumes any legal liability or responsibility for the accuracy, completeness, or usefulness of any information, apparatus, product, or process disclosed, or represents that its use would not infringe privately owned rights. Reference herein to any specific commercial product, process, or service by trade name, trademark, manufacturer, or otherwise, does not necessarily constitute or imply its endorsement, recommendation, or favoring by the United States Government or any agency thereof. The views and opinions of authors expressed herein do not necessarily state or reflect those of the United States Government or any agency thereof. 
Radioisotope Science and Technology Division

\title{
MEASURING NEPTUNIUM CONCENTRATION USING OPTICAL SPECTROMETRY FOR THE PLUTONIUM-238 SUPPLY PROGRAM
}

\author{
Luke R. Sadergaski \\ Kaara K. Patton \\ Gretchen K. Toney \\ David W. DePaoli \\ Lætitia H. Delmau
}

September 2021

Prepared by

OAK RIDGE NATIONAL LABORATORY

Oak Ridge, TN 37831-6283

managed by

UT-BATTELLE, LLC

for the

US DEPARTMENT OF ENERGY

under contract DE-AC05-00OR22725 



\section{CONTENTS}

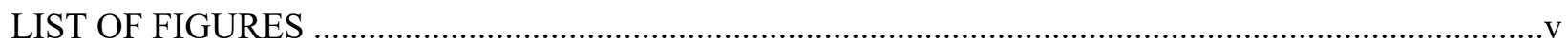

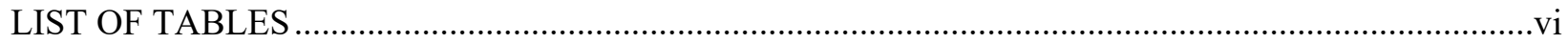

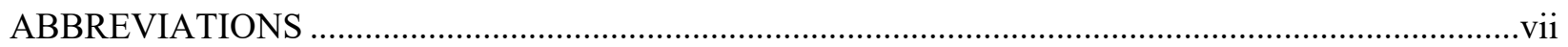

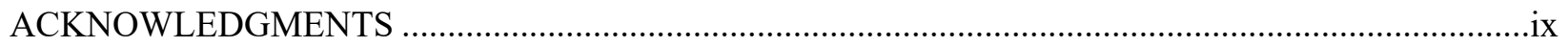

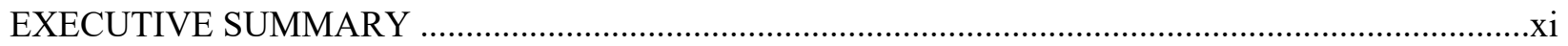

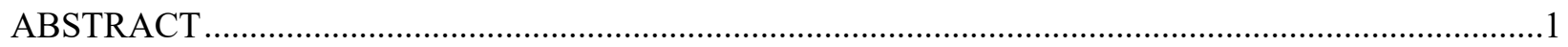

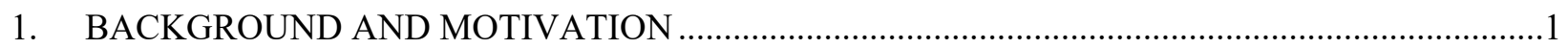

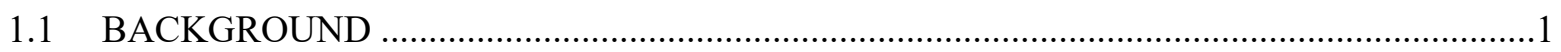

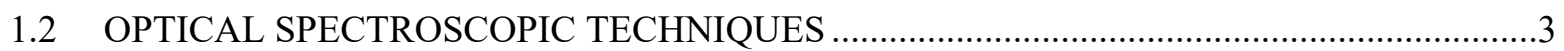

2. NEPTUNIUM RAMAN SPECTROSCOPY DEVELOPMENT …...........................................

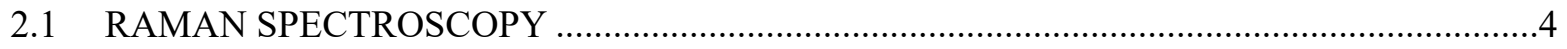

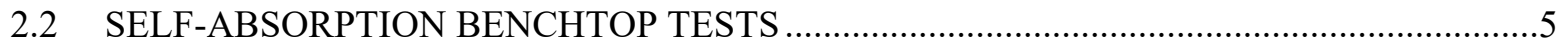

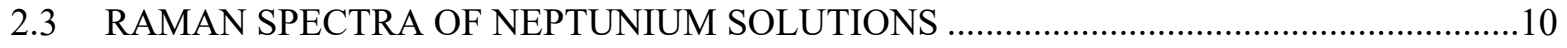

3. NEPTUNIUM SPECTROPHOTOMETRY DEVELOPMENT …..................................................13

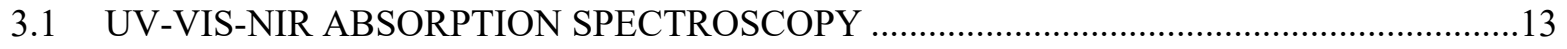

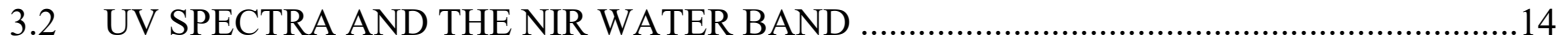

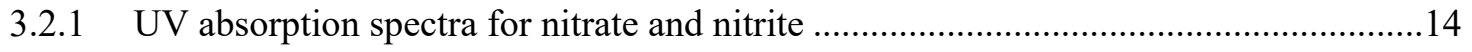

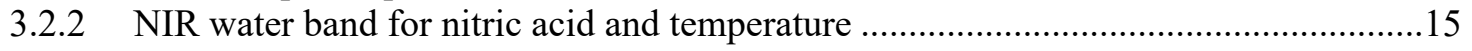

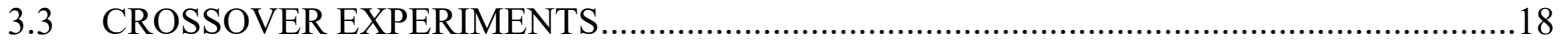

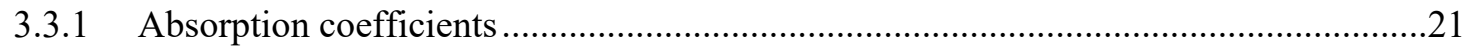

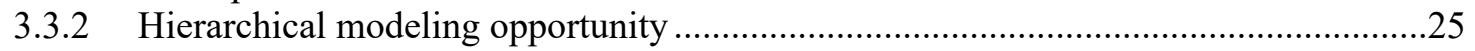

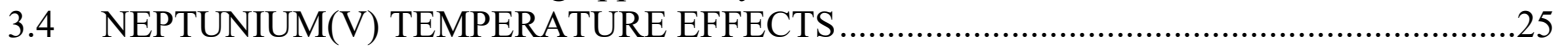

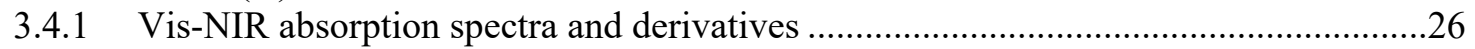

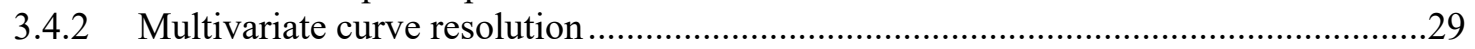

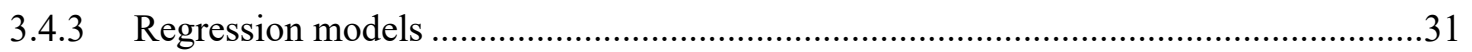

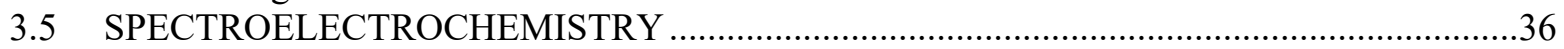

4. CHARACTERIZING NC PRODUCT BOTTLES USING SPECTROPHOTOMETRY ...................39

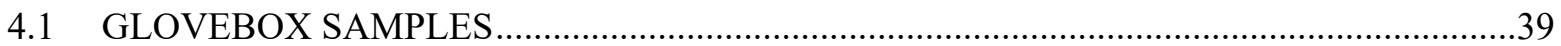

4.2 NEPTUNIUM(V) SPECTRA AND COMPARISONS TO ANALYTICAL RESULTS .........40

4.3 MIXED NP(V/VI) SPECTRA AND COMPARISONS TO ANALYTICAL AND

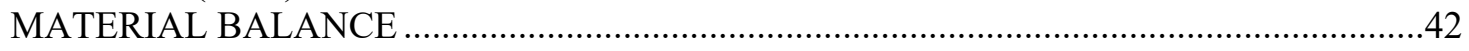

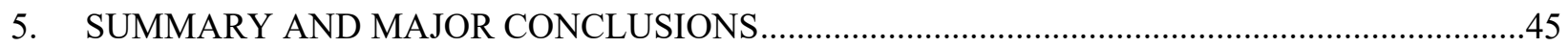

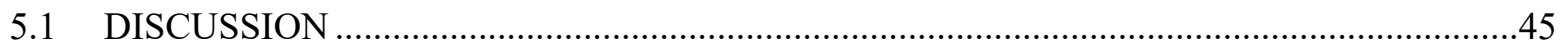

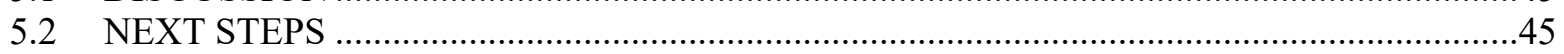

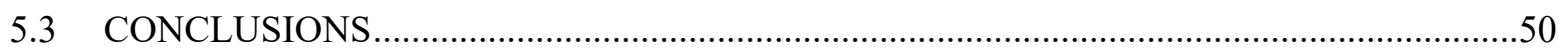

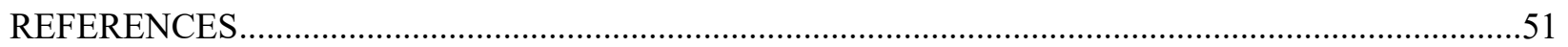





\section{LIST OF FIGURES}

Figure 2.1. Generalized Raman scattering measurements of an aqueous solution in a cuvette...................4

Figure 2.2. General-purpose Raman probe made by Spectra Solutions Inc. ...........................................6

Figure 2.3. Overlay of the absorbance spectrum of $0.25 \mathrm{M} \mathrm{Co(II)} \mathrm{nitrate} \mathrm{and} 1 \mathrm{M} \operatorname{Pr}(\mathrm{III})$ nitrate in

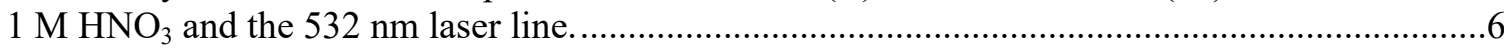

Figure 2.4. Raman spectrum of $1 \mathrm{M} \mathrm{HNO}_{3}$ and 0.05 to $1 \mathrm{M} \mathrm{Pr}\left(\mathrm{NO}_{3}\right)_{3}$ (top) and the nitrate peak

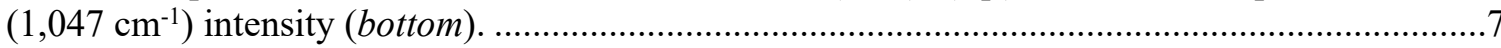

Figure 2.5. Overlay of the absorbance spectrum of $1 \mathrm{M} \mathrm{Pr}\left(\mathrm{NO}_{3}\right)_{3}$ in $1 \mathrm{M} \mathrm{HNO}_{3}$ and the Raman

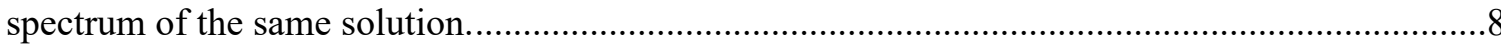

Figure 2.6. Raman spectra of $1 \mathrm{M} \mathrm{HNO}_{3}$ and varying concentrations of $\mathrm{Co}(\mathrm{II})\left(\mathrm{NO}_{3}\right)_{2}$ in $1 \mathrm{M}$ $\mathrm{HNO}_{3}$

Figure 2.7. Raman spectra of $1 \mathrm{M} \mathrm{Co}\left(\mathrm{NO}_{3}\right)_{2}$ in $1 \mathrm{M} \mathrm{HNO}_{3}$ solution with a change in the distance

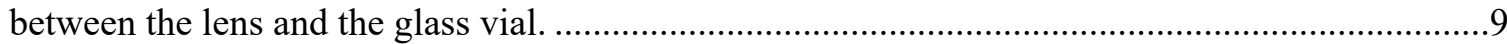

Figure 2.8. Neptunium solutions comparable composition to the MDD feed. .......................................10

Figure 2.9. Example $\mathrm{Np}(\mathrm{V})$ absorption spectrum and an example Raman spectrum taken from the

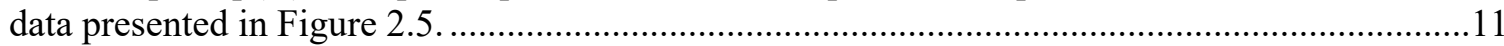

Figure 2.10. Raman spectra of $\mathrm{Np}$ solutions outlined in Figure 2.8....................................................12

Figure 3.1. UV-Vis absorbance spectra of $\mathrm{NaNO}_{3}$ and $\mathrm{NaNO}_{2}$ in water..............................................14

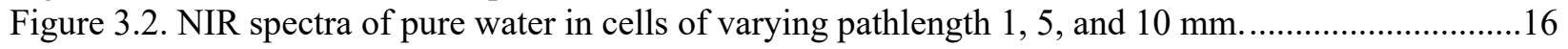

Figure 3.3. NIR absorbance spectra of water, $1 \mathrm{M} \mathrm{HNO}_{3}$, and $1 \mathrm{M} \mathrm{NaNO}_{3}$ blanked in air (left) and

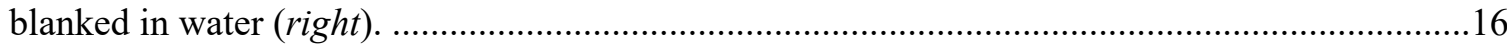

Figure 3.4. Temperature NIR absorbance spectra of water $20-80^{\circ} \mathrm{C}$ (left) and $1 \mathrm{M} \mathrm{HNO}_{3} 20-80$

${ }^{\circ} \mathrm{C}$ (right) blanked in water at $20^{\circ} \mathrm{C}$.

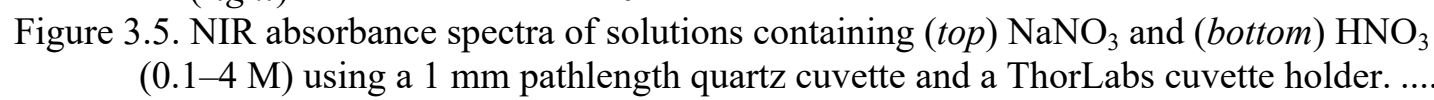

Figure 3.5. NIR absorbance spectra of solutions containing (top) $\mathrm{NaNO}_{3}$ and (bottom) $\mathrm{HNO}_{3}$
$(0.1-4 \mathrm{M})$ using a $1 \mathrm{~mm}$ pathlength quartz cuvette and a ThorLabs cuvette holder.

Figure 3.6. StellarNet cuvette holder and a Starna flow cell with a $1 \mathrm{~mm}$ pathlength, 1/16 in. tubing, and a plastic syringe.

Figure 3.7. NIR absorption spectrum of a $4.5 \mathrm{mM} \mathrm{Np}$ solution in $1 \mathrm{M} \mathrm{HNO}_{3}$ with varying optical pathlengths $(0.1-1 \mathrm{~cm})$.

Figure 3.8. A $980 \mathrm{~nm}$ peak absorbance value of a $4.5 \mathrm{mM}$ Np solution in $1 \mathrm{M} \mathrm{HNO}_{3}$ with varying pathlength $(0.1-1 \mathrm{~cm})$ and a linear regression.

Figure 3.9. Vis-NIR absorption spectrum of the stock solution $(210 \mathrm{~g} \mathrm{~Np} / \mathrm{L})$ collected with the QEPro (UV-Vis) and NIRQuest (NIR) from 450 to $1,700 \mathrm{~nm}$ using a $0.02 \mathrm{~cm}$ optical pathlength.

Figure 3.10. The $616 \mathrm{~nm}$ peak absorbance value of the $0.89 \mathrm{M} \mathrm{Np}$ solution in $1 \mathrm{M} \mathrm{HNO}_{3}$ using a $0.05,0.1,0.2$, and $0.5 \mathrm{~mm}$ optical pathlength and linear regression.

Figure 3.11. Vis-NIR spectra of varying concentration of $\mathrm{Np}(0.0089-0.89 \mathrm{M})$ using different pathlengths.

Figure 3.12. Vis-NIR spectra of varying concentration of $\mathrm{Np}(0.0089-0.89 \mathrm{M})$ using different pathlengths.

Figure 3.13. Avantes temperature-controlled cuvette holder with a $1 \mathrm{~mm}$ flow cuvette and plastic syringe in a glovebox.

Figure 3.14. Vis-NIR of a $0.34 \mathrm{M} \mathrm{Np}$ solution in $1 \mathrm{M} \mathrm{HNO}_{3}$ as a function of temperature (10$80^{\circ} \mathrm{C}$ ).

Figure 3.15. NIR spectra of a $0.17 \mathrm{M} \mathrm{Np}$ solution as a function of temperature $\left(10-80^{\circ} \mathrm{C}\right)$ with an offset baseline correction (a) first-order (b), second-order (c), and fourth-order derivative (d). 
Figure 3.16. MCR-ALS component spectra (top) and component concentration (bottom) describing the spectra variation of the $1,096 \mathrm{~nm}$ band in a $0.17 \mathrm{M} \mathrm{Np}$ solution at $1 \mathrm{M}$ $\mathrm{HNO}_{3}$.

Figure 3.17. UV-Vis spectra $(400-950 \mathrm{~nm})$ with a first-order derivative with varying temperature $10-80{ }^{\circ} \mathrm{C}$ (a) and PLSR model metrics (b).

Figure 3.18. PLSR model metrics for $\mathrm{Np}(\mathrm{V})$ concentration(a) and temperature (b) ................................34

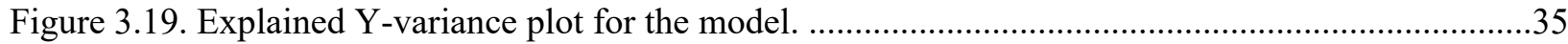

Figure 3.20. Predicted vs. reference values for $\mathrm{Np}$ concentration (top) and temperature (bottom).............36

Figure 3.21. UV-Vis-NIR absorbance spectrum of the T-504 solution after conversion to Np(VI) using a $0.5 \mathrm{~mm}$ optical pathlength.

Figure 3.22. NIR spectra corresponding to the T-504 solution from $98 \%$ to $\sim 100 \%$ converted to

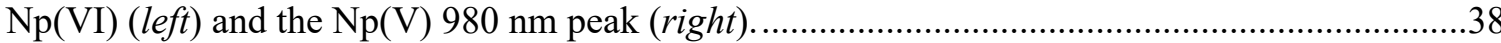

Figure 3.23. Cyclic voltammogram of the T-504 Np solution with varying scan rates in millivolts

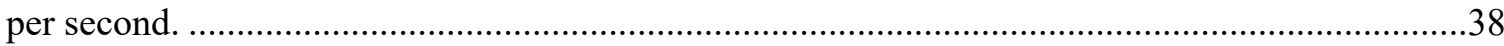

Figure 4.1. Vis (orange) and NIR (blue) absorption spectra of an undiluted P5NC10 sample.................41

Figure 4.2. Vis (orange) and NIR (blue) absorption spectra of the diluted P5NC9 consolidated sample characterized by the analytical group.

Figure 4.3 Vis (orange) and NIR (blue) absorption spectra of the undiluted P5NC9 consolidated sample.

Figure 5.1. Programmable FMI pump.

\section{LIST OF TABLES}

Table 3.1. Six samples with total $\mathrm{Np}$ concentration $(\mathrm{mM})$ and optical pathlength $(\mathrm{mm}) \ldots \ldots \ldots \ldots \ldots \ldots \ldots \ldots . . . . . . .19$

Table 3.2. Predicted temperature, deviation, and the reference temperature $\left({ }^{\circ} \mathrm{C}\right)$ with RMSEP.................33

Table 4.1. List of column runs and details regarding the sample transfers..............................................40

Table 4.2. P5NC9, P5NC10, and P5NC11 absorption measurements and analytical Np

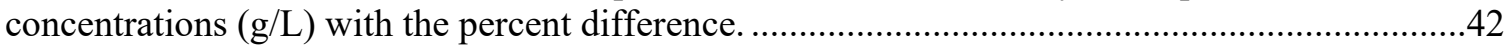

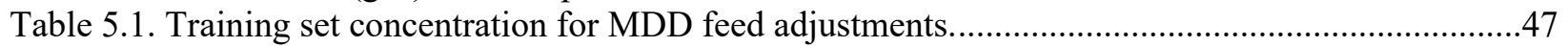

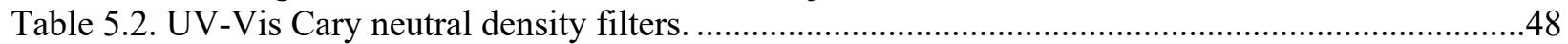

Table 5.3. UV-Vis-NIR Cary neutral density filter results........................................................................48 


\section{ABBREVIATIONS}

ICP-MS inductively coupled plasma mass spectrometry

MDD modified direct denitration

$\mathrm{NC}$ neptunium cation

NMCA nuclear material control and accountability

ORNL Oak Ridge National Laboratory

PP

Process Pulse II

PLSR partial least squares regression

REDC Radiochemical Engineering Development Center

RMSEC root-mean-square error of the calibration

RMSEV root-mean-square error of the validation

UV-Vis-NIR ultraviolet-visible/near-infrared 



\section{ACKNOWLEDGMENTS}

Funding for this program was provided by NASA's Science Mission Directorate and administered by the US Department of Energy, Office of Nuclear Energy, under contract DEAC05-00OR22725. This work used resources at the High Flux Isotope Reactor, a Department of Energy Office of Science User Facility operated by Oak Ridge National Laboratory. The authors wish to thank Kristian G. Myhre for assistance with spectropotentiometry, Tom Hylton for assistance with conceptualizing a hot cell sample introduction system, and Nonreactor Nuclear Facilities Division technicians for their assistance with hot cell operations. 



\section{EXECUTIVE SUMMARY}

Rapid quantification of concentrated $\mathrm{Np}(\sim 200 \mathrm{~g} \mathrm{~Np} / \mathrm{L})$ in nitric acid $\left(\mathrm{HNO}_{3}\right)$ solutions is necessary to improve the timeliness of Np processing efficiency, an ongoing effort at Radiochemical Engineering Development Center for the ${ }^{238} \mathrm{Pu}$ Supply Program. Two optical spectroscopic techniques, UV-Vis-NIR absorption and Raman scattering, may be used to accomplish this task. Raman spectroscopy is sensitive to molecular species (e.g., $\mathrm{NpO}_{2}{ }^{2++}$ ) and inorganic oxoanions (e.g., $\mathrm{NO}_{3}{ }^{-}, \mathrm{NO}_{2}{ }^{-}$, and $\mathrm{PO}_{4}{ }^{3-}$ ), and UV-VisNIR is sensitive to trivalent, tetravalent, and hexavalent $\mathrm{Np}$ species. The NIR water band centered at $1,450 \mathrm{~nm}$ and the Raman $\mathrm{O}-\mathrm{H}$ stretching region $\left(2,800-3,800 \mathrm{~cm}^{-1}\right)$ are also useful for determining $\mathrm{HNO}_{3}$ concentration. Proof-of-concept Raman results are presented here; however, spectrophotometry will be the primary focus because it is at a more advanced stage of development.

Quantifying the concentration of $\mathrm{Np}$ species in aqueous solutions using spectrophotometry is challenging because $\mathrm{Np}$ simultaneously exists in multiple oxidation states for which the species may have high extinction coefficients, is susceptible to hydrolysis, and tends to coordinate with a wide range of ligands. Another potentially complicating factor discovered by this work is the effect of temperature on the absorption spectrum of the pentavalent neptunyl dioxocation $\left(\mathrm{NpO}_{2}^{+}\right)$in $\mathrm{HNO}_{3}$. To address this, several glovebox experiments were performed to determine how $\mathrm{Np}(\mathrm{V})$ absorption coefficients change as a function of concentration (1-900 $\mathrm{mM} \mathrm{Np})$ and temperature $\left(10-80^{\circ} \mathrm{C}\right)$ in $1 \mathrm{M} \mathrm{HNO}_{3}$. Changes in molar absorptivity, band intensity, peak positions, and overall shape were characterized using derivative spectra and multivariate data analysis. Key findings from these exploratory studies (Sections 2 and 3 ) and a brief demonstration on how spectrophotometry was used to quantify $\mathrm{Np}$ concentration of $\mathrm{Np}$ cation exchange product bottles (Section 4) will be discussed in this report.

In summary, the spectrophotometric approach was demonstrated in proof-of-principle glovebox tests by characterizing several undiluted $\mathrm{Np}$ cation exchange product bottles and comparing the results to alpha spectroscopy data acquired by the analytical group. The results agreed, which reinforces the viability of this method and warrants the pursuit of additional work. Further tests on samples of known pedigree in glovebox experiments are necessary before implementing this approach for routine hot cell and lab 109 in building 7920 glovebox measurements. A robust hot cell and glovebox sample introduction system is also needed before adopting this method for routine analysis. With the appropriate equipment, training sets, and online monitoring software, optical spectroscopy may be used for the quantification of $\mathrm{Np}$ concentrations without sample dilution or transfer. Spectrophotometry may also be useful for determining $\mathrm{HNO}_{3}$ concentration by analyzing the water band region $(\sim 1,450 \mathrm{~nm})$ because $\mathrm{Np}(\mathrm{V})$ and $\mathrm{Np}(\mathrm{VI})$ do not absorb light in this region. Overall, the results presented here indicate that spectrophotometric measurements have great potential to improve the timeliness of important analytical measurements for the ${ }^{238} \mathrm{Pu}$ Supply Program. 



\begin{abstract}
Targets containing ${ }^{237} \mathrm{~Np}$ are irradiated at the High Flux Isotope Reactor at Oak Ridge National Laboratory to produce ${ }^{238} \mathrm{Pu}$, as plutonium dioxide $\left(\mathrm{PuO}_{2}\right)$, a heat source material for use in future NASA space missions. Kilogram quantities of $\mathrm{Np}$ are processed yearly and developing methods to efficiently characterize and monitor the Np processing streams with optical spectroscopy and real-time monitoring software is a critical aspect of this effort. Here, we evaluate how ultraviolet/visible/near-infrared (UVVis-NIR) absorbance and Raman spectroscopic techniques are applicable to characterizing concentrated $\mathrm{Np}$ solutions and provide proof-of-principle and proof-of-concept results for each technique. Both techniques were tested in lab-scale studies and should improve the timeliness of production efforts. However, spectrophotometry is the more mature option and has been successfully demonstrated in a hot cell environment. An overview of the initial findings, a brief demonstration, and areas for future work will be highlighted in this report.
\end{abstract}

\title{
1. BACKGROUND AND MOTIVATION
}

\subsection{BACKGROUND}

The ${ }^{238} \mathrm{Pu}$ Supply Program at Oak Ridge National Laboratory (ORNL) processes kilogram quantities of $\mathrm{Np}$ each year on a nearly continuous basis. ${ }^{1}$ The flow sheet consists of several feed adjustments, radiochemical separations, and other processes to recycle and purify unconverted ${ }^{237} \mathrm{~Np}$ and provide fresh ${ }^{237} \mathrm{~Np}$ from the dissolution of $\mathrm{NpO}_{2}$ to the supply chain. The quantitative determination of $\mathrm{Np}$ and nitric acid $\left(\mathrm{HNO}_{3}\right)$ concentration in feed solutions for $\mathrm{Np}$ cation (NC) exchange column runs, $\mathrm{NC}$ product bottles, and feed bottles for the modified direct denitration (MDD) process was recently identified as a high priority. ${ }^{2}$ This priority level was designated in response to the need to develop a monitoring technique for concentrated Np solutions (approximately $\leq 200 \mathrm{~g} \mathrm{~Np} / \mathrm{L}$ ) discussed by DePaoli et al. ${ }^{1}$

Implementing optical spectroscopy and real-time monitoring has great potential to improve the timeliness of these challenging analytical measurements. ${ }^{1-3}$ This approach has already been applied to monitoring solvent extraction and anion exchange column runs with great success. ${ }^{3}$ In these applications, using literature values to provide semiquantitative data was generally sufficient to meet program needs because the semi-arbitrary economy-of-accuracy scale has a steep curve. However, quantitative measurements with an accuracy threshold on the order of $\pm 2 \%$ are required for the tasks outlined in this report. Thus, it is necessary to undertake a fundamental study focused on the behavior of concentrated $\mathrm{Np}$ in $\mathrm{HNO}_{3}$ solutions because the spectra/chemistry of concentrated $\mathrm{Np}$ solutions is complicated and not fully understood in the literature..$^{2,4,5}$

Neptunium is the first transuranium element in the periodic table and exists in the +3 to +7 oxidation states in aqueous solutions. ${ }^{4,5}$ Based on literature, the monocharged pentavalent neptunyl dioxocation $\left(\mathrm{Np}(\mathrm{V})=\mathrm{NpO}_{2}{ }^{+}\right)$is the most prevalent species in aqueous $\mathrm{HNO}_{3}$ concentrations $<5 \mathrm{M}$ and in the absence of redox active species. ${ }^{4} \mathrm{At} \geq 5 \mathrm{M} \mathrm{HNO}_{3}, \mathrm{~Np}(\mathrm{~V})$ is unstable and will disproportionate, primarily because of the presence of nitrous acid $\left(\mathrm{HNO}_{2}\right)$, which exists at higher relative concentrations of $\mathrm{HNO}_{3}$ to $\mathrm{Np}$ (IV) and $\mathrm{Np}(\mathrm{VI}) \mathrm{O}_{2}{ }^{2+}$. The redox chemistry of $\mathrm{Np}$ in nitric acid is largely dictated by the equilibria $\mathrm{NpO}_{2}{ }^{2+} \rightleftharpoons$ $\mathrm{NpO}_{2}{ }^{+} \rightleftharpoons \mathrm{Np}^{4+}$ and is highly dependent on the solution composition, redox properties of $\mathrm{HNO}_{3}, \mathrm{HNO}_{2}, \mathrm{H}^{+}$ species, total nitric acid concentration, and $\mathrm{NO}_{3}{ }^{-}$coordination. ${ }^{5}$ Two $\mathrm{Np}(\mathrm{V} / \mathrm{VI})$ valences will be the primary focus of this work because these are the dominant species present in NC and MDD feed adjustments.

Studies over the last seven decades have measured Vis-NIR absorption and Raman spectral signatures of various oxidation states of $\mathrm{Np}$ in aqueous solutions. ${ }^{5-13}$ Aqueous absorption spectra of $\mathrm{Np}(\mathrm{V})$ and $\mathrm{Np}(\mathrm{VI})$ 
ions have even been characterized to determine electronic structural, optical, and magnetic properties using ab initio calculations. ${ }^{14,15}$ The intense $980 \mathrm{~nm}\left(C=395 \mathrm{M}^{-1} \cdot \mathrm{cm}^{-1}\right)$ band and a less intense band at $616 \mathrm{~nm}\left(€=22 \mathrm{M}^{-1} \cdot \mathrm{cm}^{-1}\right)$ are commonly used to determine Np concentration in the literature. ${ }^{14}$ Each peak, along with the rest of the peaks in the spectrum, follows Beer's law. Because molar absorptivity values depend on specific solution conditions and the spectral bandwidth (i.e., resolution) of a given spectrophotometer, molar absorptivity values must be acquired experimentally to obtain highly accurate concentration measurements.

Most $\mathrm{Np}$ studies aim to understand the behavior of $\mathrm{Np}$ at concentrations near $1 \mathrm{mM}$ for nuclear fuel cycle applications. ${ }^{16}$ Few systematic studies have addressed $\mathrm{Np}$ redox chemistry and the resulting UV-Vis-NIR and Raman spectral signatures at concentrations $>0.1 \mathrm{M} \mathrm{Np},{ }^{9-11}$ which is more than 100 times more concentrated than that used in most studies and relevant to multiple processes for the ${ }^{238} \mathrm{Pu}$ Supply Program. Many studies are also performed in perchlorate solutions, which may account for differences in reported values of molar absorptivity in $\mathrm{HNO}_{3}$ solutions. Additionally, spectroscopic signatures vary between published data sets under similar conditions. ${ }^{5}$

Quantifying Np concentration in solution is challenging for several reasons, including sensitivity to solution conditions, high absorptivity, simultaneous existence in multiple oxidation states, susceptibility to hydrolysis, and the ability to coordinate with a wide range of ligands. ${ }^{5}$ Additional complicating factors will be present at high concentrations $(>0.01 \mathrm{M} \mathrm{Np})$. Beer's law, which typically works very well for relatively dilute solutions $(\leq 0.01 \mathrm{M})$, states that absorbance is proportional to the concentration of an absorbing species. To quantify Np in NC and MDD feed solutions, concentration effects must also be considered because solute molecules will influence one another owing to their proximity in concentrated solutions ( $>0.1 \mathrm{M} \mathrm{Np}$ ), which in turn affects their optical properties (e.g., molar absorptivity) to a measurable extent. High concentrations of $\mathrm{Np}$ could result in concentration-dependent chemical equilibria that alter the properties of the absorbing molecule to generate new spectral signatures arising from dimeric species. For example, cation-cation interactions may contribute significantly to concentrationdependent spectral features in the $\mathrm{Np}(\mathrm{V} / \mathrm{VI})$ system. ${ }^{9-11}$

When a spectrum contains features that correspond to $\mathrm{Np}$ in multiple oxidation states, $\mathrm{Np}$ concentration can be approximated via deconvolution. Spectral deconvolution is a mathematical approach used to decompose the convoluted spectrum into pure reference spectra using an additive least squares minimization. It is sometimes referred to as digital subtraction. This method assumes experimental knowledge of the concentration of $\mathrm{Np}$ species and does not always work for the quantification of multiple species for several reasons: (1) the molar absorptivity of most $\mathrm{Np}$ species varies with solution composition, acidity, and ionic strength; (2) deconvolution does not account for the effects of interionic associations (e.g., cation-cation interactions) or disproportionation reactions; and (3) reference spectra composed of $\mathrm{Np}$ in a single oxidation state are difficult to obtain. Thus, performing a systematic study with calibration sets that span the range of expected processing conditions is necessary. Both multivariate chemometrics and univariate regression applications will be evaluated to correlate spectral features to concentration.

Researchers have also examined $\mathrm{Np}$ redox reactions and mechanisms using several techniques, including cyclic voltammetry and spectropotentiometry. ${ }^{4,5}$ This study demonstrates how a spectroelectrochemical cell can be used to simultaneously adjust valence and measure UV-Vis-NIR spectra in situ. Ex situ methods often result in the removal of controlled potential conditions and $\mathrm{Np}$ species coexisting in multiple oxidation states. Measurements with an optically transparent electrode and thin absorbance cell with an optical pathlength of $\sim 1 \mathrm{~mm}$ are ideal for these measurements. Thin-layer spectropotentiometry restricts dead volume for the auxiliary and reference electrodes and results in faster data collection, analysis, and smaller sample volumes. Electrochemical methods are more desirable than chemical 
approaches to adjust the redox state of a desired Np product because they can be more accurately controlled and do not require adding redox reagents to solution which could alter the sample.

\subsection{OPTICAL SPECTROSCOPIC TECHNIQUES}

Routinely used quantitative analytical techniques (other than UV-Vis-NIR spectroscopy) for the ${ }^{238} \mathrm{Pu}$ Supply Program that meet nuclear material control and accountability (NMC\&A) requirements are inductively coupled plasma mass spectrometry (ICP-MS) and alpha/gamma spectrometry. These techniques provide gold-standard measurements for material balance and inventory purposes. These methods require grab samples that must be transferred across hot cell cubicles and out of the hot cell entirely. The ICP-MS analyses are regularly time consuming (hours to several days) and require 100- to 10,000-fold dilutions. Dilutions may contribute a significant but unquantifiable amount of error to the analyses. Evidence of this error lies in the inconsistent reported concentration values, which tend to vary throughout the flow sheet, even though the overall material balance is typically satisfied. ${ }^{1}$ Acid/base titrations are also used to quantitatively measure $\mathrm{HNO}_{3}$ concentration for other purposes and require transferring samples across hot cell cubicles. Titrations involve transferring $0.25 \mathrm{~mL}$ of the sample solution into a beaker with approximately $40 \mathrm{~mL}$ of DI water and can be used to quantify $\mathrm{Np}$ concentration in most situations.

Optical spectrometric techniques offer several operational benefits, including no sample transfers, no sample dilution, user friendliness, and near real-time feedback. Fiber-optic cables combined with fiberoptic probes or cuvette holders allow Raman and UV-Vis-NIR absorption measurements in glovebox and hot cell environments while personnel operate the equipment in the control room. This enables the analysis of materials in harsh processing environments, such as the radiochemical hot cells in the Radiochemical Engineering Development Center (REDC) at ORNL.

UV-Vis-NIR absorbance has been used in every campaign since the start of the program, primarily to qualitatively measure $\mathrm{Np}$ and $\mathrm{Pu}$ oxidation states - an essential measurement to ensure efficient radiochemical separations. UV-Vis-NIR spectrophotometry is particularly sensitive to the valence and concentration of actinides ( $\mathrm{Np}$ and Pu species) and may also be used to quantify $\mathrm{HNO}_{3}$ concentration and temperature of the solutions via NIR water absorption bands. ${ }^{17} \mathrm{UV}$ absorption is also sensitive to oxoanions such as nitrate $\left(\mathrm{NO}_{3}^{-}\right)$and nitrite $\left(\mathrm{NO}_{2}^{-}\right)$, provided the correct light source and a short pathlength cuvette are used for the measurement (see Section 3.2.1 for details).

Raman spectroscopy was tested during Pu production Campaigns 4 and 5 for the first time at REDC. Raman spectroscopy is sensitive to molecular species such as organic compounds (e.g., TBP and Exxsol D60), inorganic oxoanions (e.g., $\mathrm{NO}_{3}{ }^{-}, \mathrm{NO}_{2}{ }^{-}$, and $\mathrm{PO}_{4}{ }^{3-}$ ), acid/base concentration, and actinyls (e.g., $\mathrm{Np}[\mathrm{V} / \mathrm{VI}]$ and $\mathrm{Pu}[\mathrm{VI}])$. It is also indirectly sensitive to other metal ion species by quantifying perturbations of the water band. The water $\mathrm{O}-\mathrm{H}$ stretching region $\left(2,800-3,800 \mathrm{~cm}^{-1}\right)$ comprises multiple overlapping $\mathrm{H}_{2} \mathrm{O}$ vibration and $\mathrm{O}--\mathrm{H}$ stretching modes. ${ }^{18}$ Changes in acid/base concentration, ionic strength, temperature, and electrolyte concentration distort the tetrahedral structure of water, which results in a spectral response that can be correlated to the concentration of analytes or external perturbation(s). A Raman system was tested in the hot cells for monitoring the caustic dissolution of aluminum alloy during Campaign $4 .{ }^{18}$ Specific details pertaining to how Raman spectroscopy could be used to quantify Np concentration can be found in Section 2.3.

Developing UV-Vis-NIR methods will be the primary focus of future work for multiple reasons: (1) transferring UV-Vis-NIR calibration models from the glovebox to the hot cell may be more straightforward than Raman, ${ }^{19,20}$ (2) technicians have more experience with UV-Vis-NIR equipment, (3) quantification by simple univariate methods is more attainable with UV-Vis-NIR than Raman spectroscopy, (4) UV-Vis-NIR methods already have adequate signal in hot cell applications, and (5) UV- 
Vis-NIR spectra may be less sensitive to concentration-dependent effects than Raman spectra. ${ }^{9}$ These aspects will be described in more detail in subsequent sections of this report.

\section{NEPTUNIUM RAMAN SPECTROSCOPY DEVELOPMENT}

\subsection{RAMAN SPECTROSCOPY}

Raman spectroscopy is a nondestructive, molecular spectroscopic technique based on the interaction of light with chemical bonds in materials. Raman scattering occurs when light interacts with molecular vibrations in a sample and causes a change in the polarizability of a bond. The most relevant modes describing how light interacts with a sample in solution are shown in Figure 2.1. Photoluminescence is also a possibility and is more likely to occur when the excitation laser wavelength becomes shorter. A vast majority of the laser light is transmitted through the sample. Most of the light scattered by molecules are Rayleigh scattered, which means that the light has the same energy as the incident laser but changes direction. The intensity of Rayleigh-scattered light is typically on the order of $0.01 \%-0.1 \%$ relative to the incident light source. An even smaller fraction of the light is Raman scattered. Raman scattering is a relatively weak process in comparison to other optical techniques such as photoluminescence. Ramanscattered photons result from both a change in the energy and direction of the incident light. Nearly 1 out of every 10 million photons is Raman scattered by a molecule, which is why lasers are normally used as an excitation source. Inelastically scattered photons are shifted to either a lower (Stokes) or higher (antiStokes) energy and analyzed with a spectrometer. Stokes-scattered radiation is more intense than antiStokes and is frequently used to elucidate the vibrational properties, and ultimately the intrinsic fingerprint, of a molecule.

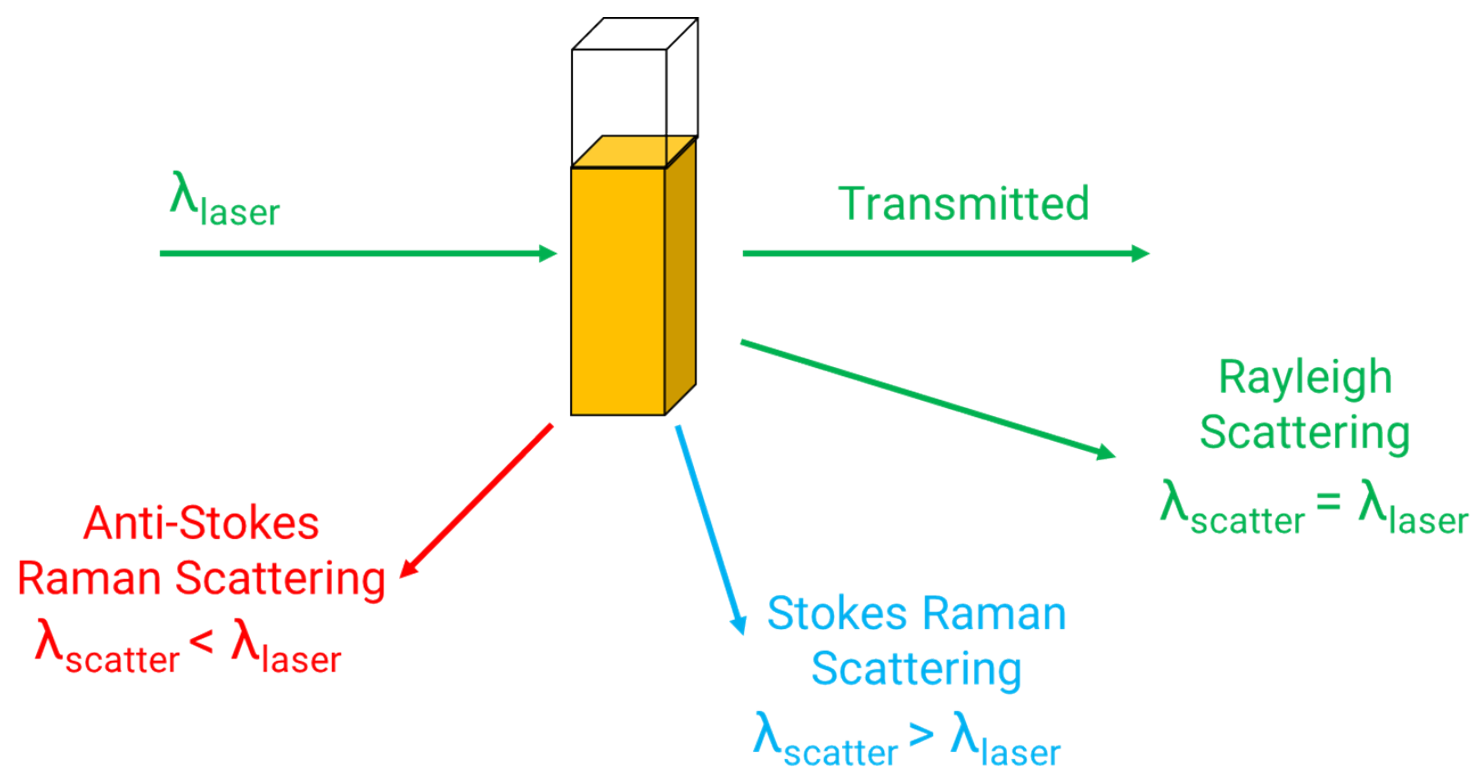

Figure 2.1. Generalized Raman scattering measurements of an aqueous solution in a cuvette.

Raman measurements require little to no sample preparation, and samples may be gas, liquid, or solid and transparent, translucent, scattering, or opaque. Raman spectroscopy may be used for rapid concentration measurements. Quantitative concentration measurements from first principles are possible, but such an approach is not normally considered. ${ }^{21}$ More often, quantitative measurements are acquired with a training set and univariate or multivariate regression approaches (e.g., partial least squares regression), which relate spectral features to analyte concentration. 
Raman scattering is isotropic, and the scattered light is generally collected in transmission mode $\left(180^{\circ}\right.$ geometry) or reflection mode using a probe. Fiber-optic probes are used to illuminate the samples with laser light and collect the scattered light in reflection mode. Under ordinary conditions, Raman signal intensity (i.e., peak area) is directly proportional to the number of molecules in a sample. ${ }^{21}$ However, when the wavelength of Raman-scattered light coincides with the absorption spectrum of a species in solution, a phenomenon known as Raman self-absorption occurs. This phenomenon also occurs when the incident excitation light reaching the sample is attenuated because it coincides with the absorption spectrum of a sample. In either case, the result is Raman spectra with a poor signal-to-noise ratio, which renders quantitative analysis challenging. However, several studies suggest that it is possible to correct for this effect. ${ }^{21,22}$

Raman self-absorption effects were encountered while monitoring the column effluent during anion exchange column runs in Campaign 4 in transmission mode with a $1 \mathrm{~cm}$ optical pathlength. ${ }^{2}$ When $\mathrm{Np}$ and the $\mathrm{Pu}$ product eluted from the column, the Raman signal intensity was almost completely lost. Results from the anion exchange column run will be discussed in more detail in a separate report. This phenomenon has not been expounded upon in relevant online monitoring nuclear fuel cycle papers ${ }^{23}$ and prompted the brief study described in Section 2.2.

\subsection{SELF-ABSORPTION BENCHTOP TESTS}

Self-absorption effects can be minimized or completely avoided by using an ideal excitation wavelength such that the incident light and scattered light do not coincide with the sample (i.e., laser with an optimal wavelength). Correction methods are generally required if the excitation source is fixed, or if the sample absorbs light at many wavelengths across the UV-Vis-NIR region. Lab-scale testing was necessary to develop a better understanding of self-absorption effects to quantify $\mathrm{NO}_{3} / \mathrm{HNO}_{3}$ and potentially to measure the concentration of the actinyl ions, that is, $\mathrm{Np}(\mathrm{V}), \mathrm{Np}(\mathrm{VI})$, and $\mathrm{Pu}(\mathrm{VI})$.

Raman spectra were collected in reflection mode using a general-purpose Raman probe made by Spectra Solutions, Inc. with a $9 \mathrm{~mm}$ focal length and a $7 \mathrm{~mm}$ working distance. The probe was used to measure solutions contained in $1.8 \mathrm{~mL}$ glass vials containing various concentrations of $\operatorname{Pr}\left(\mathrm{NO}_{3}\right)_{3}$ and $\mathrm{Co}\left(\mathrm{NO}_{3}\right)_{2}$ in $1 \mathrm{M} \mathrm{HNO}_{3}$. The vials and Raman probe were placed in a Spectra Solutions Inc. adjustable Raman probe and cuvette sample holder. Raman spectra were collected using a $532 \mathrm{~nm}$ laser and were composed of the informative Stokes Raman scattering region between $\sim 535$ and $670 \mathrm{~nm}$. The probe was pressed against the glass vial unless otherwise stated. The probe and sample apparatus are shown in Figure 2.2. The example in this figure contains a quartz flow cell with 1/16 in. tubing that could be useful for routine processing applications. In addition to the general-purpose probe, immersion probe barrels made of Inconel are also an option. 


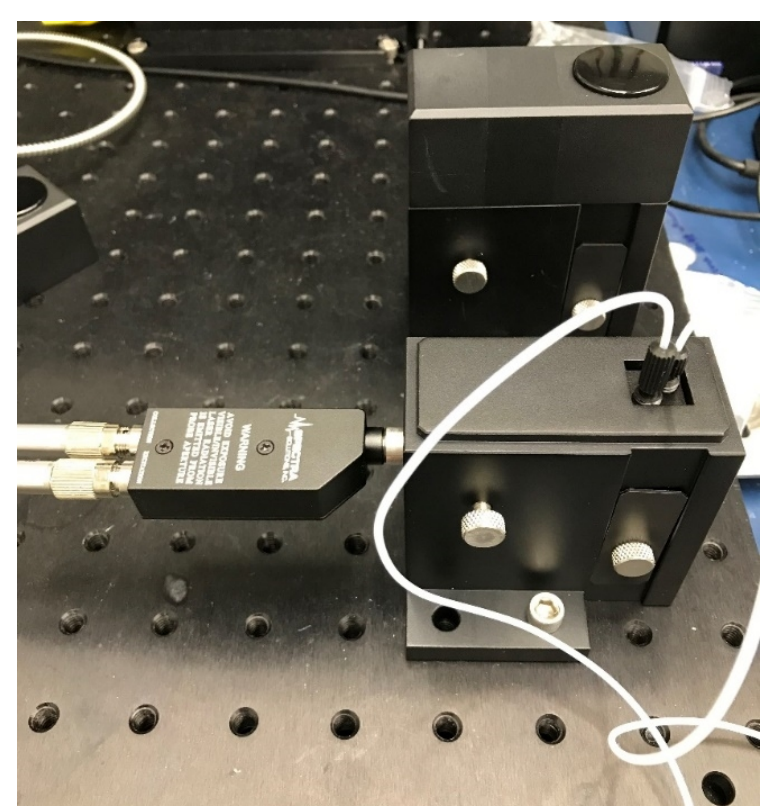

Figure 2.2. General-purpose Raman probe made by Spectra Solutions Inc. The Starna flow-cell quartz cuvette with 1/16 in. tubing and a cuvette holder was made by Spectra Solutions Inc. Note, immersion probe barrels made of Inconel are also an option.

The absorbance spectra of $\operatorname{Pr}(\mathrm{III})$ and $\operatorname{Co}(\mathrm{II})$ and incident laser light $(532 \mathrm{~nm})$ are shown in Figure 2.3. The Co(II) solution spectrum is shown in black, and the $\operatorname{Pr}(\mathrm{III})$ solution spectrum is shown in red. The green line is the $532 \mathrm{~nm}$ laser. The laser light clearly overlaps with the primary absorption band of $\mathrm{Co}$ (II) but does not overlap with the absorption bands of $\operatorname{Pr}(\mathrm{III})$. The molar extinction coefficient of $\mathrm{Co}$ (II) is $\sim 5 \mathrm{M}^{-1} \cdot \mathrm{cm}^{-1}$ at $515 \mathrm{~nm}$. This observation shows that the Raman signal will likely decrease as a result of greater self-absorption effects as the concentration of Co(II) increases. On the other hand, the Raman spectrum of the $\operatorname{Pr}(\mathrm{III})$ nitrate solution will only be affected in the 580-610 nm region where an absorption band is located. The rest of the Raman scattering region between $\sim 535$ and $670 \mathrm{~nm}$ should not be affected to a great degree.

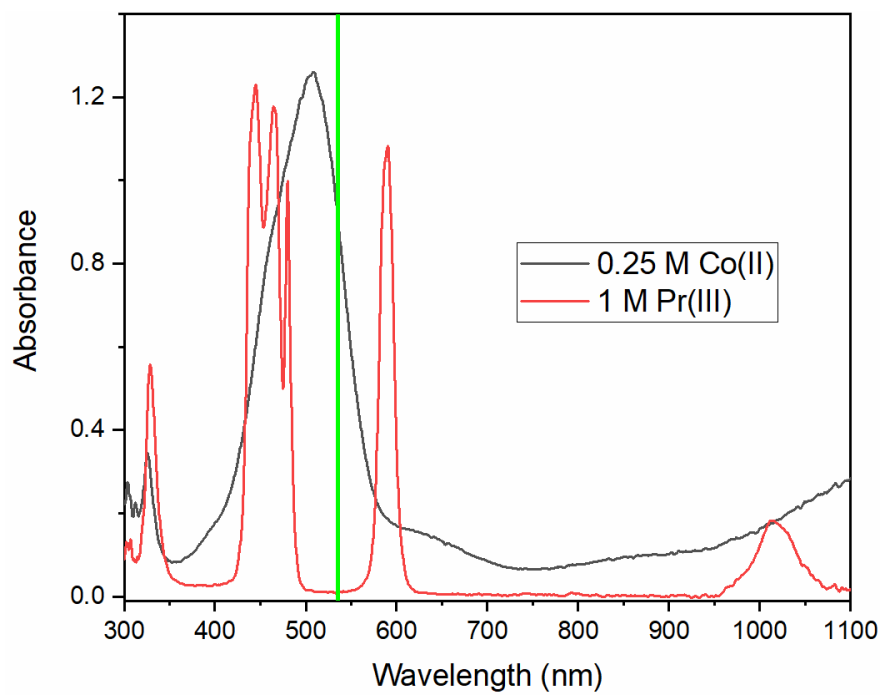

Figure 2.3. Overlay of the absorbance spectrum of $0.25 \mathrm{M} \mathrm{Co}$ (II) nitrate and $1 \mathrm{M} \operatorname{Pr}$ (III) nitrate in $1 \mathrm{M} \mathrm{HNO}_{3}$ and the $532 \mathrm{~nm}$ laser line. 
Despite the absorption of $\operatorname{Pr}(\mathrm{III})$ in the general region where excitation and Raman scattering take place, the self-absorption effect on the Raman spectra was insignificant (see Figure 2.4). The region that was altered by this effect $\left(1,500-2,300 \mathrm{~cm}^{-1}\right)$ did not contain useful information necessary to determine acid and total nitrate concentration, and the intensity of the nitrate peak $\left(1,047 \mathrm{~cm}^{-1}\right)$ increased with increasing $\operatorname{Pr}$ (III) concentration as expected (see Figure 2.4). Because the absorbance spectrum of Pr(III) did not overlap with the $532 \mathrm{~nm}$ laser, the nitrate peak, or O--H stretching region, the spectra were informative without needing a correction factor.
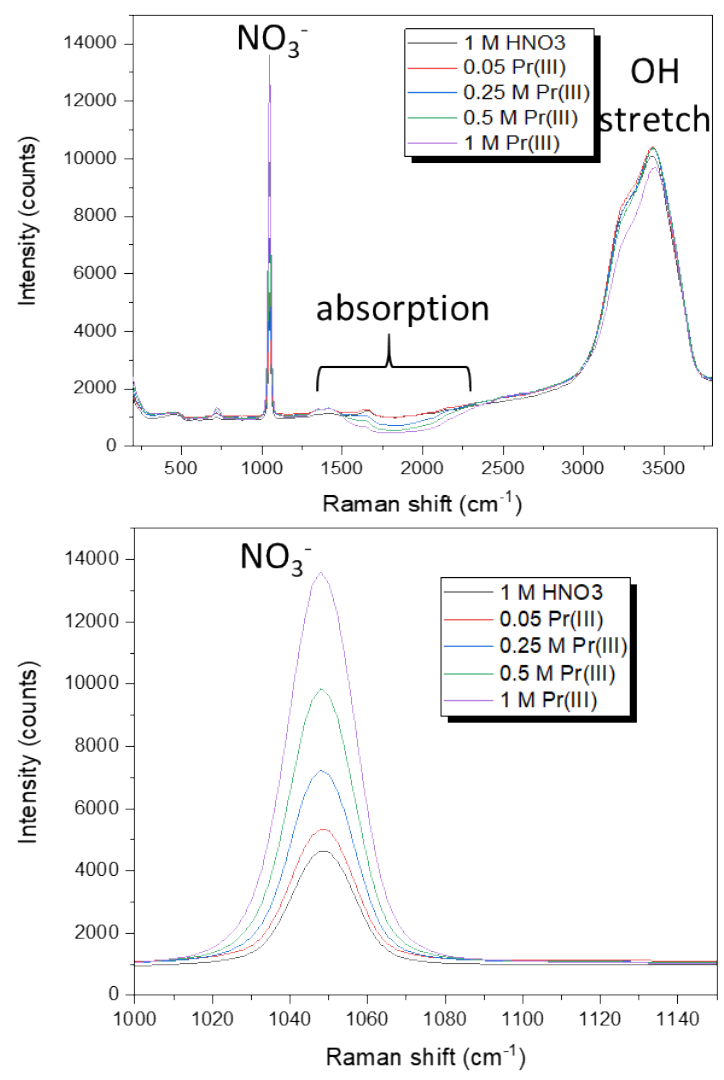

Figure 2.4. Raman spectra of $1 \mathrm{M} \mathrm{HNO}_{3}$ and 0.05 to $1 \mathrm{M} \operatorname{Pr}\left(\mathrm{NO}_{3}\right)_{3}$ (top) and the nitrate peak $\left(1,047 \mathrm{~cm}^{-1}\right)$ intensity (bottom). 


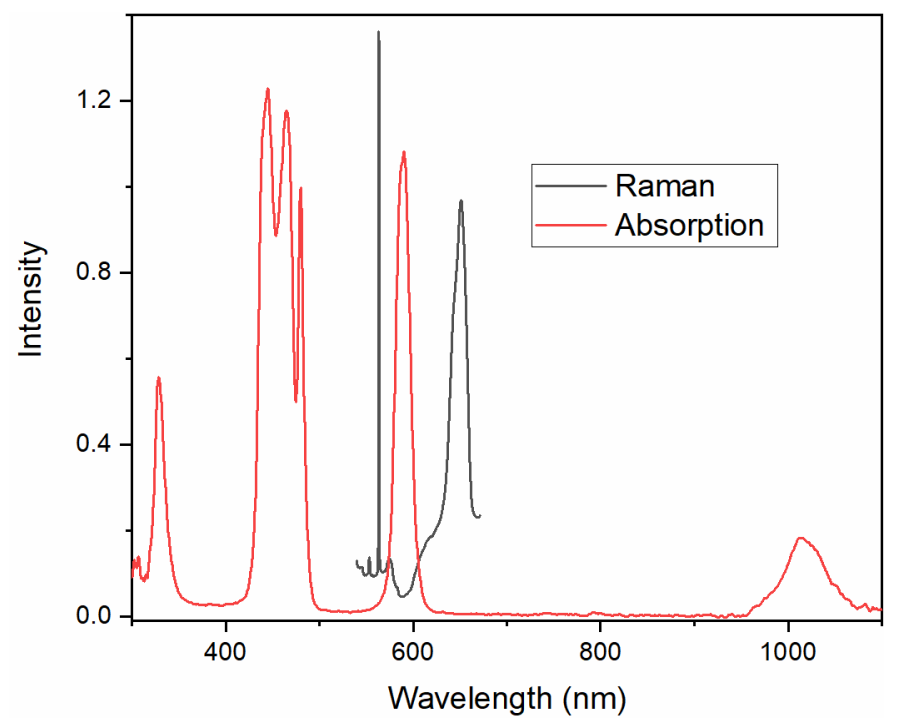

Figure 2.5. Overlay of the absorbance spectrum of $1 \mathrm{M} \mathrm{Pr}\left(\mathrm{NO}_{3}\right)_{3}$ in $1 \mathrm{M} \mathrm{HNO}$ and the Raman spectrum of the same solution. The Raman spectrum was converted from Raman shift $\left(\mathrm{cm}^{-1}\right)$ to nanometers. The probe was pressed against glass vial.

On the contrary, the self-absorption effect was significant in the Co(II) system when the probe was pressed against the vial (see Figure 2.6). The signal was lost almost entirely in the sample containing $1 \mathrm{M}$ $\mathrm{Co}(\mathrm{II})$, and the intensity of the entire spectrum sequentially decreased with increasing $\mathrm{Co}(\mathrm{II})$ concentration. The self-absorption effect in this system clearly influenced the ability to determine nitrate and $\mathrm{HNO}_{3}$ concentrations. Note, Raman self-absorption effects can only be accounted for if there is a signal to correct. Thus, the focal distance was optimized to improve the signal intensity.

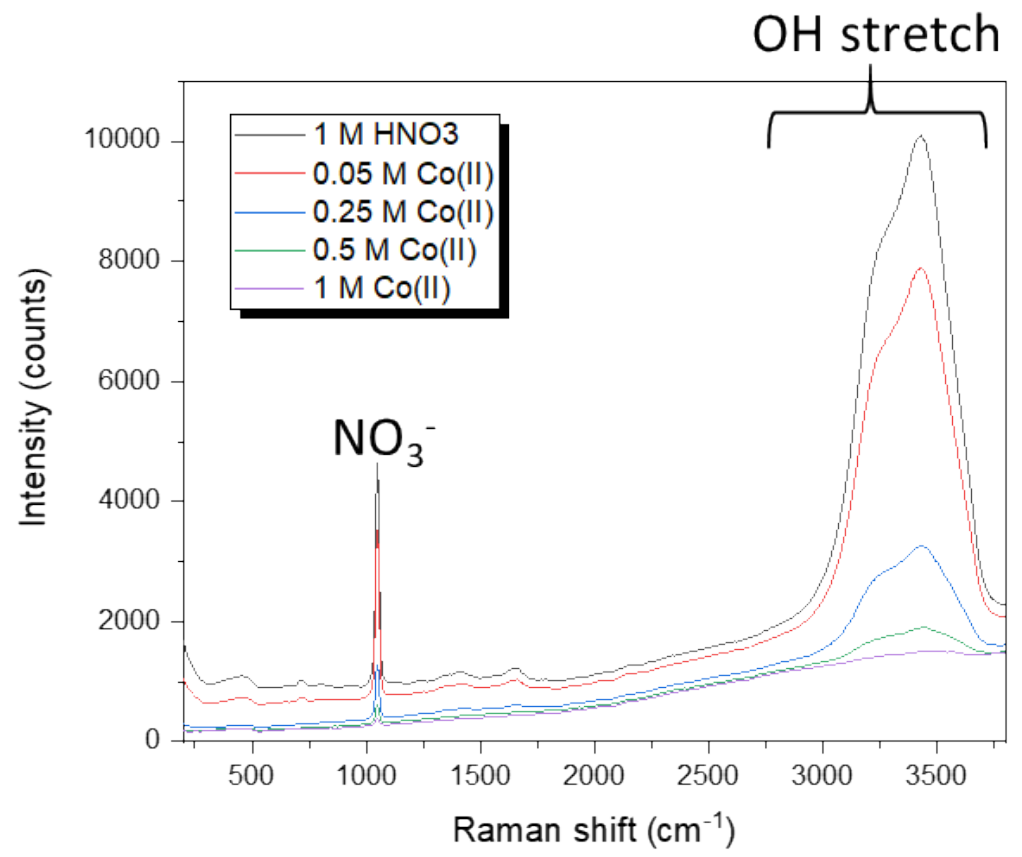

Figure 2.6. Raman spectra of $1 \mathrm{MHNO}_{3}$ and varying concentrations of $\mathrm{Co}(\mathrm{II})\left(\mathrm{NO}_{3}\right)_{2}$ in $1 \mathrm{M} \mathrm{HNO}_{3}$. The entire spectrum signal intensity decreases with increasing $\mathrm{Co}(\mathrm{II})$ concentration. The broad $\mathrm{O}-\mathrm{H}$ stretching region $(2,800-$ $3,600 \mathrm{~cm}^{-1}$ ) and the nitrate peak at $1,047 \mathrm{~cm}^{-1}$ are labeled. The probe was pressed against the glass vial. 
When the probe was pressed against the glass vial, the focal point was located near the opposite side of the sample vial. Changing the working distance (i.e., distance between the probe lens and the sample) greatly improved the Raman signal intensity (see Figure 2.7). The working distance was adjusted to optimize the focal length of the signal such that the optics were focused just past the glass and not towards the other end of the vial. Decreasing the focal length increased the signal up to a certain point. Optimizing the working distance reduced the amount of incident laser light absorbed by the sample, which in turn enhanced the Raman signal. Although there is some distortion of the spectrum, particularly in the $\mathrm{O}-\mathrm{H}$ stretching region, this is something that can likely be accounted for using multivariate data analysis. Preprocessing algorithms, such as multiplicative scattering correction factors, could be applied to the spectral data to improve the regression analyses.
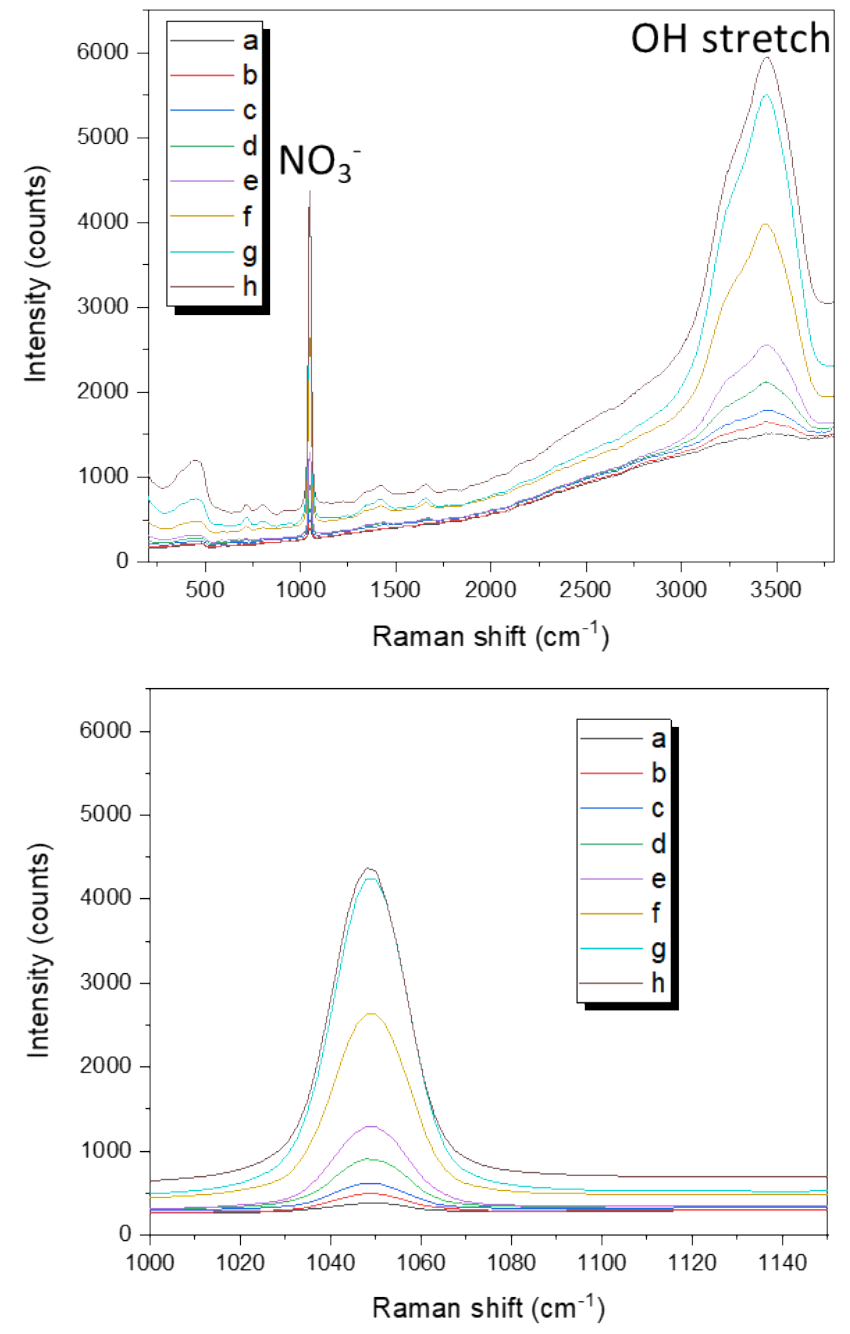

Figure 2.7. Raman spectra of $1 \mathrm{M} \mathrm{Co}\left(\mathrm{NO}_{3}\right)_{2}$ in $1 \mathrm{M} \mathrm{HNO}_{3}$ solution with a change in the distance between the lens and the glass vial. Letters a-h represent arbitrary working distances from 0 to $\sim 1 \mathrm{~cm}$ between the probe lens and the vial. Raman signal increased with increasing distance between the probe and the glass vial until an arbitrary distance $\mathrm{h}$ was achieved. The nitrate peak $\left(1,047 \mathrm{~cm}^{-1}\right)$ and the broad $\mathrm{O}-\mathrm{H}$ stretching region $\left(2,800-3,600 \mathrm{~cm}^{-1}\right)$ are labeled. Zoomed-in nitrate peak at 1,047 $\mathrm{cm}^{-1}$ (bottom). Raman measurements were collected in reflection mode using a general-purpose Raman probe made by Spectra Solutions Inc. with a $9 \mathrm{~mm}$ focal length and a $7 \mathrm{~mm}$ working distance. 
These results suggest that it would be best to change the Raman scattering experimental setup from transmission mode $\left(180^{\circ}\right)$ to reflection mode when monitoring anion exchange column effluent and other solutions containing strongly absorbing $\mathrm{Np}$ and $\mathrm{Pu}$ species. Using a general-purpose or immersion probe in reflection mode will minimize the amount of light lost because of self-absorption caused by high concentrations of $\mathrm{Np}$ and $\mathrm{Pu}$. With this scattering geometry, it is unlikely that the signal will be lost, and correction methods can be applied to the data to obtain quantitative information. Although this work suggested that Raman could be more useful for measuring $\mathrm{HNO}_{3}$ concentrations in strongly absorbing samples, testing on actual $\mathrm{Np}$ samples was required to be sure.

\subsection{RAMAN SPECTRA OF NEPTUNIUM SOLUTIONS}

Raman spectroscopy is sensitive to neptunyl (i.e., $\mathrm{NpO}_{2}{ }^{+}$and $\mathrm{NpO}_{2}{ }^{2+}$ ) symmetric stretching and bending vibrational modes. ${ }^{9}$ It can also be used to determine water structure (i.e., acid concentration) since it is sensitive to $\mathrm{O}-\mathrm{H}$ stretching modes. Thus, Raman spectrometry can be used to quantify both $\mathrm{Np}(\mathrm{V} / \mathrm{VI})$ and $\mathrm{HNO}_{3}$ concentration. A general-purpose Raman probe made by Spectra Solutions Inc. was tested on three concentrated $\mathrm{Np}$ solutions to demonstrate proof-of-concept. In Figure 2.8, the dark solution on the left (LD1) is a mixture of $\mathrm{Np}(\mathrm{V})$ and $\mathrm{Np}(\mathrm{VI})$ in $\mathrm{HNO}_{3}$ at $\sim 200 \mathrm{~g} \mathrm{~Np} / \mathrm{L}$. The green solution on the right (LD3) is primarily $\mathrm{Np}(\mathrm{V})$ at $\sim 100 \mathrm{~g} \mathrm{~Np} / \mathrm{L}$.

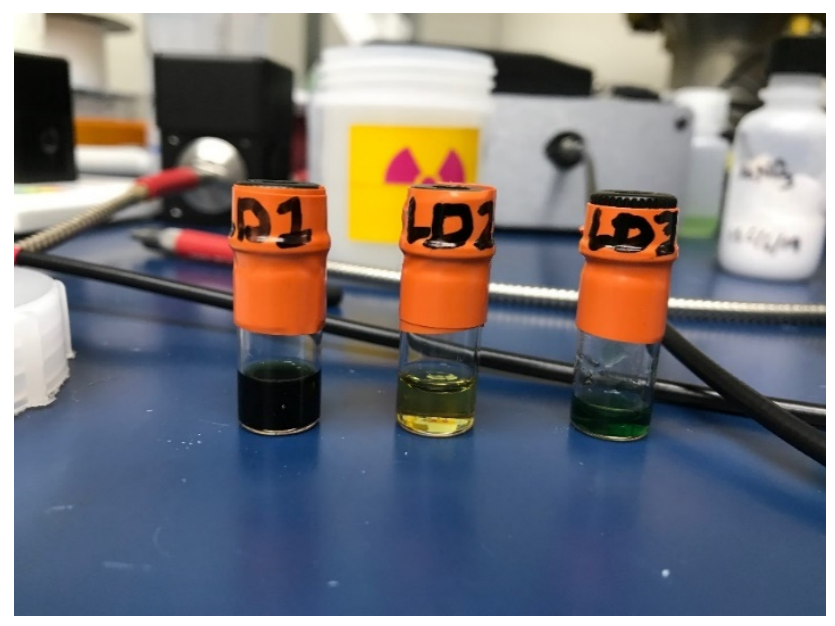

Figure 2.8. Neptunium solutions comparable composition to the MDD feed. Vial \#1 is P3NC4-Product, Vial \#2 is MDD condensate final, and Vial \#3 is P3AXNCGB-feed.

$\mathrm{Np}(\mathrm{V})$ absorbs light at most wavelengths relevant for Raman measurements using common excitation wavelengths (400-1050 nm). Attempts to analyze theses samples in transmission mode, using a cuvette holder and a standard $1 \mathrm{~cm}$ optical pathlength, were unsuccessful because of the strong self-absorption effect (data not shown here). This is consistent with the results from the Co(II) system: the excitation source (532 nm laser) and Raman scattering region (535-670 nm) overlap with the absorption spectrum of $\mathrm{Np}(\mathrm{V})$ as shown in Figure 2.9. The level of self-absorption is expected to change over this region because the molar extinction coefficient values are different. For example, the nitrate peak would not be altered to the same extent as the left-hand side of the $\mathrm{O}-\mathrm{H}$ stretching band. 


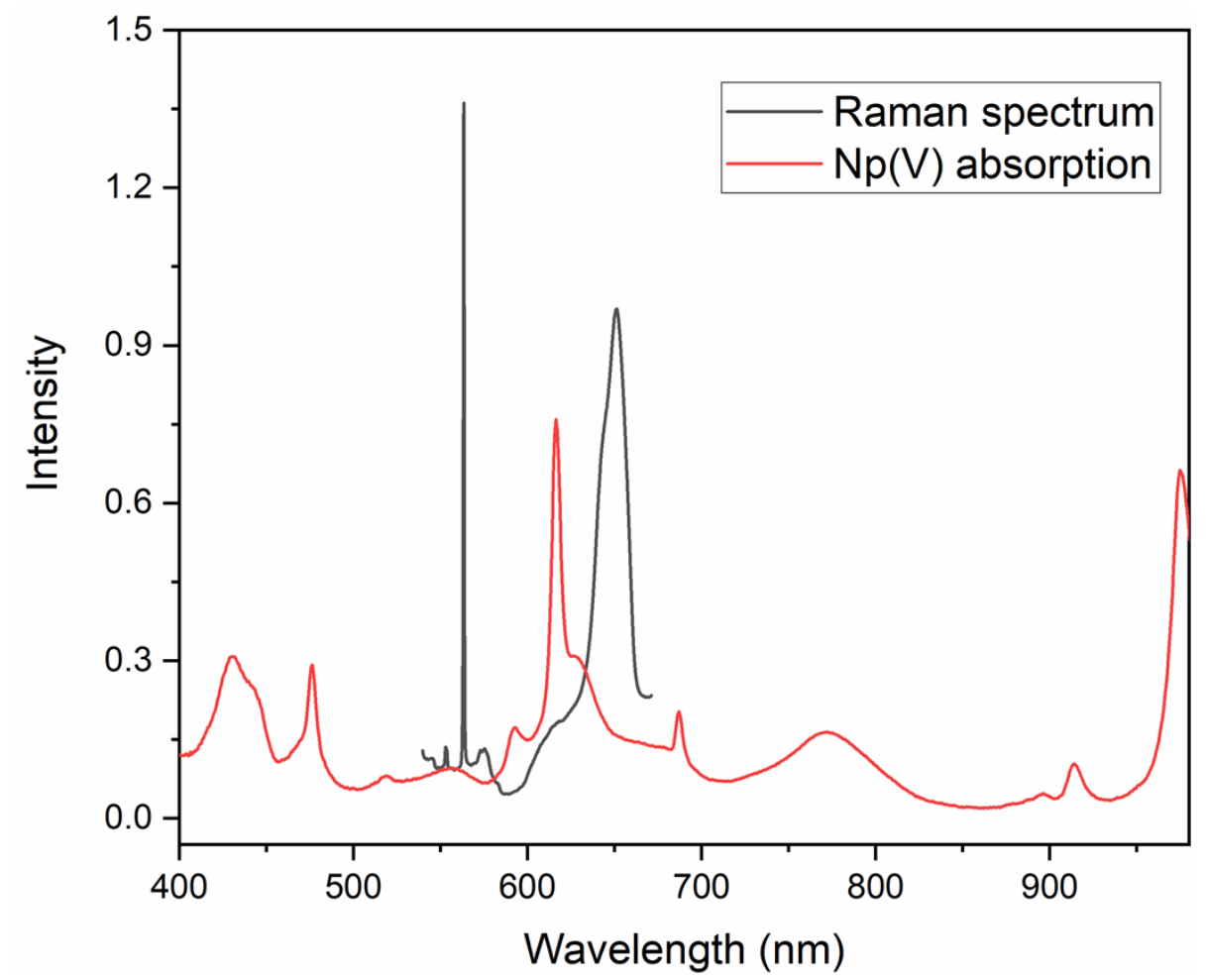

Figure 2.9. Example $\mathrm{Np}(\mathrm{V})$ absorption spectrum and an example Raman spectrum taken from the data presented in Figure 2.5.

Raman spectra corresponding to each sample are shown in Figure 2.10. The working distance was adjusted to optimize the signal by moving the probe in and out until the acquired Raman signal intensity was sufficient for analysis. The nitrate peak, $\mathrm{Np}(\mathrm{V}), \mathrm{Np}(\mathrm{VI})$, and the $\mathrm{O}-\mathrm{H}$ stretching region signals were clearly identified in samples LD1 and LD3 (see Figure 2.10). These peaks were also identified but less obvious in sample LD2. Sample LD3 appeared to be the most amenable to quantitative analysis because the distortion in the water band region $\left(2,800-3,700 \mathrm{~cm}^{-1}\right)$ was minimal. 

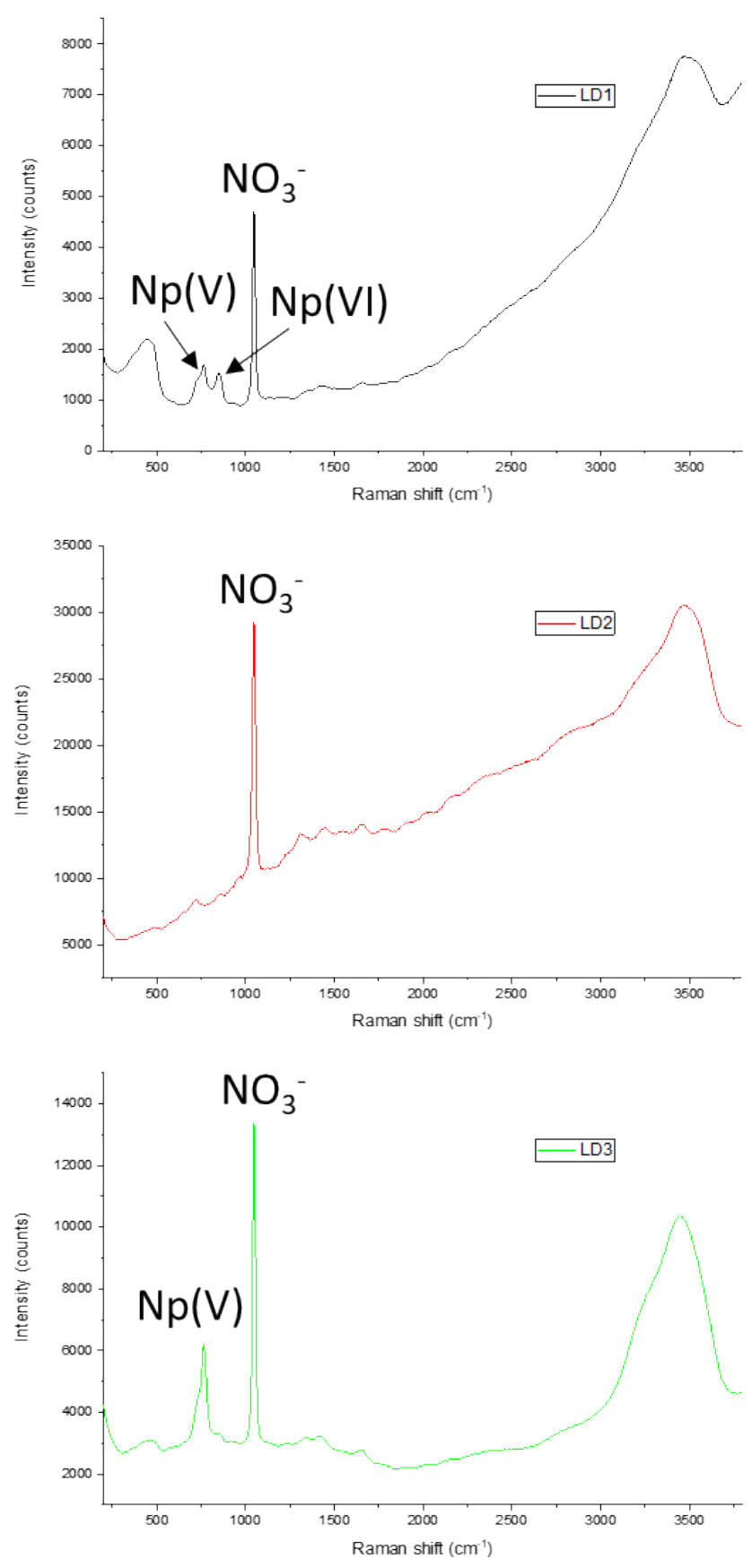

Figure 2.10. Raman spectra of Np solutions outlined in Figure 2.8. Data acquired using the Spectra Solutions Raman probe. Nitrate peak and $\mathrm{Np}(\mathrm{V})$ and $\mathrm{Np}(\mathrm{VI})$ peaks are labeled.

These results demonstrate that Raman measurements in reflection mode could be useful for quantifying a wider range of process solutions in support of the ${ }^{238} \mathrm{Pu}$ Supply Program. General-purpose probes can be used to measure concentrated $\mathrm{Np}$ solutions within a transparent container (e.g., glass), or an immersion version (Inconel barrel) may connect to the probe body and be dipped directly into the solutions. Probes with the ideal (i.e., minimal) focal length should be used. Reflection mode measurements, enabled by these probes, will increase signal intensity by minimizing the amount of excitation and scattered light that 
is absorbed by the system. Before implementing Raman in the hot cell again, new fiber-optic cables must be installed because the Raman signal intensity was weak. ${ }^{2,18}$

A Horiba iHR320 Raman spectrometer is in lab 209 and available for future Np measurements. A laser shield will be fabricated and installed on box 13 before use. Combining Raman spectroscopy with UVVis-NIR absorption spectrometry would provide a detailed understanding of the $\mathrm{Np} / \mathrm{HNO}_{3}$ system and has great potential to be published in a peer-reviewed journal. This systematic study would support program needs and provide useful data for developing new methods for quantitative Raman spectroscopy of strongly absorbing solutions. This could be a great opportunity for a summer or graduate student. Learning objectives could include developing an understanding of the relationships between absorption, concentration, and observed Raman signal intensities and developing correction methods for Raman selfabsorption. Much of this work could be done cold using lanthanide surrogates. A successful project may reveal the applicability of these techniques to more complex systems of interest to the ${ }^{238} \mathrm{Pu}$ Supply Program.

Raman probe and flow cell key points are as follows (see Figure 2.2):

1. Setup can enable measurements that are free from glass spectral signatures overlapping with analyte peaks (e.g., $\left.\mathrm{Al}(\mathrm{OH})_{4}^{-}\right)^{-}$.

2. Flow cuvette could enable the analysis of different samples using the same cell and geometry for consistency.

3. Calibration and process solutions can be pumped in and out using a syringe for testing outside the hot cell. This would require either a Fluid Metering Inc. (FMI) pump or stainless-steel syringe for in-cell applications.

4. Reflection mode geometry will minimize the Raman self-absorption effect in strongly absorbing $\mathrm{Np}$ and $\mathrm{Pu}$ solutions.

5. Setup is built from off-the-shelf parts that can be delivered in roughly 3 weeks. The cost for everything in Figure 2.2 is about $\$ 5,000$.

6. Immersion probe barrels made of Inconel are also available. These can be attached to the same probe body shown in Figure 2.2. The immersion probes on hand are 6 in. long with a fused silica window, a Kalrez o-ring compression seal, and a $1 \mathrm{~mm}$ working distance.

\section{NEPTUNIUM SPECTROPHOTOMETRY DEVELOPMENT}

\subsection{UV-VIS-NIR ABSORPTION SPECTROSCOPY}

Spectrophotometry (e.g., absorption spectroscopy) is an optical technique that quantitatively measures the amount of light absorbed by a molecule as a function of wavelength. Typically, the UV, Vis, and NIR regions of the electromagnetic spectrum are studied. When a molecule absorbs UV-Vis light, electrons are promoted to higher-energy orbitals, and the molecule is promoted to an exited state. NIR radiation does not supply enough energy to the system to promote electrons to higher orbitals, but it can change the rotational and vibrational motions of a molecule. Thus, most NIR transitions correspond to molecular vibrational modes, with exceptions found in certain forbidden $f-f$ transitions of lanthanides and actinides..$^{14,15}$ 
When a sample absorbs light, the irradiance of the incident beam of light decreases. The ratio between the incident and transmitted light is used to calculate the absorbance of a sample. Absorbance is directly proportional to the concentration of a light-absorbing species, and it can be described by Beer's law when the optical pathlength and molar absorptivity of the substance is known, and the measurement is within the dynamic range of the spectrophotometer. This univariate approach breaks down in complex systems with overlapping absorption bands, shifting baselines, and dependencies on solution conditions. However, this straightforward approach is still suitable in many situations (see Section 4 for details).

Section 3.2 summarizes how spectrophotometry can be used to quantify several solution components such as nitrate/nitrite/acid concentration and temperature. Sections 3.3-3.6 summarize the progress made during Campaign 5 glovebox and benchtop testing in support of spectrophotometric quantification of $\mathrm{Np}$ processing solutions. Many of the tests seek to understand dynamic range limitations and how molar absorptivity values change at high $\mathrm{Np}$ concentration $(>0.1 \mathrm{M} \mathrm{Np})$.

\subsection{UV SPECTRA AND THE NIR WATER BAND}

\subsubsection{UV absorption spectra for nitrate and nitrite}

To fully characterize the absorption spectra of $\mathrm{Np}$ species with a high degree of certainty, several regions of the UV-Vis-NIR spectrum were analyzed in the absence of $\mathrm{Np}$ to understand the origin of certain characteristics. Absorption spectra from 300-1700 nm are impacted by numerous species other than Np species. This includes nitrate and nitrite peaks which appear in the $300-400 \mathrm{~nm}$ region. Additionally, the water band(s) will change with varying acidity and temperature in certain spectral regions $(\sim 960, \sim 1200$ and $\sim 1440 \mathrm{~nm}$ ) which overlap with peaks originating from $\mathrm{Np}$ species. The water band contribution will change significantly depending on the optical pathlength. ${ }^{17}$ Every spectral contribution must be well accounted for to achieve highly accurate $\mathrm{Np}$ concentration measurements by spectrophotometry. It is also desirable to quantify other variables (e.g., nitrate, nitrite, nitric acid, and temperature) in addition to Np.

UV absorption measurements were collected to characterize nitrate and nitrite spectral signature(s) because the relative concentrations of these species significantly influence $\mathrm{Np}$ redox chemistry. ${ }^{24}$ Broad absorption peaks arise from nitrate and nitrite at 300 and $360 \mathrm{~nm}$ (see Figure 3.1). The bands are easily resolved at $0.1 \mathrm{M}$, despite using a relatively short $1 \mathrm{~mm}$ pathlength. Weak signals were even discernable at $0.01 \mathrm{M} \mathrm{NaNO}_{3}$ and $\mathrm{NaNO}_{2}$ concentrations but are difficult to see owing to the scale. To record a stronger signal at $0.01 \mathrm{M}$, the samples could be analyzed using a longer pathlength. UV-Vis measurements were also collected in an analogous system containing $\mathrm{NaCl}$ and $\mathrm{HCl}$ (data not shown here). There were no peaks in the UV region besides the oxygen peak near $200 \mathrm{~nm}$ in these systems; therefore, the peaks near $300 \mathrm{~nm}$ and $360 \mathrm{~nm}$ may be attributed to $\mathrm{NO}_{3}{ }^{-}$and $\mathrm{NO}_{2}^{-}$, respectively. 


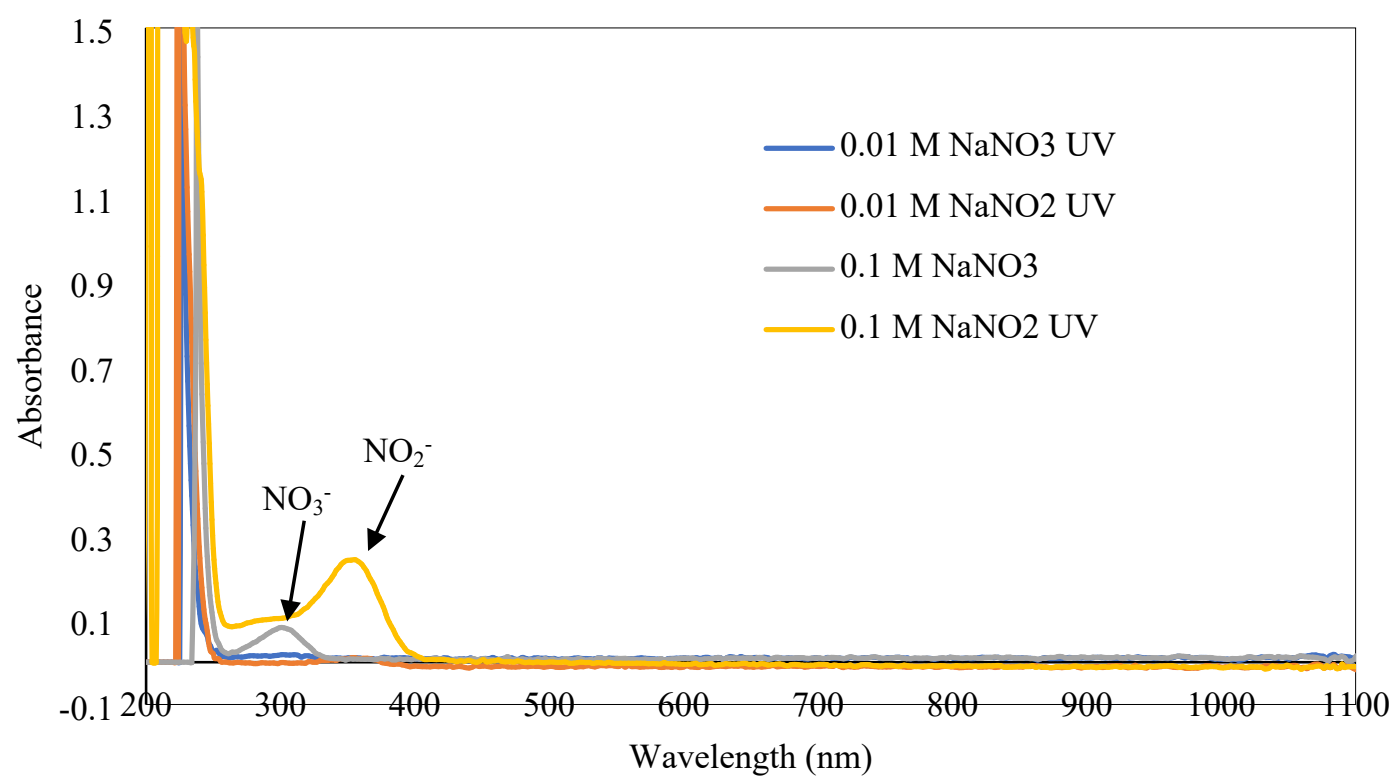

Figure 3.1. UV-Vis absorbance spectra of $\mathrm{NaNO}_{3}$ and $\mathrm{NaNO}_{2}$ in water. Spectra were collected using a $1 \mathrm{~mm}$ pathlength quartz cuvette and a StellarNet cuvette holder. Water was used as a blank.

Thus, UV absorption spectrophotometry may be used to quantify nitrate and nitrite concentrations in process solutions. Unfortunately, it is not possible to test this application in the hot cell because the hot cell fibers currently installed do not transmit UV light efficiently. Nitrite/nitrate concentrations could be measured in glovebox studies to learn more about nitrite production due to alpha-radiolysis and the consequent redox reactions that affect the valence of $\mathrm{Np}$ and $\mathrm{Pu}$ under relevant process conditions.

Raman spectroscopy is also sensitive to nitrite. Nitrite $\left(\mathrm{NO}_{2}^{-}\right)$and nitrate $\left(\mathrm{NO}_{3}^{-}\right)$can be characterized by distinct symmetric stretching Raman bands. Literature suggests the detection limits using UV resonance Raman spectroscopy are on the order of $<200$ ppb for each species. ${ }^{25}$

\subsubsection{NIR water band for nitric acid and temperature}

Initial UV-Vis and NIR spectra were collected using a StellarNet Silver Nova and Dwarf Star spectrometer to determine if NIR absorbance spectral signatures could be used to predict $\mathrm{HNO}_{3}$ concentration. NIR water bands are useful for water determination and are sensitive to changes in solution chemistry and temperature. ${ }^{26,27}$ NIR spectral signatures were characterized in benchtop studies under a variety of conditions. Findings suggest that NIR absorption spectroscopy may be useful to determine the concentration of acid, nitrate, and aqueous metal ions in critical processing stages for the ${ }^{238} \mathrm{Pu}$ Supply Program. ${ }^{17}$ This approach would be better than Raman spectroscopy because NIR spectrometers are already being routinely used. However, the spectrophotometric approach requires a $1 \mathrm{~mm}$ optical pathlength.

Most absorbance bands observed in the NIR region $(700-2,500 \mathrm{~nm})$ are caused by vibrational overtones and combinations of either $\mathrm{C}-\mathrm{H}, \mathrm{N}-\mathrm{H}$, or $\mathrm{O}-\mathrm{H}$ stretches. The extinction coefficients for $\mathrm{O}-\mathrm{H}$ bands in the 900-1,250 nm region are relatively low and can be studied using a standard pathlength of $\sim 1 \mathrm{~cm}$. Water absorbs light between $\sim 1,400$ and $1,800 \mathrm{~nm}$ so strongly that it is rarely used for quantification because the dynamic range of most spectrophotometers cannot measure the signal using cuvettes with standard 
pathlengths (i.e., $1 \mathrm{~cm}$ ). However, when short pathlengths are used (e.g., $0.5-2 \mathrm{~mm}$ ) it is possible to measure this signal.

Water bands in the NIR may be useful for determining acid concentration. Inorganic acids do not directly absorb NIR radiation, but strong acids (e.g., $\left.\mathrm{HNO}_{3}\right)$ dissociate into hydronium ions $\left(\mathrm{H}_{3} \mathrm{O}^{+}\right)$and corresponding anions that perturb the NIR water band. ${ }^{26}$ The interaction of dissociated ionic species with water molecules is not necessarily structure-specific, and the influence of species on NIR bands of water require lab-scale experiments before being applied to ${ }^{238} \mathrm{Pu}$ production. Water NIR absorption bands are broad and often result in overlapped spectra. Thus, multivariate calibration methods are employed to relate spectral variance to chemical concentrations in these systems. Absorbance measurements of strongly absorbing actinides, at concentrations relevant to the ${ }^{238} \mathrm{Pu}$ Supply Program's processing streams, may require a shorter pathlength (i.e., $1 \mathrm{~mm}$ ) than the more commonly used $10 \mathrm{~mm}$ pathlength. Thus, it may be fortuitous that the optimal pathlength for actinide measurements in the UV-Vis-NIR regions is the same as water measurements in the NIR.

Water strongly absorbs light between 1,350 and 1,700 nm (see Figure 3.2). It absorbs light so strongly in this region that the signal is not linear because the dynamic range of the StellarNet and Ocean Insight spectrometers cannot account for the high optical density using a 5 or $10 \mathrm{~mm}$ pathlength cuvette. The Cary $6000 \mathrm{i}$ could use an optical pathlength of $\leq 4 \mathrm{~mm}$ since the dynamic range is much greater than the StellarNet and Ocean Insight options. However, absorbance measurements using a $1 \mathrm{~mm}$ pathlength cuvette fall within the dynamic range of the spectrometer and fluctuation of this band intensity, and position can be correlated to the concentration of dissolved electrolytes or extent of the external perturbation (i.e., temperature) using multivariate chemometrics. ${ }^{17}$

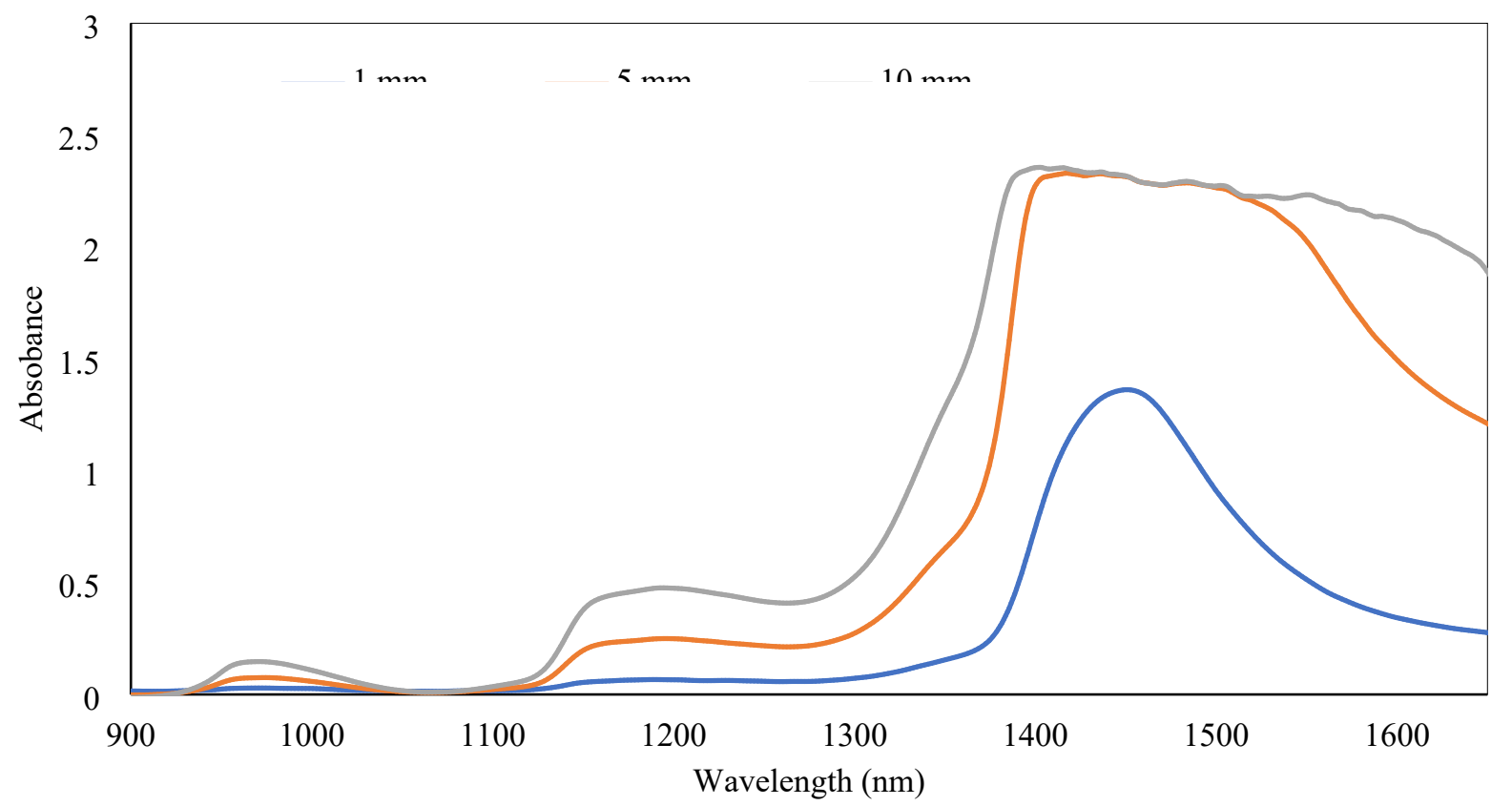

Figure 3.2. NIR spectra of pure water in cells of varying pathlength $\mathbf{1}, \mathbf{5}$, and $10 \mathrm{~mm}$. Air was used as a blank. No bands were observed in the $200-900 \mathrm{~nm}$ UV-Vis region using a $1 \mathrm{~mm}$ pathlength. Notice the signal intensity at $\sim 1,440 \mathrm{~nm}$ is not proportional to pathlength because it reaches a maximum at $\sim 2.3$ absorbance units (AU.).

Data can be acquired by referencing the spectrophotometer with a $1 \mathrm{~mm}$ cuvette either in air or in water (see Figure 3.3). The influence of $1 \mathrm{M} \mathrm{HNO}_{3}$ and $1 \mathrm{M} \mathrm{NaNO}_{3}$ is readily observed in the spectrum blanked 
in water. This experimental approach makes the most logical sense for determining $\mathrm{HNO}_{3}$ concentration in process solutions. If flow cuvettes were dry, then precipitates could adhere to the glass and alter the data. However, blanking the cuvette in air could have an added benefit if an external perturbation, such as temperature, needs to be quantified because this data would be independent of the blank temperature, which will vary from day to day.
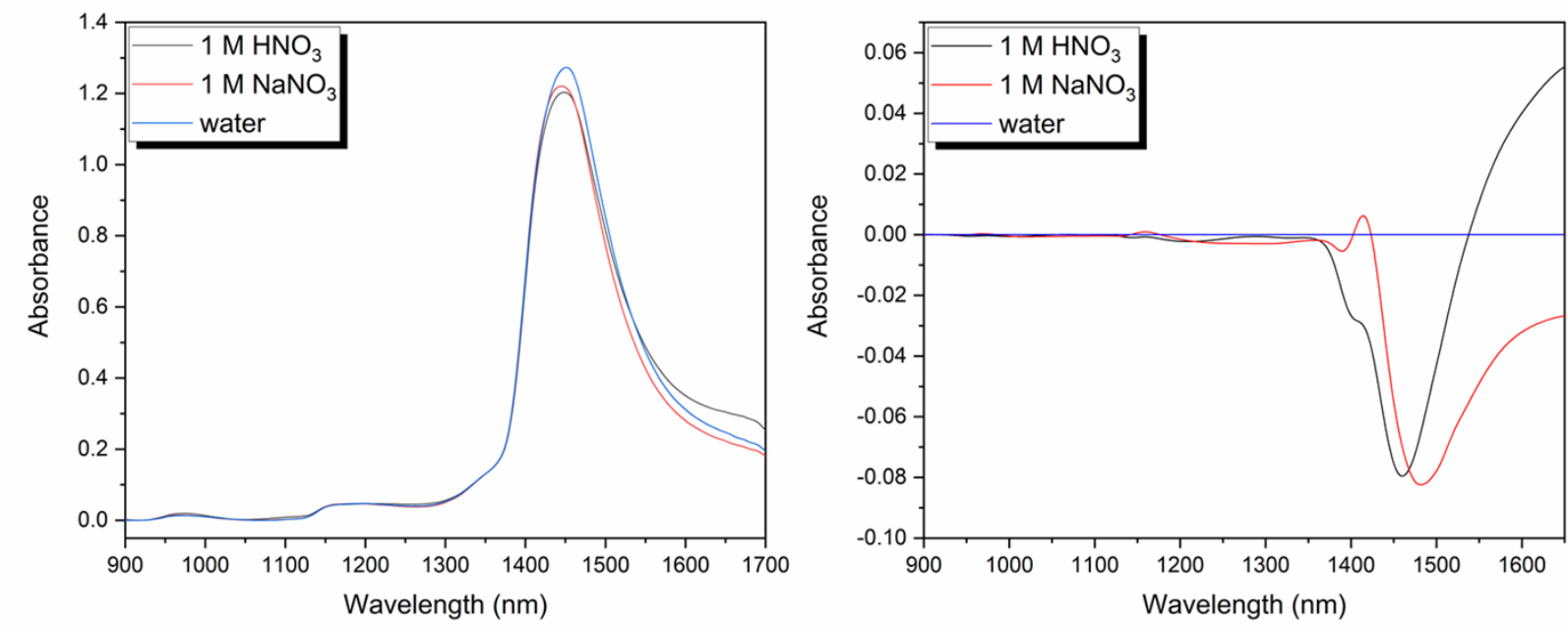

Figure 3.3. NIR absorbance spectra of water, $1 \mathrm{M} \mathrm{HNO}_{3}$, and $1 \mathrm{M} \mathrm{NaNO}_{3}$ blanked in air (left) and blanked in water (right).

The temperature of a solution can be characterized by fluctuations in the water band signal (see Figure 3.4). These samples were blanked in water at $20^{\circ} \mathrm{C}$ before adjusting the temperature using an Avantes temperature-controlled cuvette holder. If the starting temperature was fixed at $20^{\circ} \mathrm{C}$ to reference the spectrophotometer each time, then a partial least squares regression (PLSR) model built from this data could be used to determine temperature. However, if the blank temperature varies significantly, then the rest of the data will be affected. If the raw data blanked in air is collected, then the regression model can account for any reasonable blank temperatures because the temperature of the quartz cuvette and the air inside will not significantly change the reference. 

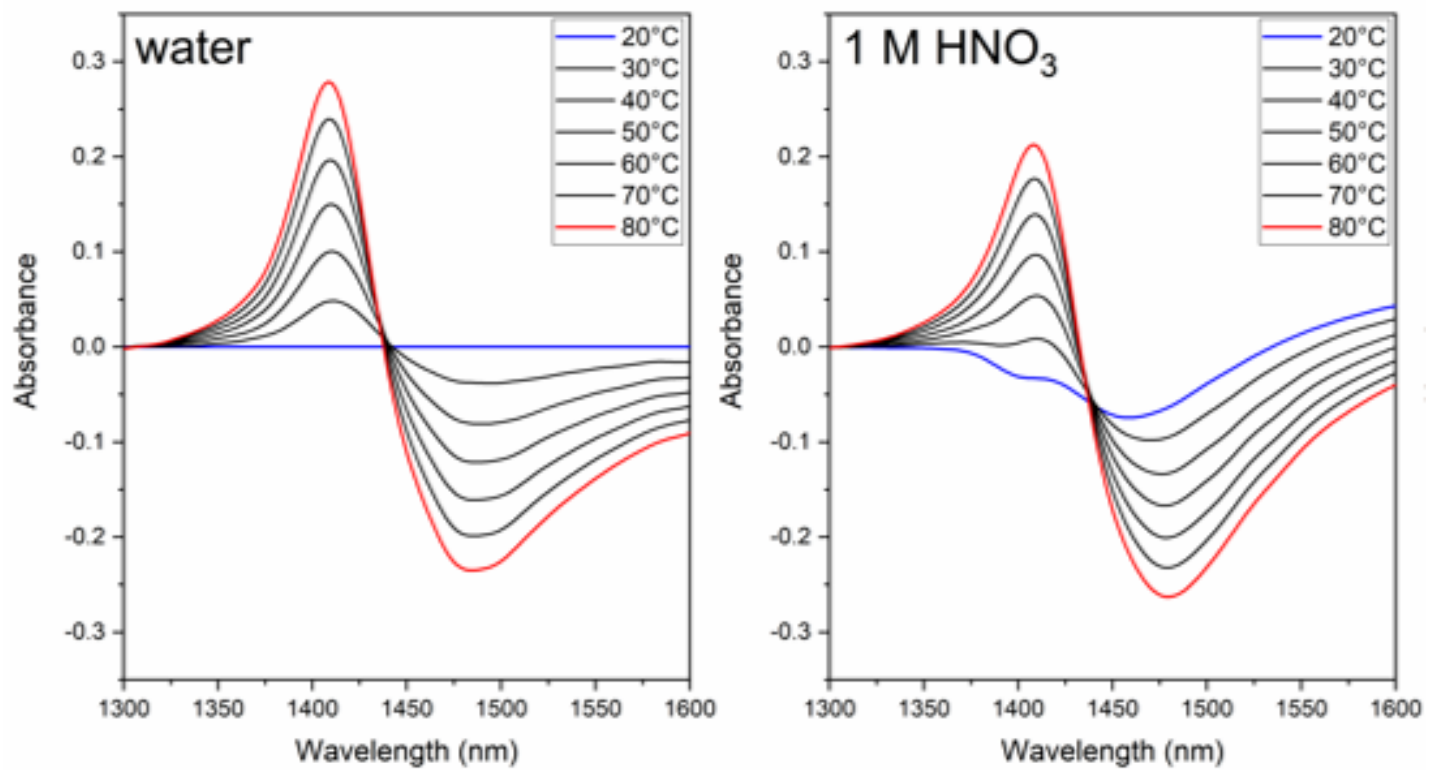

Figure 3.4. Temperature NIR absorbance spectra of water $20-80^{\circ} \mathrm{C}($ left $)$ and $1 \mathrm{M} \mathrm{HNO}_{3} 20-80^{\circ} \mathrm{C}($ (right) blanked in water at $20^{\circ} \mathrm{C}$.

The spectral response of solutions containing $\mathrm{NaNO}_{3}$ is significantly different than the spectral response of $\mathrm{HNO}_{3}$ (see Figure 3.5). The relationship between the spectral response and concentration was nearly linear over the experimental conditions shown in Figure 3.5. PLSR models were used to predict the concentration of a trained $0.7 \mathrm{M}$ solution by the correlating spectral response (i.e., absorbance) to concentration of a training set comprising $0.1,0.5,1,2$, and $4 \mathrm{M}$ calibration standards. In general, the regression parameters were satisfactory, and accurate predictions of a $0.7 \mathrm{M}$ verification solution were achieved (data not shown here). Thus, $\mathrm{H}_{3} \mathrm{O}^{+}$and $\mathrm{Na}^{+}$ions distinctly interact with water molecules. ${ }^{17} \mathrm{In}$ fact, the spectral response of most aquo cations is unique, so this approach can likely be applied to other systems containing Np. ${ }^{28}$ 

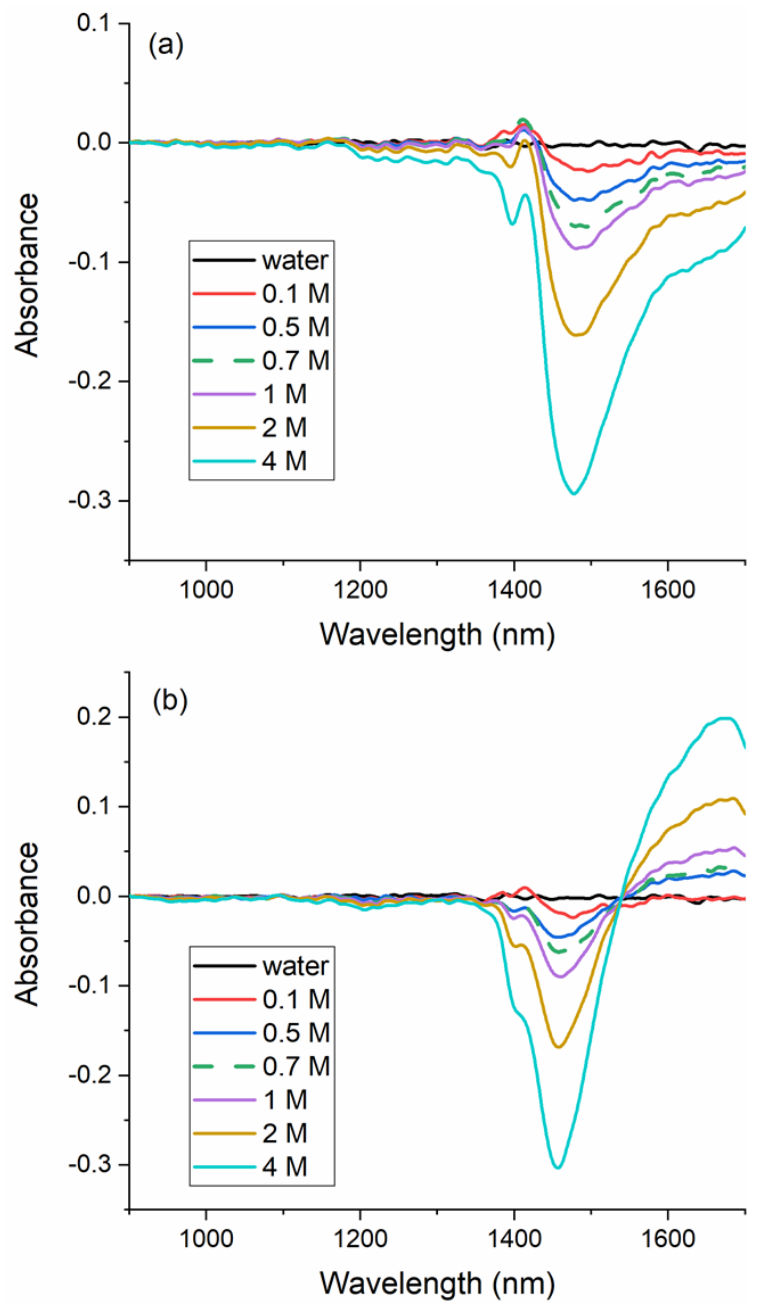

Figure 3.5. NIR absorbance spectra of solutions containing (top) $\mathrm{NaNO}_{3}$ and (bottom) $\mathrm{HNO}_{3}\left(0.1-4 \mathrm{M}_{\text {) }}\right.$ using a $1 \mathrm{~mm}$ pathlength quartz cuvette and a ThorLabs cuvette holder. Water was used as a blank.

\subsection{CROSSOVER EXPERIMENTS}

Crossover absorption experiments were performed to determine how $\mathrm{Np}$ spectral features change at high $\mathrm{Np}$ concentration and to test the dynamic range of our spectrophotometers. This experiment was the first systematic attempt taken by the program to use short pathlength cells $(<1 \mathrm{~mm})$ to enable the quantification of high concentration Np solutions by spectrophotometry. UV-Vis and NIR absorption spectra were obtained on an actual MDD feed solution (taken from tank T-504) that was diluted to make a series of $\mathrm{Np}$ concentrations, each measured using various pathlengths (see Table 3.1). The stock solution contained $210 \mathrm{~g} \mathrm{~Np} / \mathrm{L} \pm 10 \mathrm{~g} / \mathrm{L}$ at $1 \mathrm{M} \mathrm{HNO}_{3}$ based on numerous analytical measurements. Impurities included some phosphorus-containing species and a trace amount of $\mathrm{Pu}$. Neptunium concentrations were increased gradually, starting at $4.5 \mathrm{mM}$ neptunium, using four cuvettes with different pathlengths. Each of the samples was diluted in $1 \mathrm{M} \mathrm{HNO}_{3}$ to maintain a constant acidity. Data were acquired in a glovebox using various flow cells $(0.05-2 \mathrm{~mm})$, made by Starna Scientific, and standard quartz cuvettes (1-10 $\mathrm{mm})$. 
Table 3.1. Six samples with total Np concentration (mM) and optical pathlength (mm).

\begin{tabular}{cccccc}
\hline ID & $\mathbf{N p}(\mathbf{m M})$ & $\begin{array}{c}\text { Pathlength } \\
(\mathbf{m m})\end{array}$ & ID & $\begin{array}{c}\mathbf{N p} \\
(\mathbf{m M})\end{array}$ & $\begin{array}{c}\text { Pathlength } \\
(\mathbf{m m})\end{array}$ \\
\hline 1 & 4.5 & 10 & 4 & 89 & 2 \\
& & 5 & & & 1 \\
& & 2 & & & 0.5 \\
& & 1 & & & 0.2 \\
\hline 2 & 8.9 & 10 & 5 & 445 & 0.5 \\
& & 5 & & & 0.2 \\
& & 2 & & & 0.1 \\
& & 1 & & & 0.05 \\
\hline 3 & 45 & 5 & 6 & 890 & 0.5 \\
& & 2 & & & 0.2 \\
& & 1 & & & 0.1 \\
& & 0.5 & & & 0.05 \\
\hline
\end{tabular}

The experimental setup is shown in Figure 3.6. A syringe was used to introduce blank and rinse solutions and the samples. Ocean Optics QEPro and NIRQuest spectrophotometers were used to collect spectra, and the spectrometers were references to water. UV-Vis spectra included absorbance measurements every $0.72 \mathrm{~nm}$ from 199 to $985 \mathrm{~nm}$, and NIR spectra included absorbance measurements recorded every $1.65 \mathrm{~nm}$ from 897 to $1,717 \mathrm{~nm}$. A stabilized incoherent light source (Vis-NIR range 360-2,600 nm) made by Thorlabs (SLS201L) was used for each measurement. As the concentration increased from $4.5 \mathrm{mM}$ to $0.9 \mathrm{M} \mathrm{Np}$, the signal from the longest pathlength cuvette was lost, but the others were still within the dynamic range of the spectrometer. This sequential process was used to validate the data over the entire range ( $\sim 5 \mathrm{mM}$ up to $\sim 1 \mathrm{M} \mathrm{Np}$ ) so that true spectral deviations, or simply spectrophotometer artifacts, could be recognized.

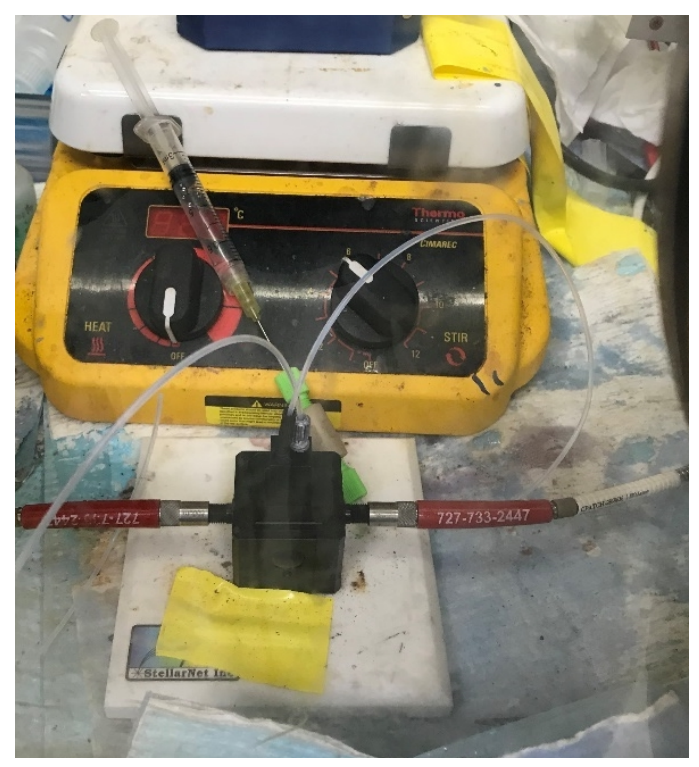

Figure 3.6. StellarNet cuvette holder and a Starna flow cell with a $1 \mathrm{~mm}$ pathlength, $1 / 16 \mathrm{in}$. tubing, and a plastic syringe. 
The dynamic range of the Ocean Optics spectrophotometers was tested to ensure that the data being collected accurately reflected the correct optical density of the samples. To test this, the absorbance of the $980 \mathrm{~nm}$ peak resulting from the $4.5 \mathrm{mM} \mathrm{Np}$ solution was studied as a function of pathlength. The $980 \mathrm{~nm}$ peak is the most intense peak in the $\mathrm{Np}(\mathrm{V})$ spectrum. The NIR absorption spectra appeared smooth and correlated at a first glance (see Figure 3.7). However, the $980 \mathrm{~nm}$ peak did not follow Beer's law over this range of optical pathlengths $(0.1-1 \mathrm{~cm})$. A linear regression of the $980 \mathrm{~nm}$ absorbance values vs. pathlength indicates that linearity is not conserved as the pathlength increases (see Figure 3.8). The absorptivity ( $\varepsilon$ ) of the $980 \mathrm{~nm}$ peak was calculated to be $350 \mathrm{M}^{-1} \cdot \mathrm{cm}^{-1}$ using the smallest pathlength $(0.1$ $\mathrm{cm})$ data point. This value agrees with a recent study but is lower than previously reported values $\left(395 \mathrm{M}^{-}\right.$ ${ }^{1} \cdot \mathrm{cm}^{-1}$ in $\left.\mathrm{HClO}_{4}\right) .5,14$ This discrepancy could be attributed to missing the maximum peak intensity in the spectrum because of poor spectral resolution. Nonetheless, it highlights the need for this crossover study, which identified spectral irregularities possibly resulting from spectrophotometer shortcomings. Even though the spectrum collected with the $0.5 \mathrm{~cm}$ cuvette does not appear to be distorted or noisy, it is not responding properly: the measured absorbance is 0.66 but should be $\sim 0.75$ based on the measurements using the 0.1 and $0.2 \mathrm{~cm}$ pathlength cuvettes. This suggests that the $980 \mathrm{~nm}$ absorption band is only quantitative below $\sim 0.5 \mathrm{AU}$ using the NIRQuest. This result is contrary to data acquired using other peaks in the $\mathrm{Np}(\mathrm{V})$ spectrum (e.g., $1096 \mathrm{~nm}$ band).

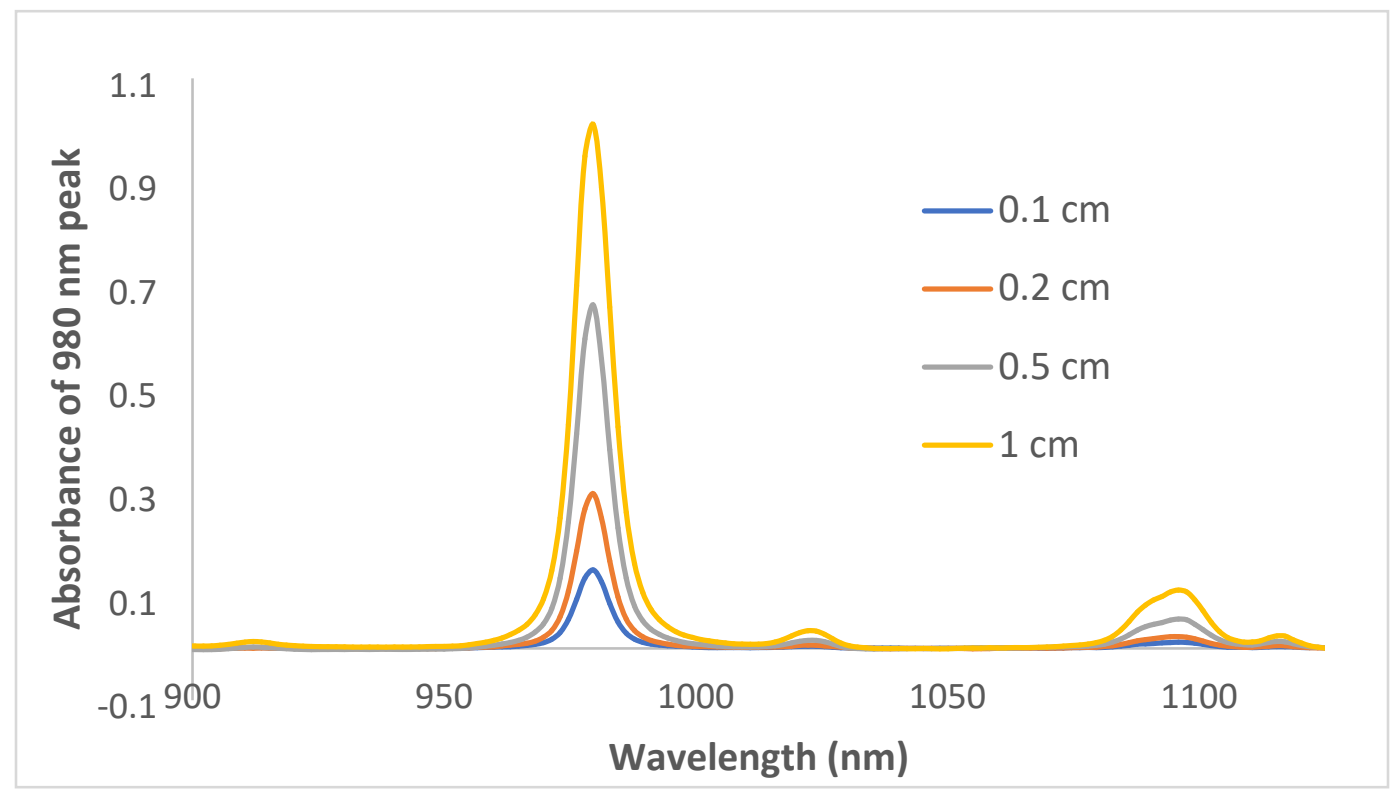

Figure 3.7. NIR absorption spectrum of a $4.5 \mathrm{mM}$ Np solution in $1 \mathrm{M} \mathrm{HNO}_{3}$ with varying optical pathlengths $(0.1-1 \mathrm{~cm})$. 


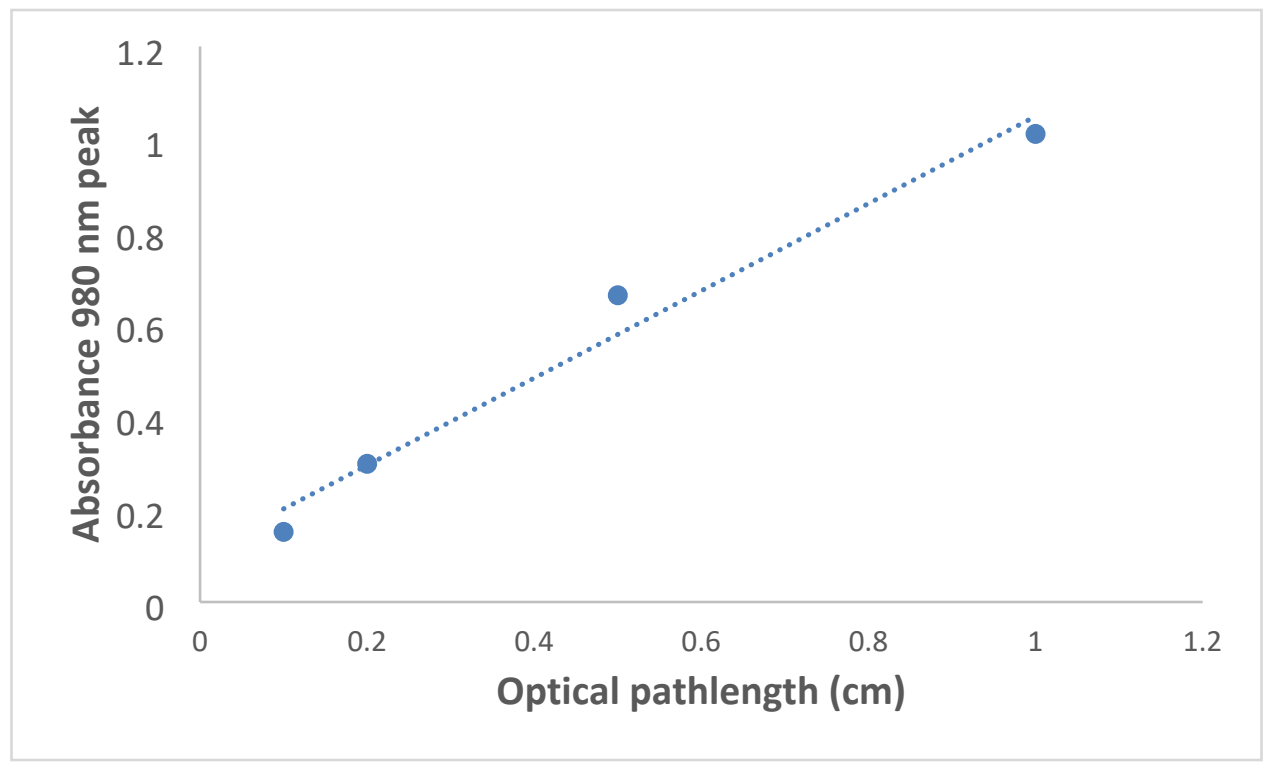

Figure 3.8. A $980 \mathrm{~nm}$ peak absorbance value of a $4.5 \mathrm{mM}$ Np solution in $1 \mathrm{M} \mathrm{HNO}_{3}$ with varying pathlength $(0.1-1 \mathrm{~cm})$ and a linear regression.

\subsubsection{Absorption coefficients}

The absorption spectrum of the $210 \mathrm{~g} \mathrm{~Np} / \mathrm{L}$ solution is shown in Figure 3.9. Using standard molar absorptivity values of 39 for the $\mathrm{Np}(\mathrm{VI}) 1,222 \mathrm{~nm}$ peak and 22 for the $\mathrm{Np}(\mathrm{V}) 616 \mathrm{~nm}$ peak, concentrations were calculated to be $8 \mathrm{~g} \mathrm{~Np}(\mathrm{VI}) / \mathrm{L}$ and $165 \mathrm{~g} \mathrm{~Np}(\mathrm{~V}) / \mathrm{L}$ for a total of $172 \mathrm{~g} \mathrm{~Np} / \mathrm{L}$. This value is not in good agreement with the concentration reported by the analytical group because it differs by $\sim 18 \%$. This calculation assumed that the molar absorptivity of $\mathrm{Np}(\mathrm{V})$ did not change at high concentrations, which subsequent testing revealed is an incorrect assumption. 


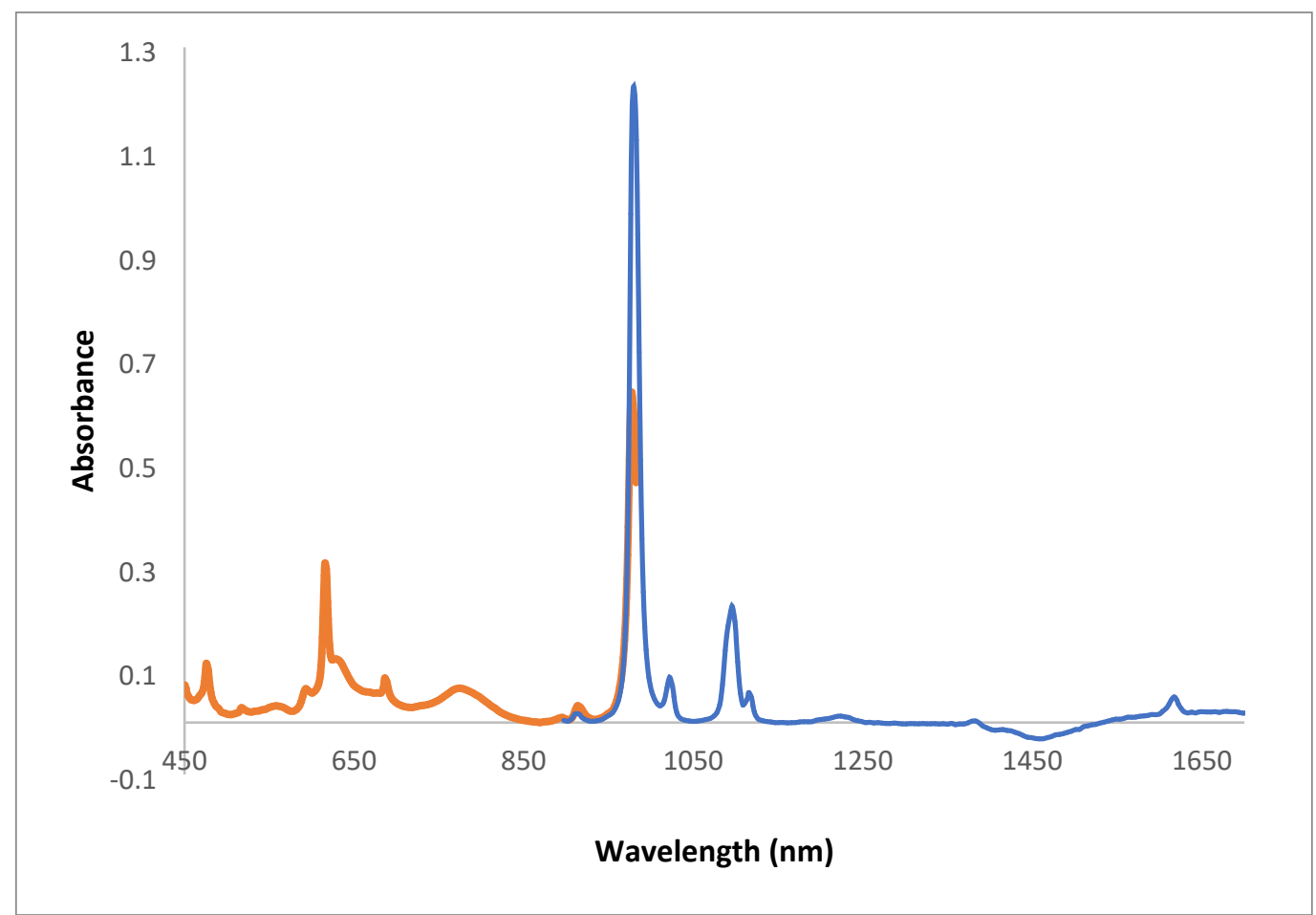

Figure 3.9. Vis-NIR absorption spectrum of the stock solution $(210 \mathrm{~g} \mathrm{~Np} / \mathrm{L})$ collected with the QEPro (UVVis) and NIRQuest (NIR) from 450 to $1,700 \mathrm{~nm}$ using a $0.02 \mathrm{~cm}$ optical pathlength.

The molar absorptivity of the $616 \mathrm{~nm}$ peak at moderate and high $\mathrm{Np}$ concentrations was determined by plotting the absorbance of one solution vs. a variety of pathlengths. If Beer's law is satisfied and the cuvettes have consistent optical pathlengths, then the data points form a straight line in $y=m x+b$ form. The intercept $(b)$ should be near zero (i.e., at zero concentration, zero absorbance should occur). The average molar extinction coefficient for all pathlengths is then calculated by dividing the slope $m$, which is in units of inverse centimeters $\left(\mathrm{cm}^{-1}\right)$, by the concentration of the solution.

Molar absorptivity values for the $616 \mathrm{~nm}$ peak were calculated for three Np solutions: $22.3(\sim 0.089 \mathrm{M}$ $\mathrm{Np}), 22.2(\sim 0.44 \mathrm{M} \mathrm{Np})$, and $17.6(0.886 \mathrm{M} \mathrm{Np}) \mathrm{M}^{-1} \cdot \mathrm{cm}^{-1}$. An example regression of the data collected on the stock solution $(0.886 \mathrm{M} \mathrm{Np})$ is shown in Figure 3.10. An $R^{2}$ value close to one indicates that the pathlengths of each cuvette are accurate, and the spectral response is within the dynamic range of the spectrophotometer. A concentration of $214 \mathrm{~g} \mathrm{~Np} / \mathrm{L}$ was thus determined by spectrophotometery, using molar absorptivity of 39 for the $\mathrm{Np}(\mathrm{VI}) 1,222 \mathrm{~nm}$ peak and 17.6 for the $\mathrm{Np}(\mathrm{V}) 616 \mathrm{~nm}$ peak. Individual concentrations were $8 \mathrm{~g} \mathrm{~Np}(\mathrm{VI}) / \mathrm{L}$ and $206 \mathrm{~g} \mathrm{~Np}(\mathrm{~V}) / \mathrm{L}$. Total concentration agrees with the concentration reported by the analytical group of $210 \mathrm{~g} \mathrm{~Np} / \mathrm{L} \pm 10 \mathrm{~g} / \mathrm{L}$. Overall, these results suggest that the molar extinction coefficient for the $\mathrm{Np}(\mathrm{V}) 616 \mathrm{~nm}$ peak does not change significantly up to $\sim 0.45 \mathrm{M} \mathrm{Np}(\sim 100 \mathrm{~g}$ $\mathrm{Np} / \mathrm{L})$. Additional data sets must be acquired to determine an accurate molar extinction coefficient for $\mathrm{Np}(\mathrm{VI})$ at high $\mathrm{Np}$ concentrations. 


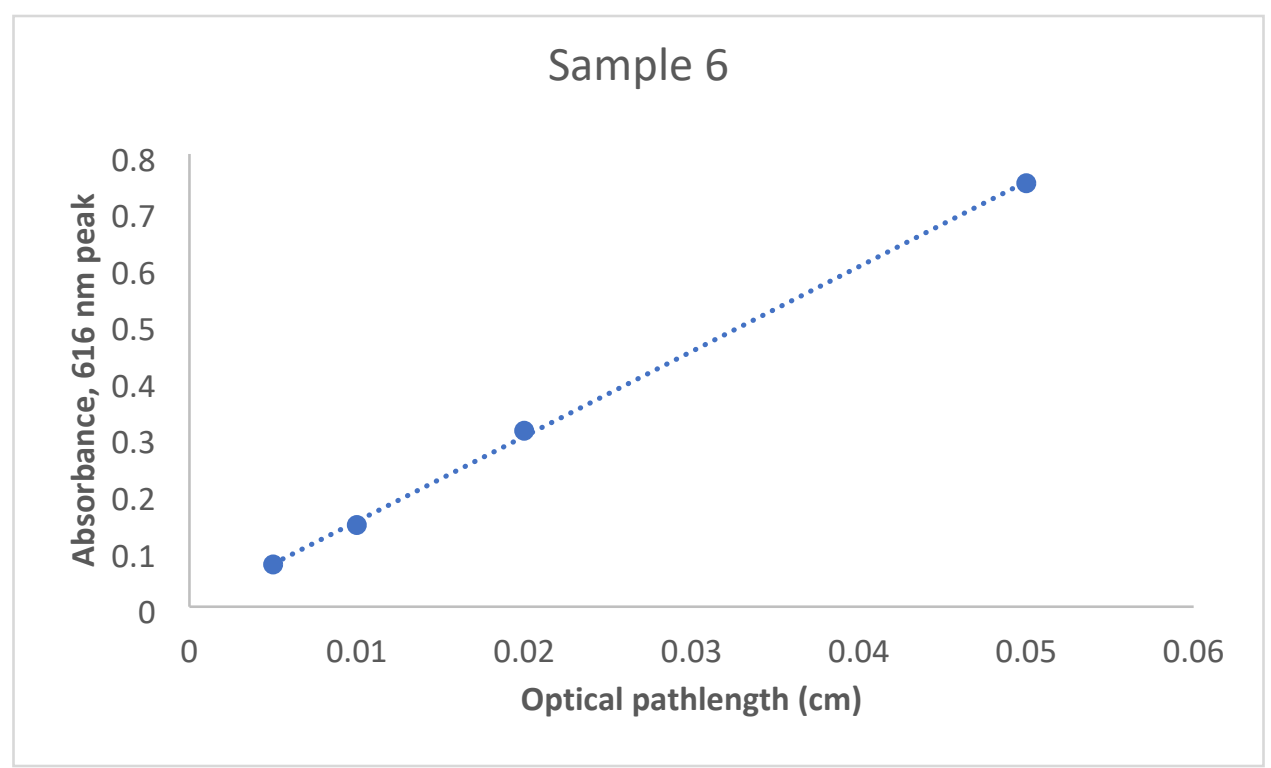

Figure 3.10. The $616 \mathrm{~nm}$ peak absorbance value of the $0.89 \mathrm{M}$ Np solution in $1 \mathrm{M} \mathrm{HNO}_{3}$ using a $0.05,0.1,0.2$, and $0.5 \mathrm{~mm}$ optical pathlength and linear regression. The average epsilon value for each cuvette was calculated by dividing the slope by the $\mathrm{Np}(\mathrm{V})$ concentration.

Significant differences in peak shape and intensity occur as a function of $\mathrm{Np}$ concentration. The most significant changes occur between 630 and $850 \mathrm{~nm}$ (see Figure 3.11). Spectra corresponding to sample 2 $(1 \mathrm{~cm})$, sample $3(0.2 \mathrm{~cm})$, sample $4(0.1 \mathrm{~cm})$, sample $5(0.02 \mathrm{~cm})$, and sample $6(0.02 \mathrm{~cm})$ were scaled using the $616 \mathrm{~nm}$ peak. Samples 2-5 had almost identical absorbance values at $616 \mathrm{~nm}$ in the unscaled spectra. The distortions could relate to either the formation of $\mathrm{Np}(\mathrm{V})-\mathrm{Np}(\mathrm{V})$ dimers or $\mathrm{Np}(\mathrm{V})-\mathrm{Np}(\mathrm{VI})$ interactions arising from high concentration effects. These interactions could result in changing molar absorptivity values at high $\mathrm{Np}$ concentration $(>100 \mathrm{~g} \mathrm{~Np} / \mathrm{L})$. Additional studies are needed to confirm this finding. Tacit knowledge suggests that as the concentration of $\mathrm{Np}$ increases, slightly more $\mathrm{Np}(\mathrm{VI})$ tends to be in equilibrium with $\mathrm{Np}(\mathrm{V})$. The change in $\mathrm{Np}(\mathrm{V}) / \mathrm{Np}(\mathrm{VI})$ equilibrium could partially account for these discrepancies; however, it is unlikely that it fully accounts for these differences. Much of the distortion could be attributed to $\mathrm{Np}(\mathrm{V})-\mathrm{Np}(\mathrm{V})$ interactions. 


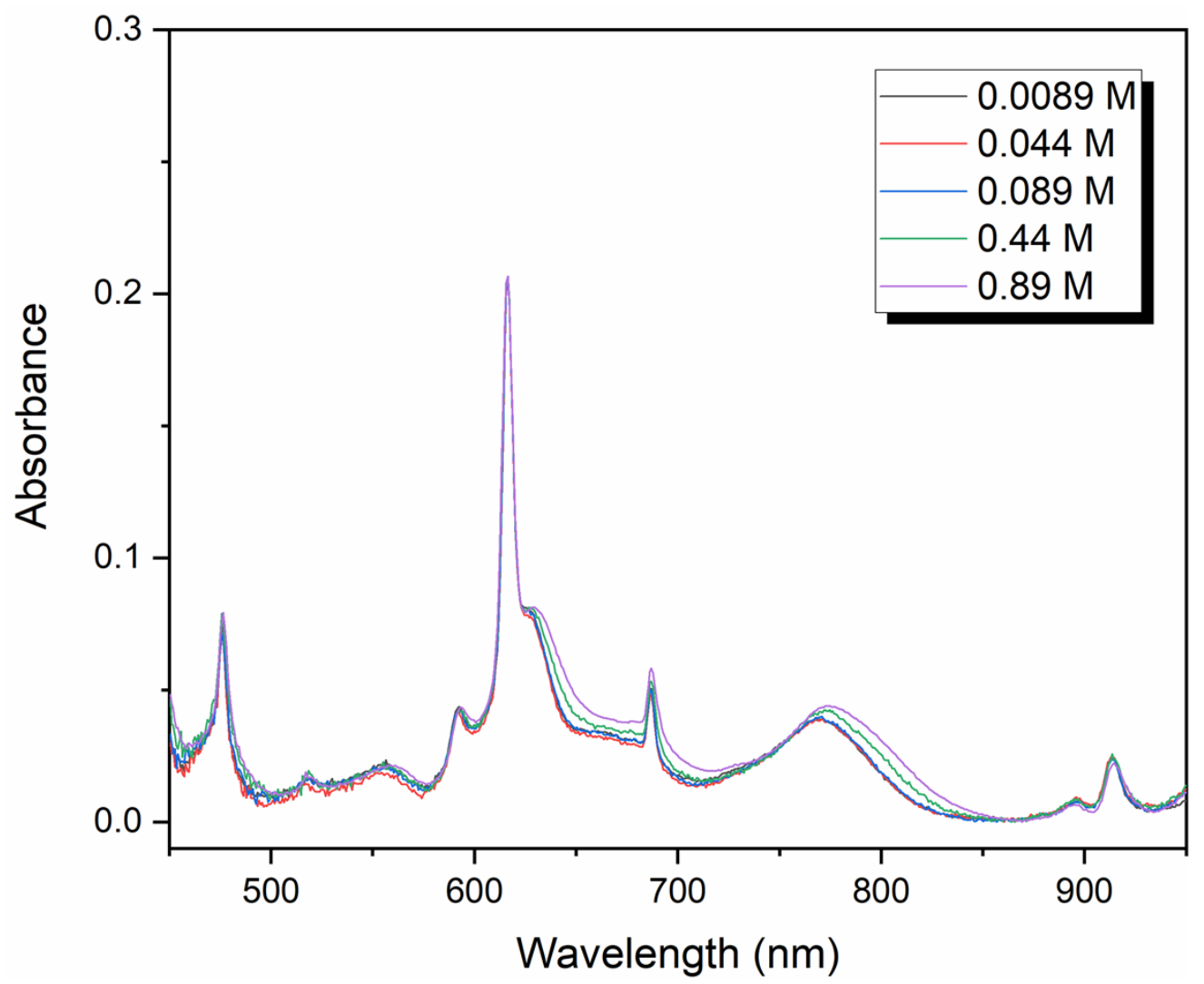

Figure 3.11. Vis-NIR spectra of varying concentration of $\mathrm{Np}(0.0089-0.89 \mathrm{M})$ using different pathlengths $(\mathbf{0 . 0 2}-\mathbf{1} \mathbf{~ c m})$. The data was scaled slightly, using arbitrary factors, to assign the same absorbance value to the 616 $\mathrm{nm}$ peak in each spectrum so that changes in spectral shape and position could be identified.

The molar absorption coefficient of every peak in the absorption spectrum of $\mathrm{Np}(\mathrm{V})$ appeared to change with increasing $\mathrm{Np}$ concentration above $\sim 0.4 \mathrm{M} \mathrm{Np}$. The molar extinction coefficient of the $\mathrm{Np}(\mathrm{V}) 475$, $686,774,915$, and $1,096 \mathrm{~nm}$ peaks were calculated to be $\sim 8,6,4.5,2.5$, and $27 \mathrm{M}^{-1} \cdot \mathrm{cm}^{-1}$, respectively, for concentrations below $\sim 0.4 \mathrm{M} \mathrm{Np}$. However, the absorption coefficients in the most concentrated solution (sample 6) for the 475, 686, 774, 915, and 1,096 peaks changed to $\sim 6,5,3.5,2$, and $22 \mathrm{M}^{-1} \cdot \mathrm{cm}^{-1}$. Only the $1,022 \mathrm{~nm}$ peak did not appear to change significantly but remained at nearly $9 \mathrm{M}^{-1} \cdot \mathrm{cm}^{-1}$ for each concentration. This inconsistent result could be a result of the formation of $\mathrm{Np}(\mathrm{V})-\mathrm{Np}(\mathrm{VI})$ cation-cation complexes at elevated concentration that blueshifts a portion of the $980 \mathrm{~nm}$ peak intensity as a result of the formation of a new band at $990 \mathrm{~nm} .{ }^{10}$ This new peak could result in an increased background contribution to the $1,021 \mathrm{~nm}$ absorption band. This conclusion is supported by the maximum peak position shift from $1,023 \mathrm{~nm}$ at lower concentrations to $1,021 \mathrm{~nm}$ at high concentrations. This is a topic that will be further investigated. Regardless of the outcome, it appears that the $\sim 1,022 \mathrm{~nm}$ peak is not well suited for quantitative concentration measurements in this system.

Another data set was collected on several $\mathrm{Np}$ solutions using a $1 \mathrm{~mm}$ optical pathlength. The response is linear up to a concentration of $\sim 0.5 \mathrm{M} \mathrm{Np}(120 \mathrm{~g} \mathrm{~Np} / \mathrm{L})$ but clearly deviates from linearity above this concentration (see Figure 3.12). A linear regression of first six data points from 0.014 to $0.51 \mathrm{M} \mathrm{Np}$ is $y=$ $2.0634+0.0132$ with $R^{2}=0.9995$. The regression of the three concentrations $0.51,0.69$ and $0.89 \mathrm{M} \mathrm{Np}$ above this region is $y=0.939 x+0.5866$ with $R^{2}=0.9979$. This relationship could be used to quantify $\mathrm{Np}$ concentration above $0.5 \mathrm{M} \mathrm{Np}$ because the peak deviates from Beer's law at these concentrations. Similar relationships were also evident for additional absorption bands $(475,686,915$, and 1,096 nm). The dynamic range of the QEPro is linear up to 1.5 AU, so this response results from the chemistry. 


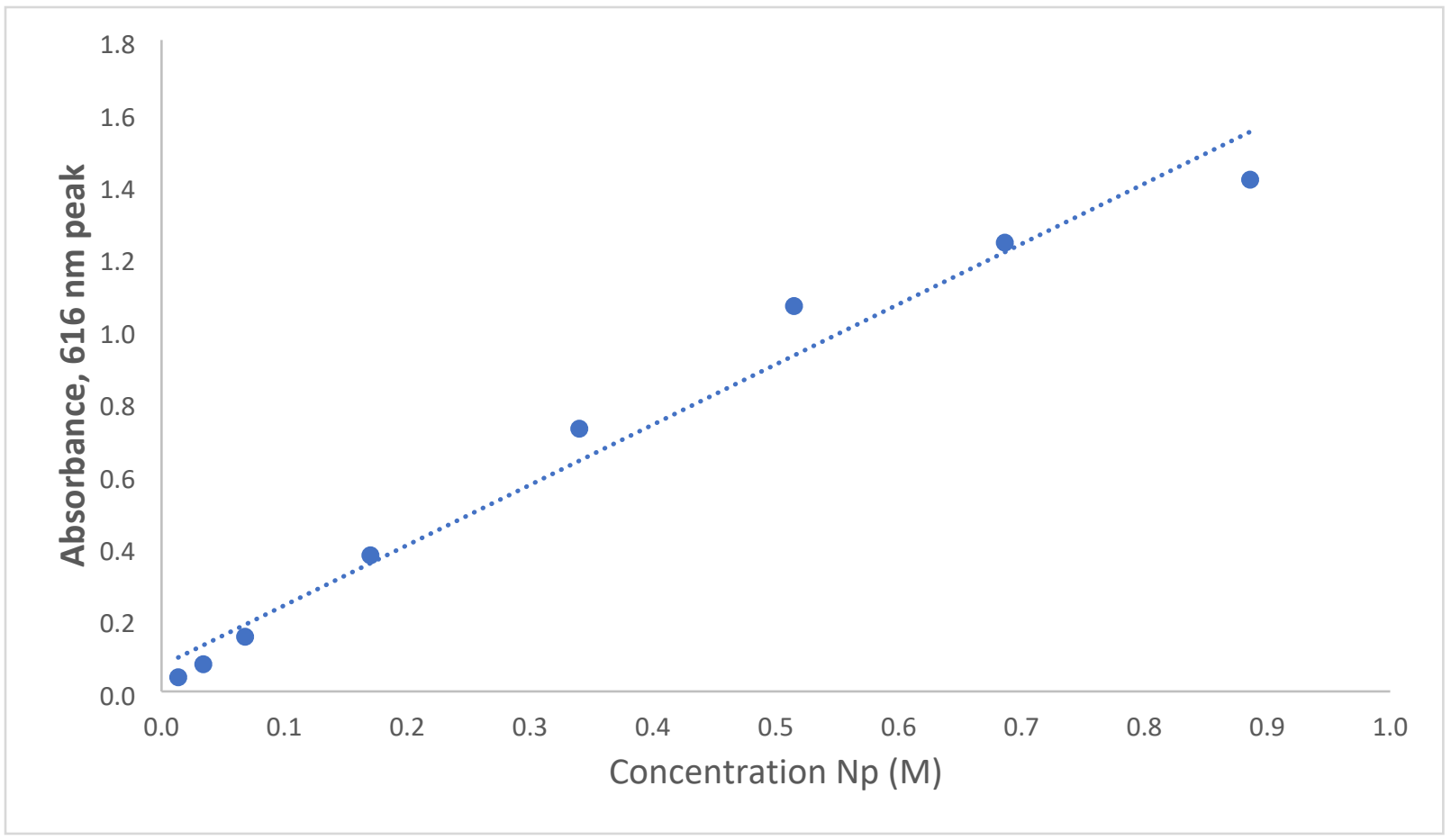

Figure 3.12. Absorbance value of the $616 \mathrm{~nm}$ peak versus $\mathrm{Np}$ concentration (M). The linear regression shows deviation from Beer's near 0.5 M Np. Data were collected using a $1 \mathrm{~mm}$ optical pathlength.

\subsubsection{Hierarchical modeling opportunity}

Neptunium(V) has multiple absorbance bands with molar absorptivity values spanning more than two orders of magnitude from 2 to $\sim 395 \mathrm{M}^{-1} \cdot \mathrm{cm}^{-1}$, in which the lowest and highest values correspond to the peaks near 911 and $980 \mathrm{~nm}$, respectively. The significant difference in the molar extinction coefficients for multiple absorption bands could be used to quantify $\mathrm{Np}(\mathrm{V})$ concentration over several orders of magnitude using a single optical pathlength $(1 \mathrm{~mm})$ and a hierarchical multivariate model. This model could be particularly useful for monitoring the effluent stream during $\mathrm{NC}$ column runs in detail. As certain regions of the spectrum fall within the dynamic range of the spectrophotometer $(\sim 1.5 \mathrm{AU})$, those regions could be used for quantification, and the others could be ignored. This approach could also be applied to other nuclear fuel cycle applications and for monitoring Pu(VI) concentration. ${ }^{29}$ Additionally, it could be applied to environmental applications requiring real-time spectroscopic measurements over a wide range of conditions.

\subsection{NEPTUNIUM(V) TEMPERATURE EFFECTS}

The Vis-NIR electronic absorption spectrum of $\mathrm{Np}(\mathrm{V})$ comprises numerous $f-f$ electronic transitions with dynamic temperature dependencies that are not well documented in the literature. Spectra will be obtained as a function of temperature to determine how spectral features will be influenced because the temperature may range from at least 15 to $45^{\circ} \mathrm{C}$ in glovebox or hot cell operations. An Avantes temperature-controlled cuvette holder (CUV-UV/VIS-TC-ABS/FL) was installed in a glovebox (see Figure 3.13). A USB connection was installed on the box so that the software installed on a computer could communicate with the device. Additionally, a water bath that was already connected to the box was used to moderate the temperature of the cuvette holder. This accessory enables absorption and even fluorescence measurements as a function of temperature. The temperature can be set anywhere between -30 and $105^{\circ} \mathrm{C}$ with an accuracy of $0.05^{\circ} \mathrm{C}$. Data sets collected from 10 to $80{ }^{\circ} \mathrm{C}$ revealed interesting behavior in the system. Multivariate analysis models appear to be able to account for the observed 
spectral changes. Samples were equilibrated for roughly two minutes at each temperature because no spectral variations were observed at longer equilibration time frames.

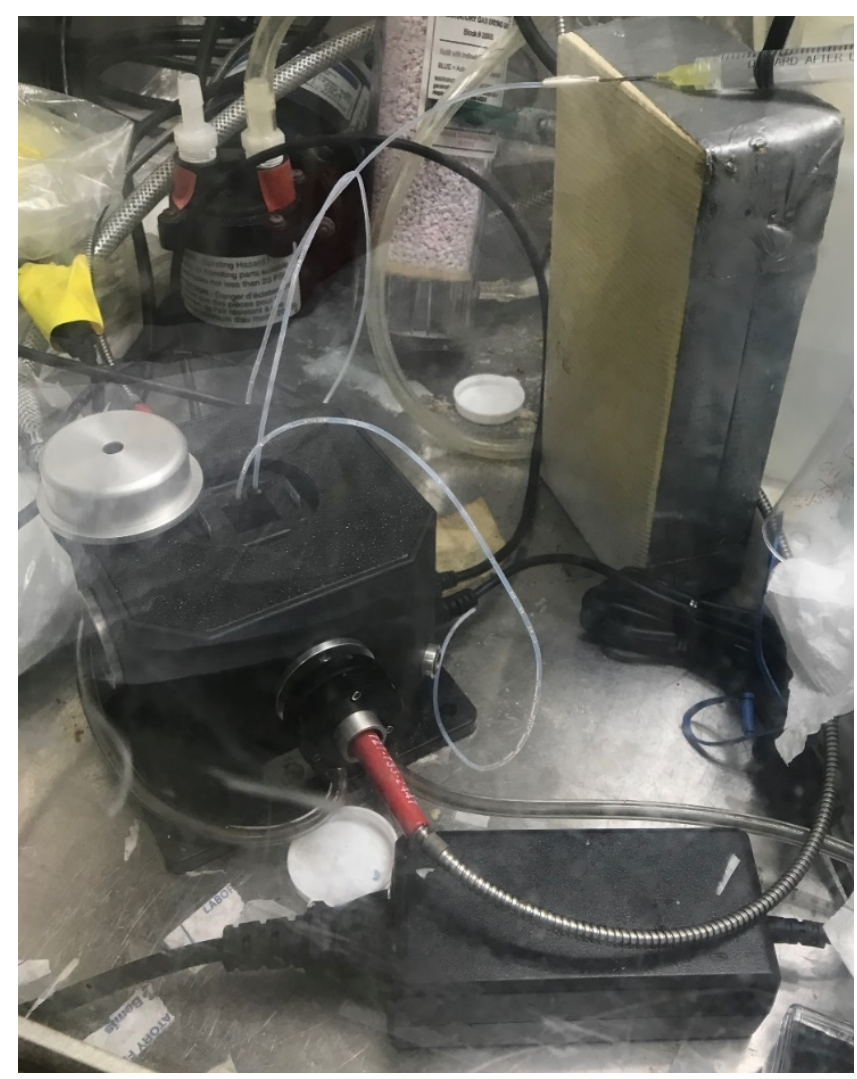

Figure 3.13. Avantes temperature-controlled cuvette holder with a $1 \mathrm{~mm}$ flow cuvette and plastic syringe in a glovebox.

\subsubsection{Vis-NIR absorption spectra and derivatives}

Processing data sets using derivatives can help smooth the data, correct for baseline offsets, resolve convoluted peaks, discriminate between broad and narrow peaks, and suppress broad matrix effects. Derivatives can also be used to identify hidden peaks. First, second, third, and fourth order derivatives were computed using the Unscrambler X software (version 10.4) by Camo Analytics. The SavitzkyGolay algorithm works by taking the derivative of a least squares linear regression fit of a polynomial around each point in the spectrum. The order of the derivative and the number of adjacent variables included in the calculation can be varied to optimize the smoothing factor.

Spectra of $1 \mathrm{M} \mathrm{HNO}_{3}$ as a function of temperature were recorded to determine whether background components would affect the spectra. UV-Vis spectra change over this temperature range as a slight, uniform shift to negative absorbance values (gains light). Spectral features in the NIR can be attributed to changes in water structure at $960,1,150$, and $1,450 \mathrm{~nm}$, but the changes at 960 and 1,150 nm are small because the pathlength is $1 \mathrm{~mm}$. If a longer pathlength were used, then these regions would contribute much more significantly to variability in the spectra.

Outside the closed shell, $\mathrm{Np}(\mathrm{VI})$ has one $5 f$ electron $\left(f^{1}\right)$ and $\mathrm{Np}(\mathrm{V})$ has two $5 f$ electrons $\left(f^{2}\right)$. In these systems, $f-f$ transitions and relatively weak charge-transfer transitions occur. Electron transfer transitions also take place in analogous $\mathrm{UO}_{2}{ }^{2+}$ and $\mathrm{PuO}_{2}{ }^{2+}$ systems and tend to be in the $\mathrm{UV}-\mathrm{V}$ is region for both $\mathrm{NpO}_{2}{ }^{2+}$ and $\mathrm{NpO}_{2}{ }^{+}$. All transitions starting at $12,300 \mathrm{~cm}^{-1}(\sim 800 \mathrm{~nm})$ for $\mathrm{Np}(\mathrm{VI})$ and $23,000 \mathrm{~cm}^{-1}(\sim 435$ 
$\mathrm{nm})$ and below for $\mathrm{Np}(\mathrm{V})$ can be attributed to electron transfer transitions. ${ }^{14}$ The rest of the transitions occur within the $f^{n}$ configuration, and these electric dipole transitions are formally forbidden by Laporte's rule because a change in parity must take place to allow the transitions. The induced electric dipole transitions are generally much weaker than allowed transitions and arise from non-centrosymmetric interactions that break the inversion center. Temperature effects on $\mathrm{Np}(\mathrm{V})$ absorption bands have not been studied in detail in the literature, besides evidence for a blueshift and decreasing intensity of the $980 \mathrm{~nm}$ peak. ${ }^{30}$ This study corroborated those findings and presents spectral variations taking place for the rest of the $\mathrm{Np}(\mathrm{V})$ absorption peaks.

UV-Vis and NIR absorption spectra were collected on solutions composed of $\sim 0.01 \mathrm{~Np}-0.89 \mathrm{M} \mathrm{Np}$ in 1 $\mathrm{M} \mathrm{HNO}_{3}$ as a function of temperature between 10 and $80^{\circ} \mathrm{C}$. An example spectrum is shown in Figure 3.14. Each peak in the spectrum decreased in intensity, and most shifted in wavelength position as temperature was increased. Some peaks experienced a blueshift (e.g., 915, 980, and 1,022 nm), and others experienced a redshift (e.g., 616, 686, and 1,615 nm). Other peaks did not appear to shift an appreciable amount with temperature (e.g., $475 \mathrm{~nm}$ ). The wavelength changed linearly with increasing temperature, which is consistent with a previous study that examined the $980 \mathrm{~nm}$ peak. ${ }^{30}$ This result could be explained in part by the different mechanisms that allow these forbidden transitions to take place. For example, theorists suggest that the $1,615 \mathrm{~nm}$ peak is a result of a magnetic dipole-allowed transition, whereas the $980 \mathrm{~nm}$ peak is a result of electric dipole-allowed transitions. The vibrational structure of these different mechanisms may be affected oppositely. Interestingly, $\mathrm{Np}$ (VI) concentration did not increase with increasing temperature despite literature reports that suggest otherwise.${ }^{13} \mathrm{~A}$ possible explanation is the relatively low acidity $\left(1 \mathrm{M} \mathrm{HNO}_{3}\right)$ in these experiments. These fluctuations could arise from alterations of the primary or secondary hydration sphere surrounding the $\mathrm{Np}(\mathrm{V})$ ion. The changes likely cannot be attributed to nitrate because it does not interact strongly with $\mathrm{Np}(\mathrm{V})$ ions at these $\mathrm{HNO}_{3}$ concentrations. ${ }^{31}$ 


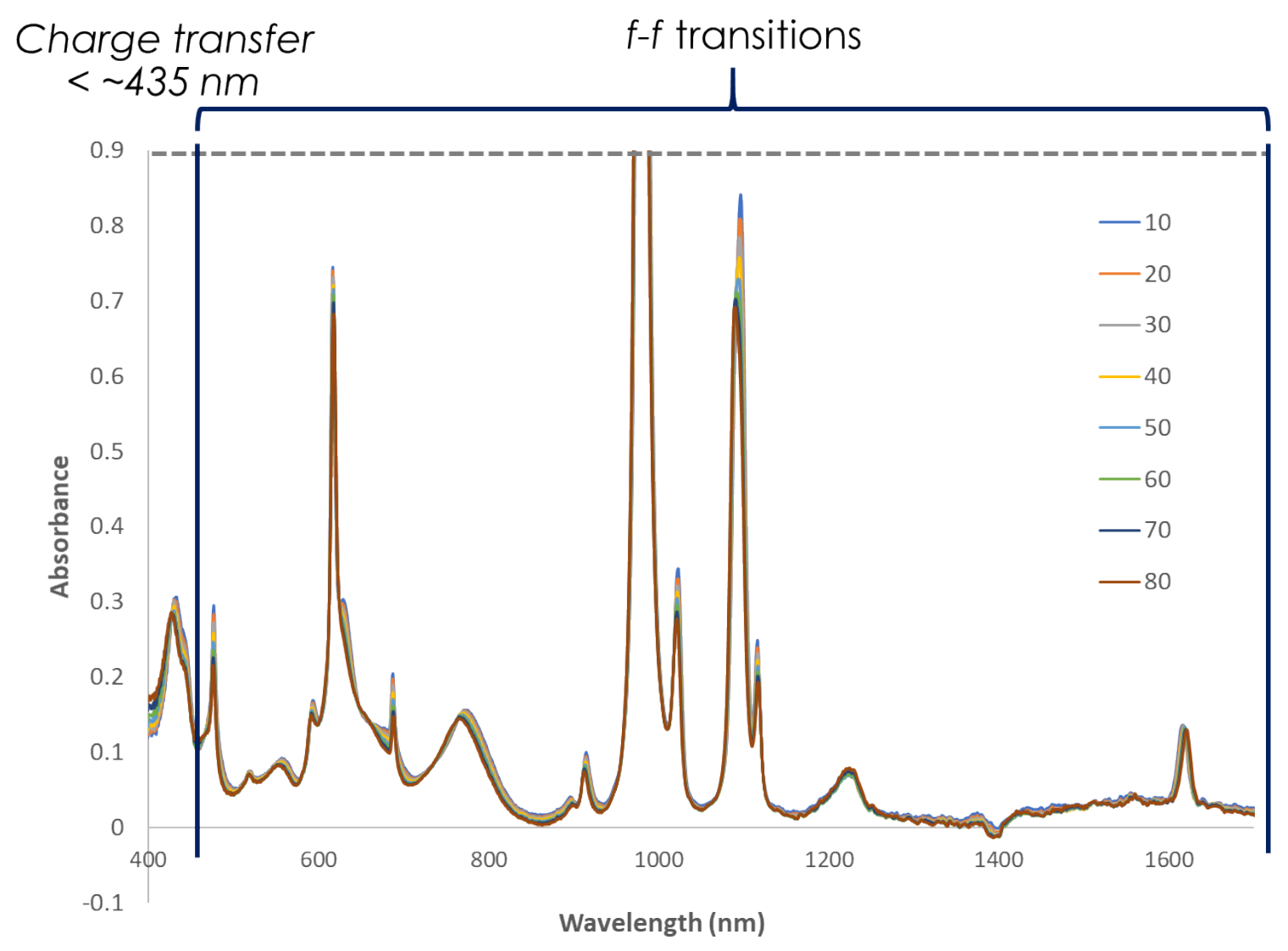

Figure 3.14. Vis-NIR of a $0.34 \mathrm{M}$ Np solution in $1 \mathrm{M} \mathrm{HNO}_{3}$ as a function of temperature $\left(10-80^{\circ} \mathrm{C}\right)$.

To obtain an indication of where the original spectral features could be found, derivatives were applied to the spectra. ${ }^{32} \mathrm{~A}$ first-order derivative passes through zero at the maximum wavelength position of a peak with negative and positive bands on either side at the same wavelength as the inflection points. Second order derivatives are characterized by a negative band with a minimum at the same wavelength as the maximum peak position in the zero-order spectrum. It also shows two positive satellite peaks on either side of the main band. Fourth-order derivatives show a positive band at the maximum wavelength position with two positive and two negative satellite peaks.

Temperature-dependent changes were greatest for the $1,096 \mathrm{~nm}$ band because the peak shifted more than any other peak in both position and intensity (see Figure 3.11). Zero, first, second, and fourth order derivative spectra are shown in Figure 3.14. The second- and fourth-order derivative spectra suggest that the $1,096 \mathrm{~nm}$ band may comprise more than one electronic transition, as suggested by previous authors in 1966. ${ }^{33}$ Second- and fourth-order derivative spectra would normally show three or five peaks if the band comprised a single component. The peak at $1,022 \mathrm{~nm}$ follows this trend. However, an extra peak appears in the second and fourth derivative spectra of the $1,096 \mathrm{~nm}$ peak (see Figure $3.15 \mathrm{c}, \mathrm{d}$ ). This suggests that the $1,096 \mathrm{~nm}$ band could correspond to two electronic transitions taking place at 1,087 and 1,096 nm. Another interesting feature is that the intensity of the $1,086 \mathrm{~nm}$ component increases in intensity, but the intensity of every other peak in the spectrum deceases with increasing temperature. 

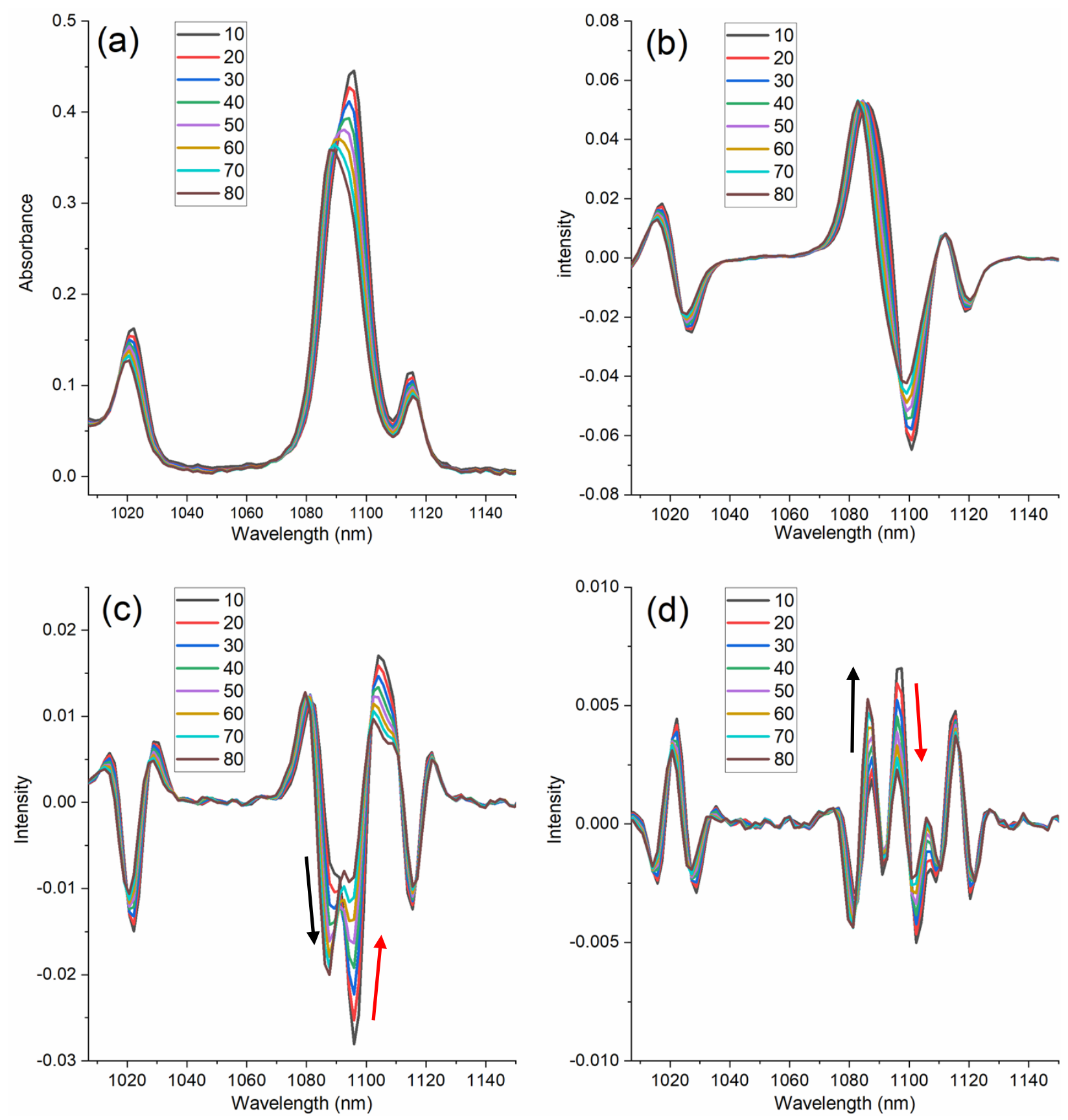

Figure 3.15. NIR spectra of a $0.17 \mathrm{M}$ Np solution as a function of temperature $\left(10-80{ }^{\circ} \mathrm{C}\right)$ with an offset baseline correction (a) first-order (b), second-order (c), and fourth-order derivative (d). Arrows represent the general direction in peak intensity of the 1,088 and 1,097 nm components of the complicated 1,096 nm band.

\subsubsection{Multivariate curve resolution}

Multivariate curve resolution-alternating least squares (MCR-ALS) methods are used to recover concentration, $\mathrm{pH}$, time/kinetics and elution profiles, and response profiles (i.e., spectra) in an unresolved mixture with minimal user input. MCR-ALS results are unique compared to other exploratory methods because they provide non-chemometricians (i.e., chemists) with components that are easily understood. In general, profiles and pure contributions (i.e., component spectra) mimic the instrumental responses expected from the chemical species being studied. Spectrophotometric measurements are particularly 
amenable to analysis by MCR-ALS, which describes the data as the sum of signal contributions coming from individual components using a bilinear model.

The changes in the 1,096 nm peak can be modeled using MCR-ALS analysis. These MCR-ALS models can be used as predictive models to predict relative concentrations using Process Pulse II. ${ }^{3}$ The Unscrambler X (version 10.4) was used for MCR-ALS analysis. Nonnegative concentration and nonnegative spectra constraints were selected, and the sensitivity and maximum ALS iterations were set to 50 and 100. The primary results of an MCR-ALS analysis on a data set collected on a $0.17 \mathrm{M} \mathrm{Np}$ solution $\left(10-80^{\circ} \mathrm{C}\right)$, the same data set represented in Figure 3.15, are shown in Figure 3.16. The results include two concentration matrices (relative concentrations) and sources (spectra). The estimated concentration values are in relative units, much like an arbitrary scaling factor that can be multiplied by the component spectra to recalculate the original spectrum. The analysis reveals two primary components that can be used to effectively account for all the spectra variation in the data set. A primary component at $1,086 \mathrm{~nm}$ and another at $1,097 \mathrm{~nm}$ align well with the results obtained by second and fourth derivative spectra. This analysis also reveals that the $1,114 \mathrm{~nm}$ peak shifts to $1,117 \mathrm{~nm}$ with increasing temperature. The total residuals plot suggests that two components are optimal, and the low residual of $1.05 \times 10^{-5}$ suggests that the variation is well accounted for. Additional details on this approach and other approaches such as two-dimensional correlation spectroscopy will be discussed in a research publication. 

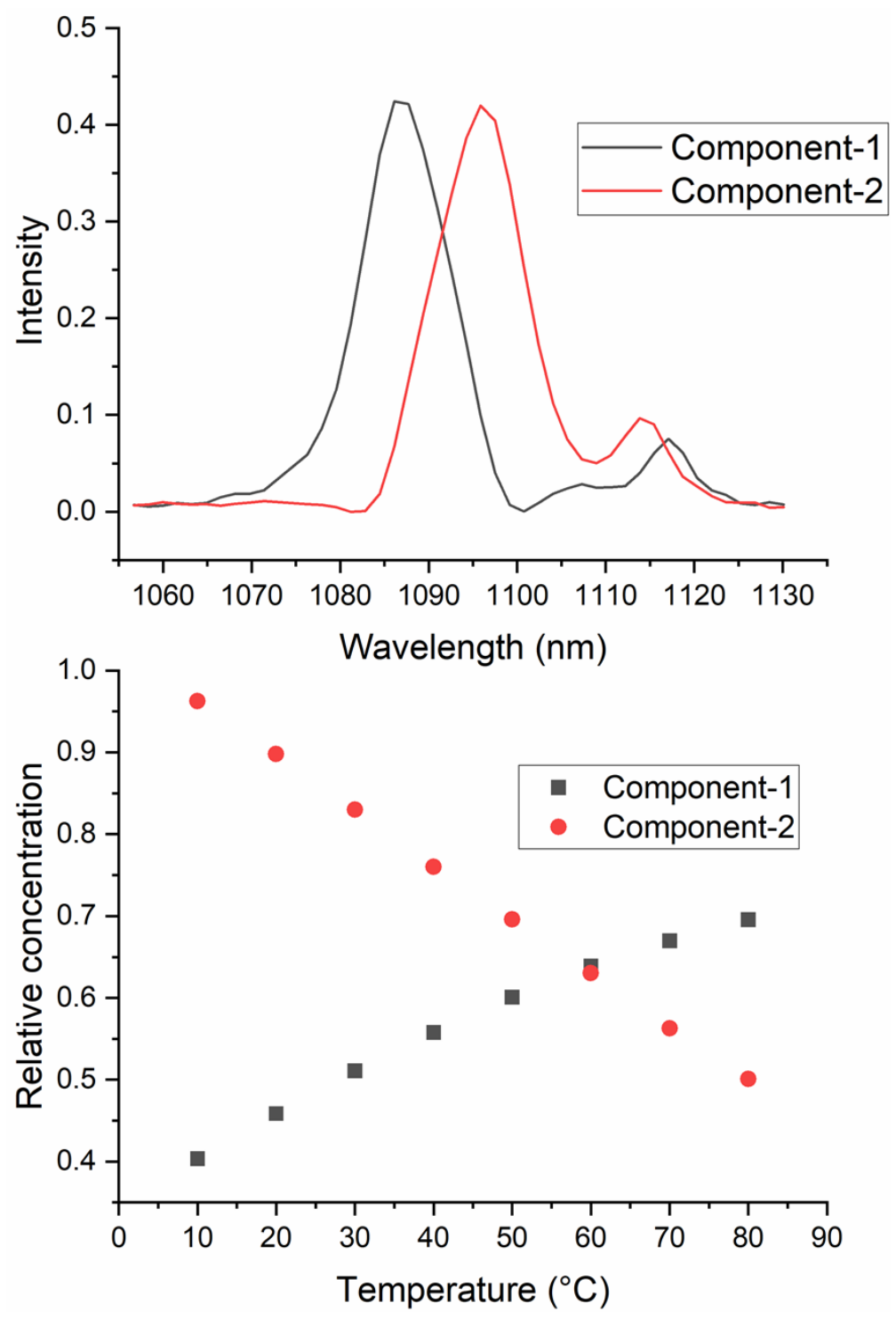

Figure 3.16. MCR-ALS component spectra (top) and component concentration (bottom) describing the spectra variation of the $1,096 \mathrm{~nm}$ band in a $0.17 \mathrm{M}$ Np solution at $1 \mathrm{M} \mathrm{HNO}_{3}$.

\subsubsection{Regression models}

\subsubsection{Modeling temperature by partial least squares regression}

UV-Vis-NIR spectra were recorded on a solution of $1 \mathrm{M} \mathrm{HNO}_{3}$ to determine background effects on the $\mathrm{Np}$ spectra. The baseline in UV-Vis spectra, between 400 and $950 \mathrm{~nm}$, gradually shifted to negative absorbance values as temperature increased, but the shift was minimal: approximately $-0.006 \mathrm{AU}$. Applying a first derivative (second order with 11 adjacent variables) to the Vis spectra (412-940 nm) removes the nearly uniform shift in baseline because the rate of change of a flat line is zero. A first derivative preprocessing method corrects for background baseline changes and makes a regression analysis for $\mathrm{Np}$ concentration insensitive to the temperature of the blank solution used to reference the spectrophotometer. UV-First-order derivative Vis-NIR spectra collected on a solution that was diluted twofold from the $210 \mathrm{~Np} / \mathrm{L}$ stock solution from 10 to $80^{\circ} \mathrm{C}$ are shown in Figure 3.17 a. The inflection points, located at 613 and $619 \mathrm{~nm}$ of the $616 \mathrm{~nm}$ absorption band, dominate the spectrum. The peak at 
$613.4 \mathrm{~nm}$ gradually shifts to $614.2 \mathrm{~nm}$ and the peak at $619.4 \mathrm{~nm}$ shifts to $620.2 \mathrm{~nm}$ as the temperature increases.

A PLSR model was built using the data shown in Figure 3.17 a. A PLSR analysis is a multivariate approach used to find the covariance between independent $\mathrm{X}$ (spectra) and dependent $\mathrm{Y}$ (concentration) data matrices. A parity plot and PLSR metrics are in Figure $3.17 \mathrm{~b}$. The slope, root-mean-square error of the calibration (RMSEC, blue) and validation (RMSECV, red), and $R^{2}$ values were evaluated to determine how the model performed. A slope closer to one implies that the data is better modeled. The Pearson $R^{2}$ value is the square of the correlation values, and values closer to one imply a better fit. Both RMSEC and RMSEP have units in molarity and should be close to one another. RMSECV measures how well the samples are correlated when cross validation is used. Overall, the model had satisfactory regression statistics. Even though the explained variance in the model only increased slightly from $99.8 \%$ to $99.95 \%$ from factor- 1 to factor-2, the prediction performance for temperature increased significantly. This suggests that significant temperature-induced fluctuations in the spectra are accounted for in factor-2 and should be included in the model. The PLSR model can find correlations that are not readily apparent by simply observing the data.
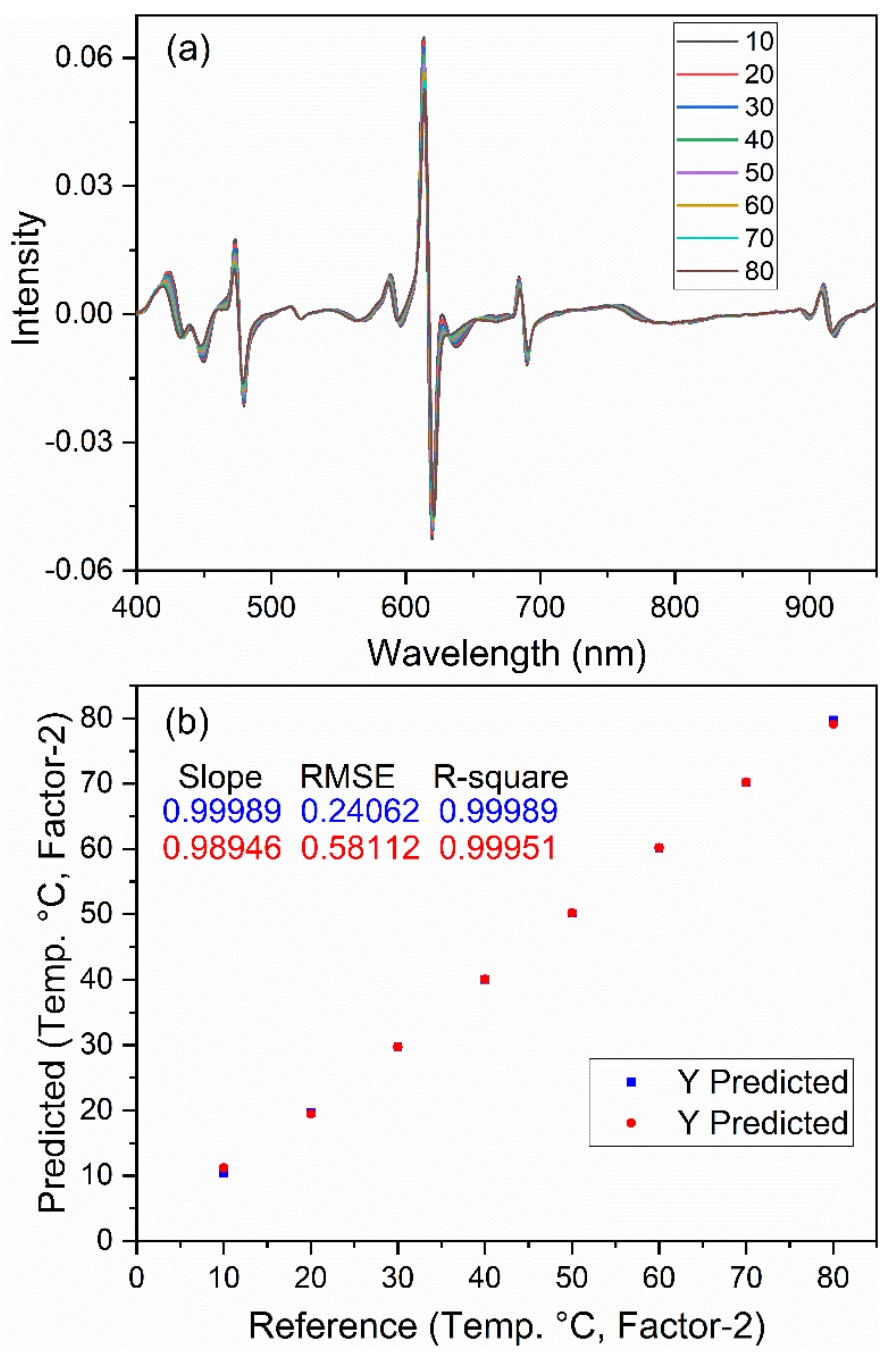

Figure 3.17. UV-Vis spectra $(400-950 \mathrm{~nm})$ with a first-order derivative with varying temperature $10-80^{\circ} \mathrm{C}$ (a) and PLSR model metrics (b). Blue data points represent calibration, and red points represent validation. 
The RMSECV was more than two times greater than the RMSEC, indicating either that the model could be unstable, or simply that it does not contain redundant information. When a sample is excluded for cross validation, the model loses information that is significant to its performance. The RMSEP was calculated based on the following equation:

$$
R M S E=\sqrt{\frac{\sum_{i=1}^{n}\left(\hat{y}_{i}-y_{i}\right)^{2}}{n}},
$$

where $\hat{y}_{i}$ is the predicted analyte concentration, $y_{i}$ is the measured analyte concentration, and $n$ is the number of samples. RMSEP is the ultimate measure of prediction performance and has the same units as the samples. The prediction performance of this PLSR model was evaluated using the 12 validation samples shown in Table 3.2. An RMSEP of 0.28 is in good agreement with the RMSEC value of 0.24 . The RMSEP value of 0.28 is $\sim 0.8 \%$ of the midway point between 10 and $80^{\circ} \mathrm{C}$, indicating that the model is performing well. This approach will also be validated with data blanked at different temperatures and applied to data sets collected at multiple concentrations.

Table 3.2. Predicted temperature, deviation, and the reference temperature $\left({ }^{\circ} \mathrm{C}\right)$ with RMSEP.

\begin{tabular}{cccc}
\hline ID & $\begin{array}{c}\text { Predicted Temp. } \\
\left({ }^{\circ} \mathbf{C}\right)\end{array}$ & Deviation & $\begin{array}{c}\text { Reference } \\
\left({ }^{\circ} \mathbf{C}\right)\end{array}$ \\
\hline 1 & 14.78 & 0.53 & 15 \\
2 & 16.33 & 0.48 & 16.5 \\
3 & 23.63 & 0.43 & 24 \\
4 & 24.68 & 0.40 & 25 \\
5 & 34.68 & 0.42 & 35 \\
6 & 45.28 & 0.47 & 45 \\
7 & 49.19 & 0.43 & 48.8 \\
8 & 55.24 & 0.47 & 55 \\
9 & 56.46 & 0.45 & 56.2 \\
10 & 65.20 & 0.40 & 65 \\
11 & 71.69 & 0.59 & 71.4 \\
12 & 74.78 & 0.49 & 75 \\
\hline RMSEP & & & 0.28 \\
\hline
\end{tabular}

\subsubsection{Modeling Np concentration and temperature}

Another PLSR model was developed using UV-Vis data spanning the concentration range from 0.45 to $0.89 \mathrm{M} \mathrm{Np}$ at $1 \mathrm{M} \mathrm{HNO}_{3}$. This concentration range covers what is expected in terms of Np concentration for the MDD feed adjustment. However, varying nitric acid concentration (0.5-1 M HNO3) is also expected in MDD feed adjustments but wasn't incorporated here. This proof-of-principle example was developed to demonstrate that a single multivariate model could account for both dynamic temperature and non-linear concentration effects using UV-Vis-NIR spectral data.

Spectra recorded at $10{ }^{\circ} \mathrm{C}$ increments were included for each concentration in the regression. The RMSEC and RMSECV are listed in tables within the parity plots shown in Figure 3.18. The Np concentration RMSECV (0.0058), which approximates the error in the predicted values, is very low $(<1 \%)$ with respect to the highest $\mathrm{Np}$ concentration included in the model $(0.89 \mathrm{M})$. The temperature RMSECV (1.563) is low compared to the highest temperature $\left(80^{\circ} \mathrm{C}\right)$ but much larger than the RMSEC (0.4347). This indicated that the model either isn't balanced or that removing samples from the regression 
model, which iteratively takes place during cross validation, has a deleterious influence on crossvalidation statistics. In this situation, it is more likely the later since the RMSEP and RMSEC agreed.
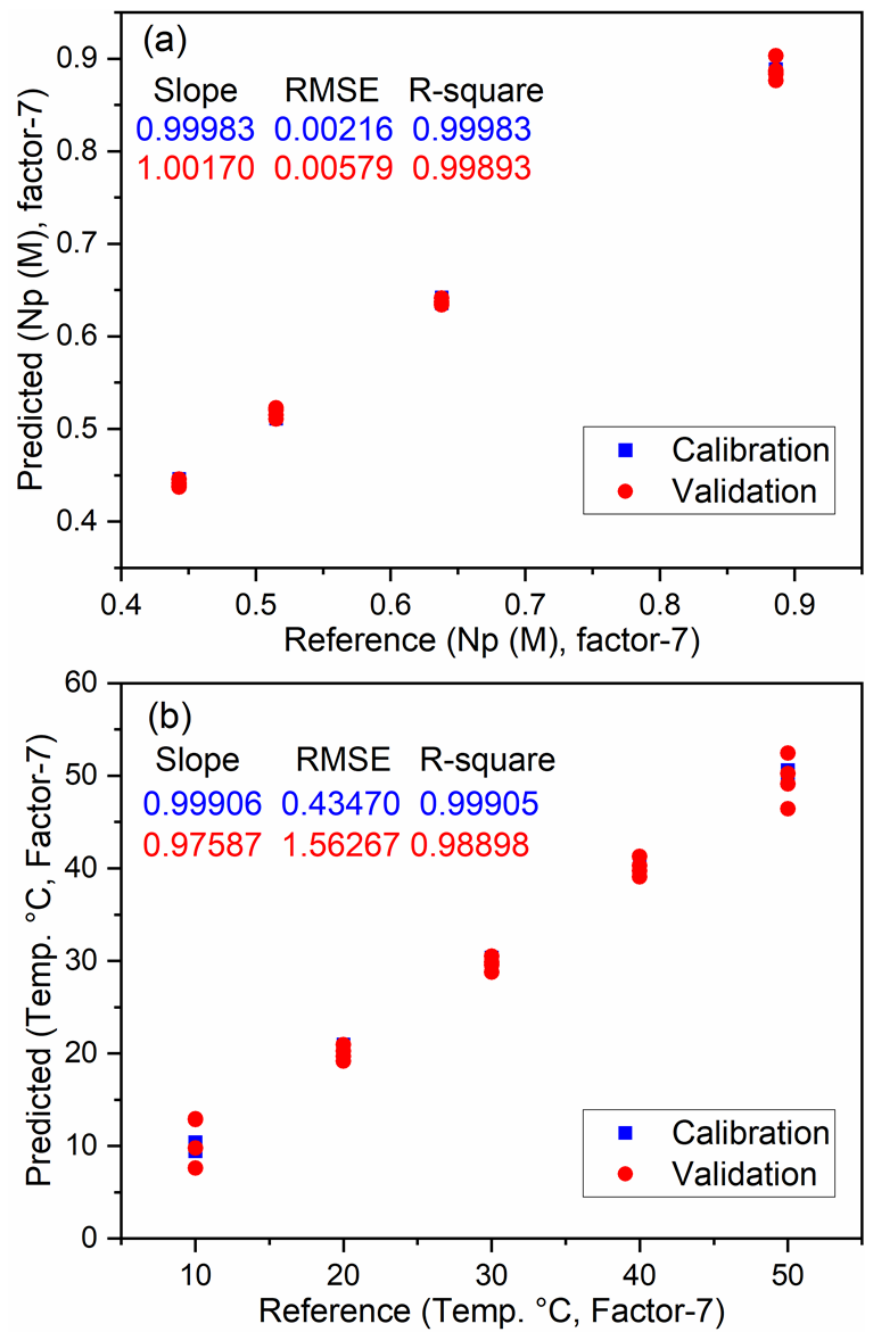

Figure 3.18. PLSR model metrics for $\mathbf{N p}(\mathrm{V})$ concentration(a) and temperature (b). Blue data points represent calibration, and red points represent validation.

An explained variance plot shows the percentage of the total variation in $\mathrm{X}$ (dependent) or $\mathrm{Y}$ (independent) data that is modeled by a given number of factors. A total of seven factors were included in the model, which is more than expected because only two factors (i.e., Np concentration and temperature) were varied (see Figure 3.19). The calibration and validation did not deviate significantly, indicating that the test data is representative and that the model is expected to effectively describe new data. The additional factors may be necessary to account for temperature fluctuations (e.g., peak shifting) and nonlinear response owing to high $\mathrm{Np}$ concentration that are not easily observable. The explained $\mathrm{Y}$ variance of the calibration increased from $99.54 \%$ to $99.94 \%$, and the variance of the cross validation increased from $98.66 \%$ to $99.40 \%$ when increasing the factors from five to seven. Despite this relatively small increase in explained variance, the prediction performance significantly improved when the model comprising seven factors was used compared to five components. 


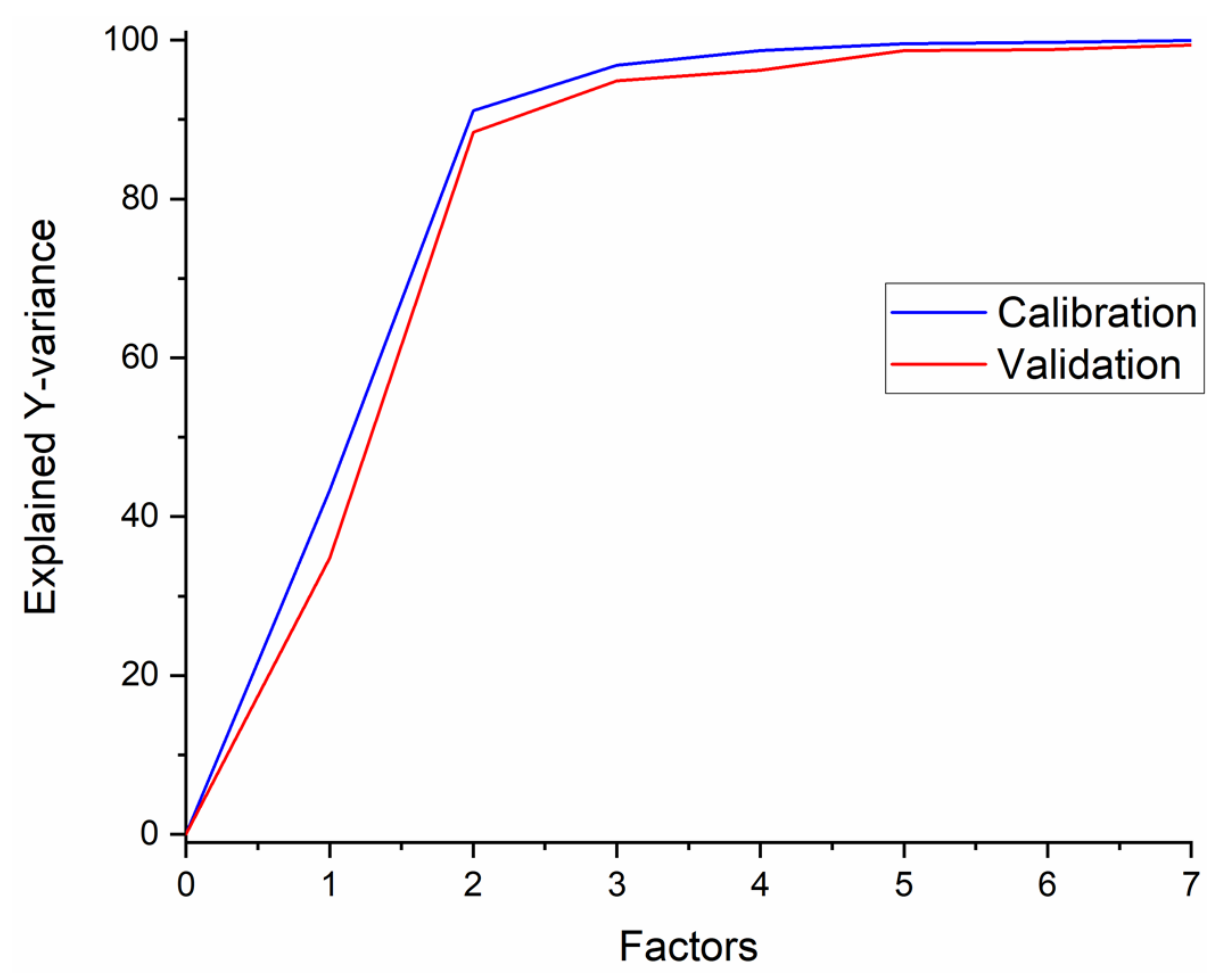

Figure 3.19. Explained Y-variance plot for the model. Blue data points represent calibration, and red points represent validation.

Spectral data at temperatures not included in the model were used for validation $(15,16.5,24,25,35,45$, and $48.8^{\circ} \mathrm{C}$ ). Parity plots of the predicted $\mathrm{Np}$ concentration and temperature of these solutions are shown in Figure 3.2. The RMSEP for Np (M) was 0.00467, which agreed with the RMSEC of 0.00216. RMSEP is generally in units of the predicted analyte and considered to be the \pm deviation associated with each measurement. The low RMSEP value implies that the $2 \%$ error threshold, with respect to Np concentration, can be achieved since 0.00467 is $\sim 1 \%$ of $0.45 \mathrm{M} \mathrm{Np}$. However, the prediction performance of this model should be further validated on additional samples containing $\mathrm{Np}$ concentrations not included in the training set. The RMSEP for temperature $\left({ }^{\circ} \mathrm{C}\right)$ improved from 1.15 to 0.648 when using five or seven factors, respectively. Thus, factors 6 and 7 are not describing noise and contribute useful information to the model. The RMSEP of 0.648 is in good agreement with the RMSEC value of 0.4347 . This agreement suggests that temperature intervals at a minimum of $10{ }^{\circ} \mathrm{C}$ increments should be included in the model. 

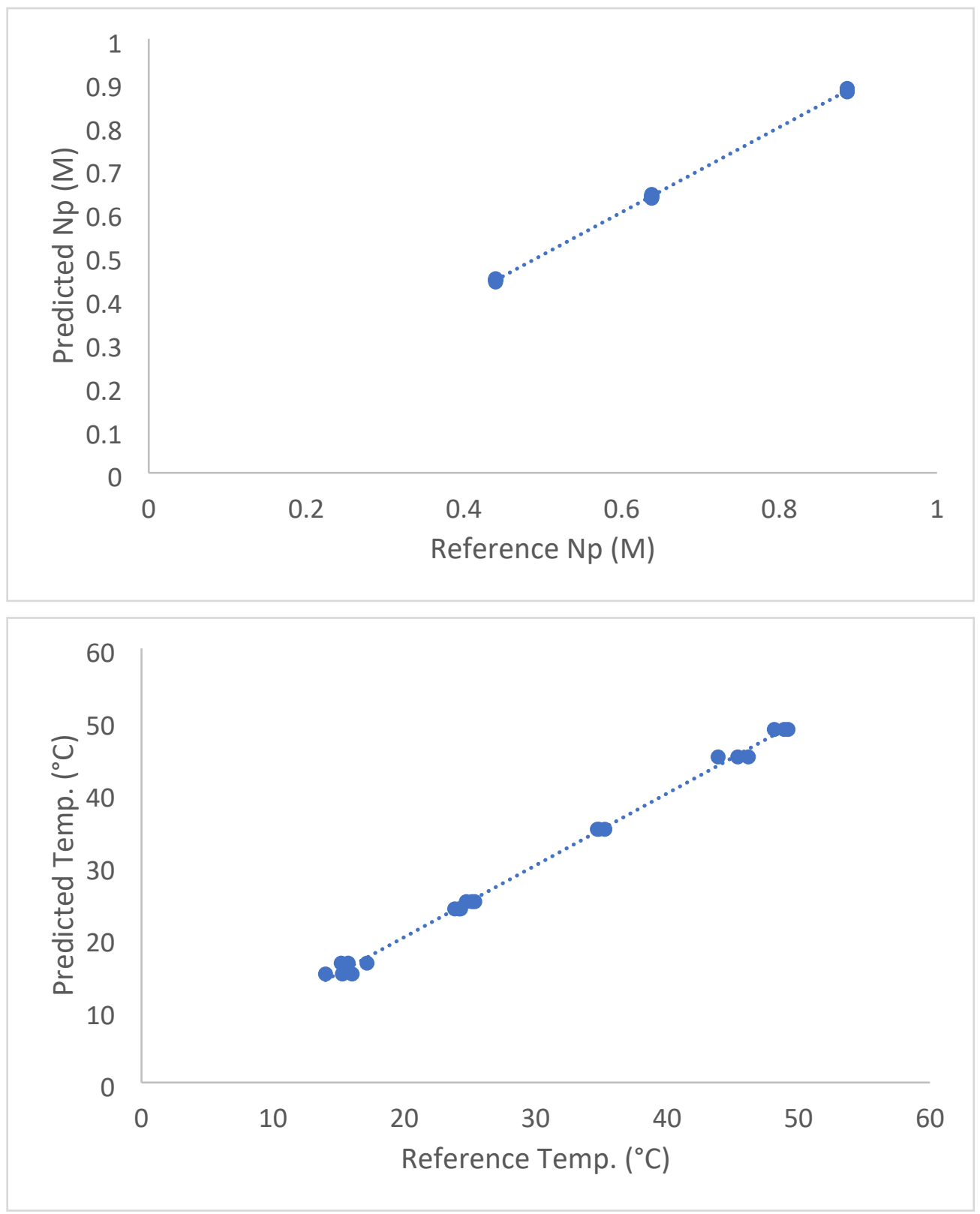

Figure 3.20. Predicted vs. reference values for Np concentration (top) and temperature (bottom).

\subsection{SPECTROELECTROCHEMISTRY}

Generating a representative spectral database will be challenging owing to multiple experimental difficulties, including the isolation and stabilization of $\mathrm{Np}$ species in pure oxidation states and the high absorbance properties of concentrated $\mathrm{Np}$ solutions. Cyclic voltammetry is a commonly used electrochemical technique for investigating redox processes of molecular species. A three-electrode setup is normally used to acquire data with a working electrode, counter electrode, and reference electrode (e.g., $\left.\mathrm{Ag}^{+} / \mathrm{AgCl}\right){ }^{34}$

Spectroelectrochemistry is an established technique that combines electrochemistry with spectroscopy. UV-Vis-NIR and Raman are both amenable to monitoring this approach. ${ }^{5}$ Thin-layer (short pathlength) spectropotentiometry restricts the dead volume for the auxiliary and reference electrodes, which results in 
faster data collection and smaller sample volumes. The electrodes are in contact with the solution, which is where light passes through the sample cell. Electrochemical methods are more desirable than chemical approaches to adjust redox states because they are more accurately controlled and do not add chemical reagents to the solution that could alter spectral features.

Measurements with an optically transparent electrode and thin absorbance cell ( $\leq 1 \mathrm{~mm}$ pathlength) are ideal for measurements that require adjusting the valence of $\mathrm{Np}$. A spectroelectrochemical static cell with a $0.5 \mathrm{~mm}$ pathlength was ordered from BioLogic. The system comprises three electrodes in contact with the solution, including a Pt wire (counter electrode), Pt grid metal working electrode, and a reference $\mathrm{Ag} / \mathrm{AgCl}$ electrode. Voltammetry was tested, along with UV-Vis-NIR spectroscopy, to quantify concentrated Np solutions. Absorption was measured through the working electrode where $\mathrm{Np}$ redox reactions occur.

The cell and a potentiostat were used to drive the $\mathrm{Np}(\mathrm{V})$ to nearly $100 \% \mathrm{~Np}(\mathrm{VI})$ for analysis by setting the system at $1.4 \mathrm{~V}$ (see Figure 3.21). The conversion took several hours to complete. Using a cell with more ideal geometry could reduce the amount of time necessary for this conversion. UV-Vis-NIR spectra were collected during the entire process at a rapid interval of $\sim 100 \mathrm{~ms}$. If an absorptivity of 36 is used for the $\mathrm{Np}$ (VI) $1220 \mathrm{~nm}$ peak, instead of a more common value of $\sim 40$, the absorbance of 1.59 can be readily converted to $209.4 \mathrm{~g} \mathrm{~Np} / \mathrm{L}$ using Beer's law. This concentration is in good agreement with the concentration reported by the analytical group. It is possible that this measurement was outside the dynamic range of the spectrophotometer. Thus, using Vis peaks in the 500-600 nm region may be more advantageous for quantification. For example, the peak at $654 \mathrm{~nm}$ with a molar absorptivity of $\sim 6.6 \mathrm{M}^{-1} \mathrm{~cm}^{-1}$ could be used for quantification. This absorbance value is comparable to $\mathrm{Np}(\mathrm{V})$ bands in this general region of the spectrum.

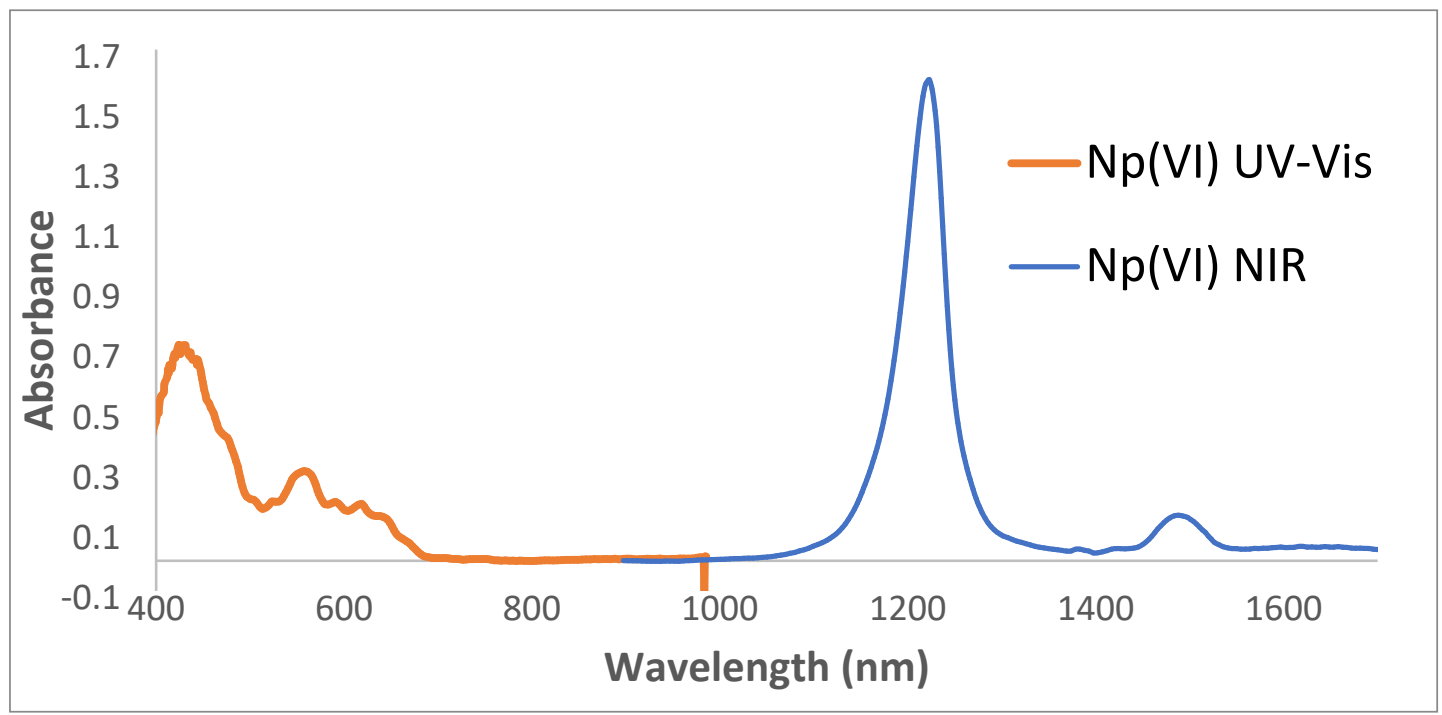

Figure 3.21. UV-Vis-NIR absorbance spectrum of the T-504 solution after conversion to Np(VI) using a $0.5 \mathrm{~mm}$ optical pathlength. The $\mathrm{Np}(\mathrm{VI}) 1,222 \mathrm{~nm}$ peak and a molar absorptivity of $36 \mathrm{M}^{-1} \cdot \mathrm{cm}^{-1}$ was used to calculate $209.4 \mathrm{~g} / \mathrm{L}$.

Neptunium participates in concentration-dependent chemical equilibria, which will result in changes of absorptivity with concentration. These may include cation-cation interactions as well as changes in redox equilibria at high concentrations. Additional spectra collected during the coulometric titrations are shown in Figure 3.22. Potentiostatic coulometry was used to hold the current (amperes) constant while measuring electrical potential. $\mathrm{Np}(\mathrm{V})-\mathrm{Np}(\mathrm{VI})$ interactions explain the doublet $980 \mathrm{~nm}$ peak with position corresponding to 980 and $991 \mathrm{~nm}$. These band positions match literature values well. ${ }^{10}$ 

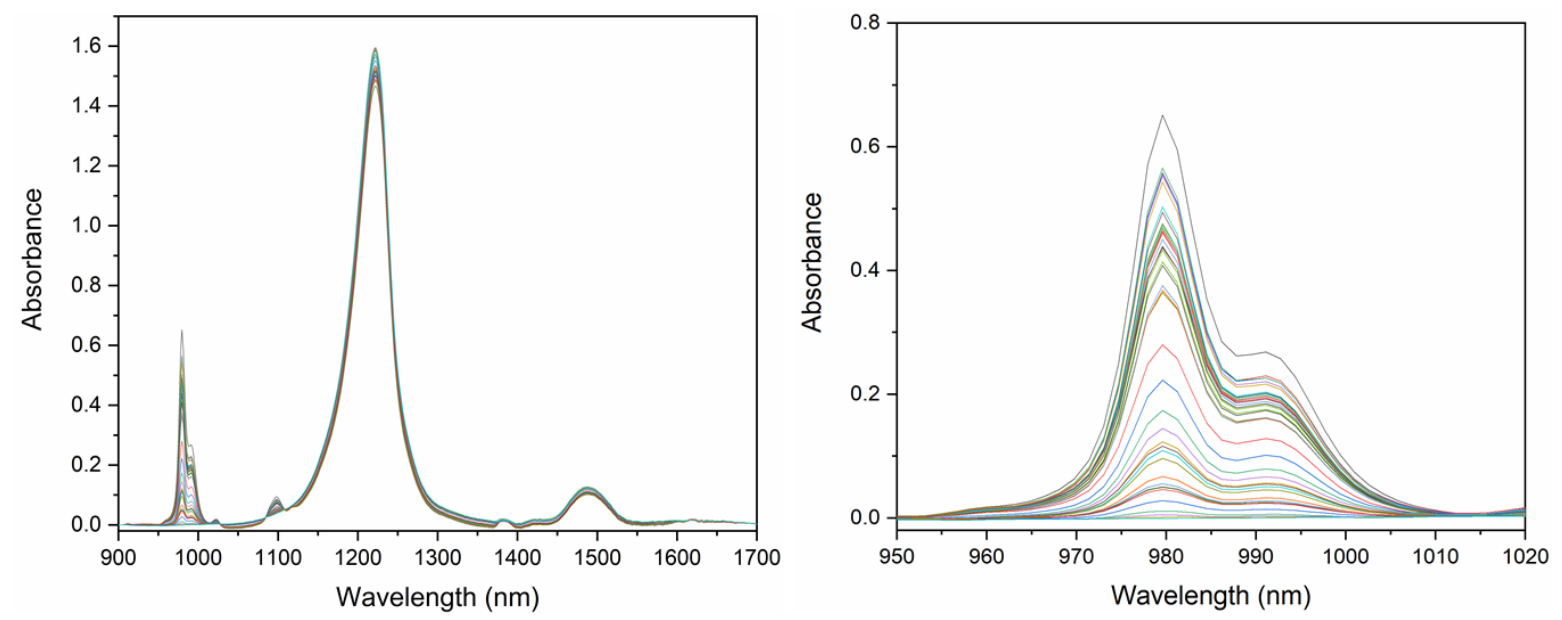

Figure 3.22. NIR spectra corresponding to the T-504 solution from $98 \%$ to $\sim 100 \%$ converted to $\mathrm{Np}$ (VI) (left) and the $\mathrm{Np}(\mathrm{V}) 980 \mathrm{~nm}$ peak region $($ right $)$. The primiary $\mathrm{Np}(\mathrm{VI})$ peak appeared near $1222 \mathrm{~nm}$ while the $\mathrm{Np}(\mathrm{V})$ and $\mathrm{Np}(\mathrm{V})-\mathrm{Np}(\mathrm{VI})$ (i.e., cation-cation) peaks appeared near 980 and $991 \mathrm{~nm}$ respectively.

Initial cyclic coulometric results indicated a substantial shift in the $\mathrm{Np}(\mathrm{V} / \mathrm{VI})$ redox potential from 0.93 to $0.86 \mathrm{~V}$. Neptunium(VI) nitrate complexes at high concentrations, which may cause the shift; other causes may include actinyl cation-cation interactions, nonideal system performance, or a combination of these reasons. This experiment should be tested again using a setup optimized specifically for voltammetry. The voltammogram qualitatively had the characteristic duck shape. However, the measurements suffered from ohmic loss (IR drop), which occurred for several reasons: (1) counter electrode surface area was much smaller than working electrode, (2) scan rates were too fast, (3) cell geometry restricted flow to reference from working electrodes, and (4) electrolyte concentration $\left(\mathrm{HNO}_{3}\right)$ was low compared to the redox active species $(\mathrm{Np})$.

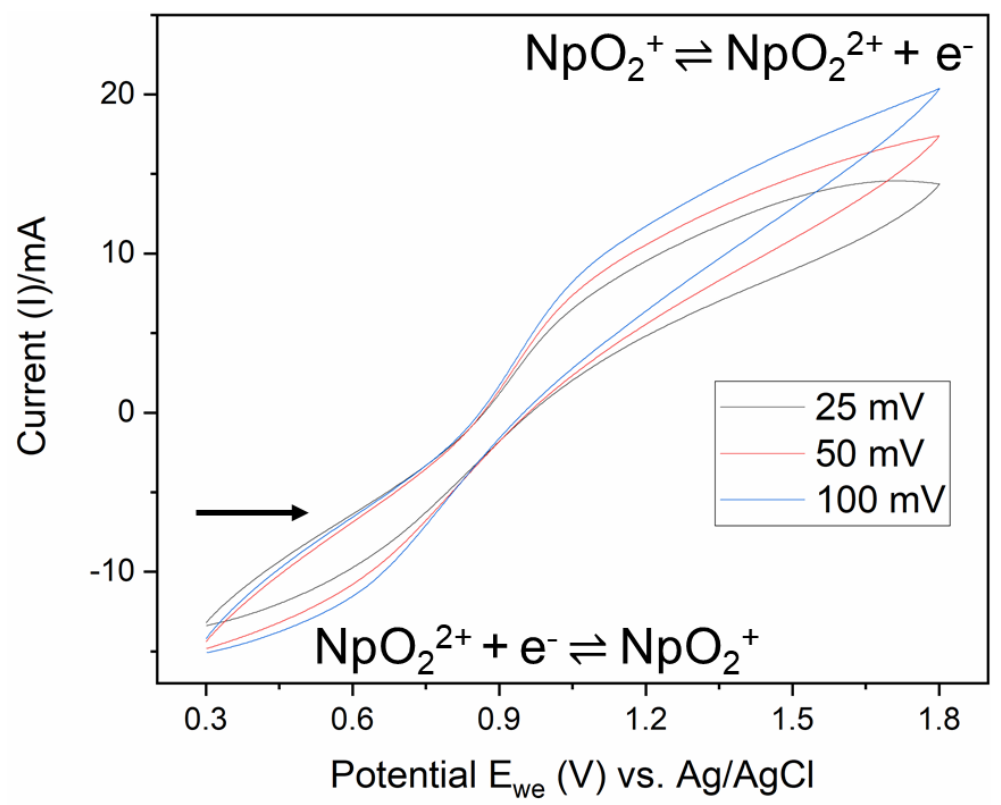

Figure 3.23. Cyclic voltammogram of the T-504 $\mathrm{Np}$ solution with varying scan rates in millivolts per second. The arrow indicates the beginning and sweep direction (forward scan). 
This experiment demonstrated that electrochemistry can be used to help characterize $\mathrm{Np}(\mathrm{V} / \mathrm{VI})$ solutions by converting $\mathrm{Np}$ to a single oxidation state and solutions composed of both $\mathrm{Np}(\mathrm{V})$ and $\mathrm{Np}(\mathrm{VI})$ at a fixed total $\mathrm{Np}$ concentration. Neptunium(V) will always be in equilibrium with neptunium(VI), and some processing solutions, particularly after the dissolution of $\mathrm{NpO}_{2}$, have nearly a 50:50 mixture of $\mathrm{Np}(\mathrm{V}): \mathrm{Np}(\mathrm{VI})$ (see example in Section 4.3). Therefore, it is necessary to account for the different valences. In fact, if the appropriate training set is acquired, this system could be modeled by total Np concentration, not necessarily individual $\mathrm{Np}$ oxidation states.

Future tests will include reversing the polarity of the measurements (i.e., make the working electrode the counter electrode) and testing a new honeycomb spectroelectrochemical cell by Pine Research. The new honeycomb cell has better geometry and the ideal electrode surface area, but it has a longer optical path of $1.7 \mathrm{~mm}$. The holes in the honeycomb pattern allow light to pass through the active surface of the working electrode. The kit came with both Pt and Au honeycomb electrodes, and it will also be easier to handle and more amenable to glovebox operations in lab 109 if electrochemistry is necessary. This cell is much easier to handle in the glovebox than the BioLogic options because the electrodes are 3D printed on an electrode card that has a single specialty cell kit connector.

Because the pathlength is fixed at $1.7 \mathrm{~mm}$, studies should be carried out at $<100 \mathrm{~g} \mathrm{~Np} / \mathrm{L}$ with the Ocean Optic spectrophotometers or at elevated Np concentration using the new Cary 6000i because a $200 \mathrm{~g}$ $\mathrm{Np}(\mathrm{V}) / \mathrm{L}$ or $\mathrm{Np}(\mathrm{VI})$ solution would have an absorbance value of $\sim 3(616 \mathrm{~nm}$ peak) and $\sim 6(1,222 \mathrm{~nm}$ peak) AU, respectively, using a $1.7 \mathrm{~mm}$ pathlength cuvette. Other peaks in the spectrum could be used for quantification if these prove to be outside the dynamic range of the spectrophotometer.

The ${ }^{238} \mathrm{Pu}$ Supply Program recently procured an SP-300 potentiostat made by BioLogic. Ultralow current and high-voltage $( \pm 48 \mathrm{~V})$ upgrades were including in the system to enable highly sensitive glovebox tests and glovebox operations, respectively. The ultralow current option lowers the base current range from 1 $\mu \mathrm{A}$ to $1 \mathrm{pA}$, thus the resolution increases. Additionally, plug-and-play booster boards can be placed in parallel to increase the current of a particular channel.

\section{CHARACTERIZING NC PRODUCT BOTTLES USING SPECTROPHOTOMETRY}

\subsection{GLOVEBOX SAMPLES}

The Np samples were from Campaign 5 (P5) material (reprocessed). A complete discussion of $\mathrm{Np}$ processing can be found in a 2020 ORNL report by DePaoli et al. ${ }^{1}$ In summary, irradiated campaign targets (designated $\mathrm{P} \#$ ) are dissolved in hot cells. Solvent extraction recovers the product $\mathrm{Pu}$ and reusable $\mathrm{Np}$, separating them from fission products. The reusable Np remains in a process tank and is feed adjusted to the necessary downstream processing parameters. When preparing to transfer material from the hot cell to the glovebox laboratories, a portion of the material is removed from the tank and treated with an NC column to remove ${ }^{233} \mathrm{~Pa}$, the inherent daughter product from ${ }^{237} \mathrm{~Np}$. Protactinium- 233 grows in continuously until it reaches secular equilibrium and contributes most of the worker dose associated with the plutonium-238 glovebox work.

The UV-VIS samples in this report were obtained from three different transfers, each associated with a designated column run (see Table 4.1). The column eluent collects in $1 \mathrm{~L}$ plastic bottles. Additional raffinates and rinses were collected before and after the bottles. 
Table 4.1. List of column runs and details regarding the sample transfers.

\begin{tabular}{|c|c|c|c|c|}
\hline Column run & Transfer date & $\begin{array}{l}\text { Total initial } \\
\text { volume } \\
\text { (L) }\end{array}$ & $\begin{array}{c}\text { Estimated transfer } \\
\text { qty. } \\
\text { (g) }\end{array}$ & $\begin{array}{c}\text { TAL analytical } \\
\text { transfer qty. } \\
\text { (g) }\end{array}$ \\
\hline P5NC9 & $05 / 03 / 21$ & 3 & 142.4 & 121.7 \\
\hline P5NC10 & $05 / 11 / 21$ & 4 & 175.0 & 150.4 \\
\hline P5NC11 & $05 / 17 / 21$ & 5 & 203.0 & 203.6 \\
\hline
\end{tabular}

The NC column will only remove ${ }^{233} \mathrm{~Pa}$ and not retain ${ }^{237} \mathrm{~Np}$ if the acidity of the solution is low $(\sim 0.5-0.6$ $\mathrm{N}$ ), and the concentration of the ${ }^{237} \mathrm{~Np}$ is $\sim 30-200 \mathrm{~g} / \mathrm{L}$. On the other hand, if the acidity is too high, Np retention decreases but $\mathrm{Th}$ and $\mathrm{Pu}$ retention also decreases due to competition with free acid. The apparent optimal concentrations of $\mathrm{Np}(\mathrm{V})$ and nitric acid in the feed is approximately $0.8 \mathrm{M}$ each. The concentration of $\mathrm{Np}$ varies between recycle runs and dissolved oxide. It would be reasonable to adjust a dissolved oxide solution to $\sim 175 \mathrm{~g} \mathrm{~Np} / \mathrm{L}$. This would simultaneously reduce the risk of low $\mathrm{Pa} / \mathrm{Pu}$ removal and minimize product bottle concentration adjustments. The recycle $\mathrm{NC}$ column run product bottles evaluated in this study are in the range of $30-50 \mathrm{~g} \mathrm{~Np} / \mathrm{L}$. The preferred MDD feed is low in ${ }^{233} \mathrm{~Pa}$, high in ${ }^{237} \mathrm{~Np}(\sim 150-180 \mathrm{~g} / \mathrm{L})$, and low in volume to limit MDD run time. The column run bottles should be consolidated before MDD. Therefore, repeatable, accurate, and rapid measurements in the ranges of $\sim 30-50 \mathrm{~g} \mathrm{~Np} / \mathrm{L}$ and $\sim 150-220 \mathrm{~g} / \mathrm{L}$ are the desired goal.

The product bottles for runs P5NC9, P5NC10, and P5NC11 were transferred to lab 209 where they were sampled and measured, then boiled down to consolidate for MDD. Samples were taken from each bottle for total alpha $(0.15 \mathrm{~mL}$ aliquot directly from the bottle and diluted in $2.0 \mathrm{~mL}$ of $0.5 \mathrm{M}$ acid $)$. Additional small $1 \mathrm{~mL}$ undiluted samples were moved from the boiling glovebox to the UV-VIS glovebox, measured, and put back into the bottles for consolidation.

For P5NC9 and P5NC10, a consolidated product sample was also measured, and the data retained. The discussion below focuses on implementing spectroscopy for timely glovebox analyses.

\subsection{NEPTUNIUM(V) SPECTRA AND COMPARISONS TO ANALYTICAL RESULTS}

An example $\mathrm{Np}(\mathrm{V})$ absorption spectrum collected on a P5NC10 sample is shown in Figure 4.1. This spectrum is composed nearly entirely of $\mathrm{Np}(\mathrm{V})$. The relatively small peak, which is close to the main $\mathrm{Np}(\mathrm{VI})$ peak at $1,222 \mathrm{~nm}$, is centered at $1,229 \mathrm{~nm}$ and is likely attributable to the water band. Regardless, even if this did correspond to $\mathrm{Np}(\mathrm{VI})$, it would account for $<1 \%$ of the measured $\mathrm{Np}$ concentration. Based on the literature, the highest concentration of $\mathrm{Np}$ that can be measured without any spectral contribution from dimer (cation-cation) species is $\sim 50 \mathrm{~g} \mathrm{~Np} / \mathrm{L} .{ }^{9}$ Thus, $\mathrm{Np}(\mathrm{V})$ spectra below this threshold are relatively straightforward to interpret and amenable to quantitative analysis without much data processing. A multivariate regression model could be used to calculate $\mathrm{Np}(\mathrm{V})$ and temperature based on the changing the band position as a function of both variables. 


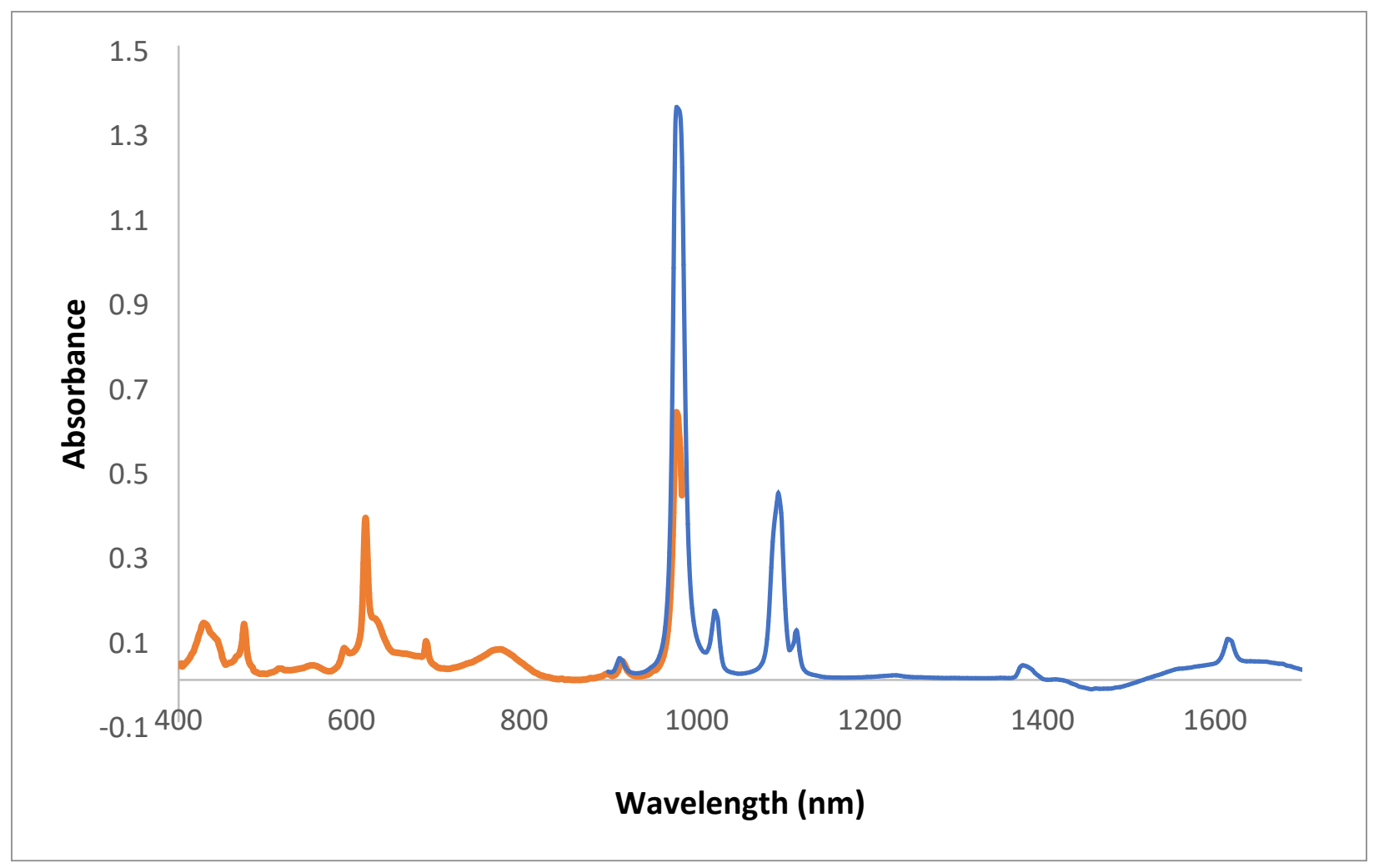

Figure 4.1. Vis (orange) and NIR (blue) absorption spectra of an undiluted P5NC10 sample.

The concentration of $\mathrm{Np}(\mathrm{V})$ in each $\mathrm{P} 5 \mathrm{NC}$, $\mathrm{P} 5 \mathrm{NC} 10$, and $\mathrm{P} 5 \mathrm{NC} 11$ sample (12 total) was calculated using Beer's law. The absorbance value of the $616 \mathrm{~nm}$ peak was divided by the pathlength $(0.1 \mathrm{~cm})$ and a molar absorptivity of $21.5 \mathrm{M}^{-1} \cdot \mathrm{cm}^{-1}$ after applying a baseline offset correction to each spectrum. The baseline correction adjusted the spectral offset by subtracting the minimum point in the spectrum (i.e., a point near $860 \mathrm{~nm}$ ) from each point in the spectrum. Because $\mathrm{Np}(\mathrm{V})$ was the only species present in each sample, the concentration of $\mathrm{Np}(\mathrm{V})$ was equal to the total $\mathrm{Np}$ concentration.

Table 4.2 lists the concentrations determined by absorption spectrophotometry compared to analytical results (alpha spectrometry) and the percent difference. The average percent difference for the three sample sets was 3.6\% (P5NC9), 1.2\% (P5NC10), and 2.6\% (P5NC11). The difference was largest for P5NC9 data because a fresh bottle was not used for the second or third samples (P5NC9-2 and P5NC9-3). Sample P5NC9-2 was potentially diluted by droplets of the first sample, which was at a lower concentration, resulting in a low measurement. Sample P5NC9-3 was potentially diluted by droplets of the second sample, which was at a higher concentration, resulting in a high measurement. This result demonstrates how sensitive this approach is to sample preparation, as is the case for any dependable analytical method. Overall, the concentration derived by optical spectroscopy and alpha spectroscopy were in good agreement. These measurements could be accomplished with spectroscopy in the hot cell if the appropriate sample introduction system is established. This topic is presented in Section 5. 
Table 4.2. P5NC9, P5NC10, and P5NC11 absorption measurements and analytical Np concentrations (g/L) with the percent difference.

\begin{tabular}{lccc}
\hline Bottle ID & $\begin{array}{c}\text { Absorption } \mathbf{N p} \\
(\mathbf{g} / \mathbf{L})\end{array}$ & $\begin{array}{c}\text { Analytical } \mathbf{~} \mathbf{p} \\
\mathbf{( g / \mathbf { L } )}\end{array}$ & $\begin{array}{c}\text { Difference } \\
\mathbf{( \% )}\end{array}$ \\
\hline P5NC9-1 & 30.76 & 30.84 & 0.26 \\
\hline P5NC9-2 & 45.41 & 49.01 & 7.35 \\
\hline P5NC9-3 & 43.17 & 41.85 & 3.15 \\
\hline P5NC10-1 & 20.03 & 20.38 & 1.69 \\
\hline P5NC10-2 & 42.14 & 42.41 & 0.62 \\
\hline P5NC10-3 & 46.36 & 46.81 & 0.96 \\
\hline P5NC10-4 & 40.12 & 40.75 & 1.56 \\
\hline P5NC11-1 & 29.1 & 29.74 & 2.3 \\
\hline P5NC11-2 & 43.4 & 45.16 & 3.9 \\
\hline P5NC11-3 & 43.9 & 42.96 & 2.3 \\
\hline P5NC11-4 & 43.7 & 45.16 & 3.2 \\
\hline P5NC11-5 & 41.1 & 40.63 & 1.3 \\
\hline
\end{tabular}

\subsection{MIXED NP(V/VI) SPECTRA AND COMPARISONS TO ANALYTICAL AND MATERIAL BALANCE}

A Vis-NIR spectrum collected on a diluted P5NC9 sample $(0.15 \mathrm{~mL}$ in a total of $2.15 \mathrm{~mL})$ using a $1 \mathrm{~cm}$ optical pathlength quartz cuvette is shown in Figure 4.2. The broad $N p(V)$ band at $765 \mathrm{~nm}$ and the $\mathrm{Np}(\mathrm{V})$ peak at $915 \mathrm{~nm}$ are fully resolved from $\mathrm{Np}(\mathrm{VI})$ and could be used for quantification with Beer's law in this instance, with prior knowledge of the temperature. The background for both peaks will not be affected by the absorption of water, which is sensitive to electrolyte concentration, $\mathrm{pH}$, and temperature, because water does not absorb NIR light until $\sim 960 \mathrm{~nm}$. Neptunium(VI) does not absorb light from $\sim 800$ to $1050 \mathrm{~nm}$ (see Figure 3.15 above). If a molar absorptivity of $39 \mathrm{M}^{-1} \cdot \mathrm{cm}^{-1}$ is applied to the $\mathrm{Np}(\mathrm{VI})$ peak at $1,222 \mathrm{~nm}$, and $4.5 \mathrm{M}^{-1} \cdot \mathrm{cm}^{-1}$ is used to determine the $\mathrm{Np}(\mathrm{V})$ concentration using the $765 \mathrm{~nm}$ band, then the concentration of total $\mathrm{Np}$ by spectrophotometry is $5.74 \mathrm{~g} / \mathrm{L}$. This measurement was in good agreement with the $5.73 \mathrm{~g} \mathrm{~Np} / \mathrm{L}$ concentration calculated by the analytical group using the alpha spectrometry. 


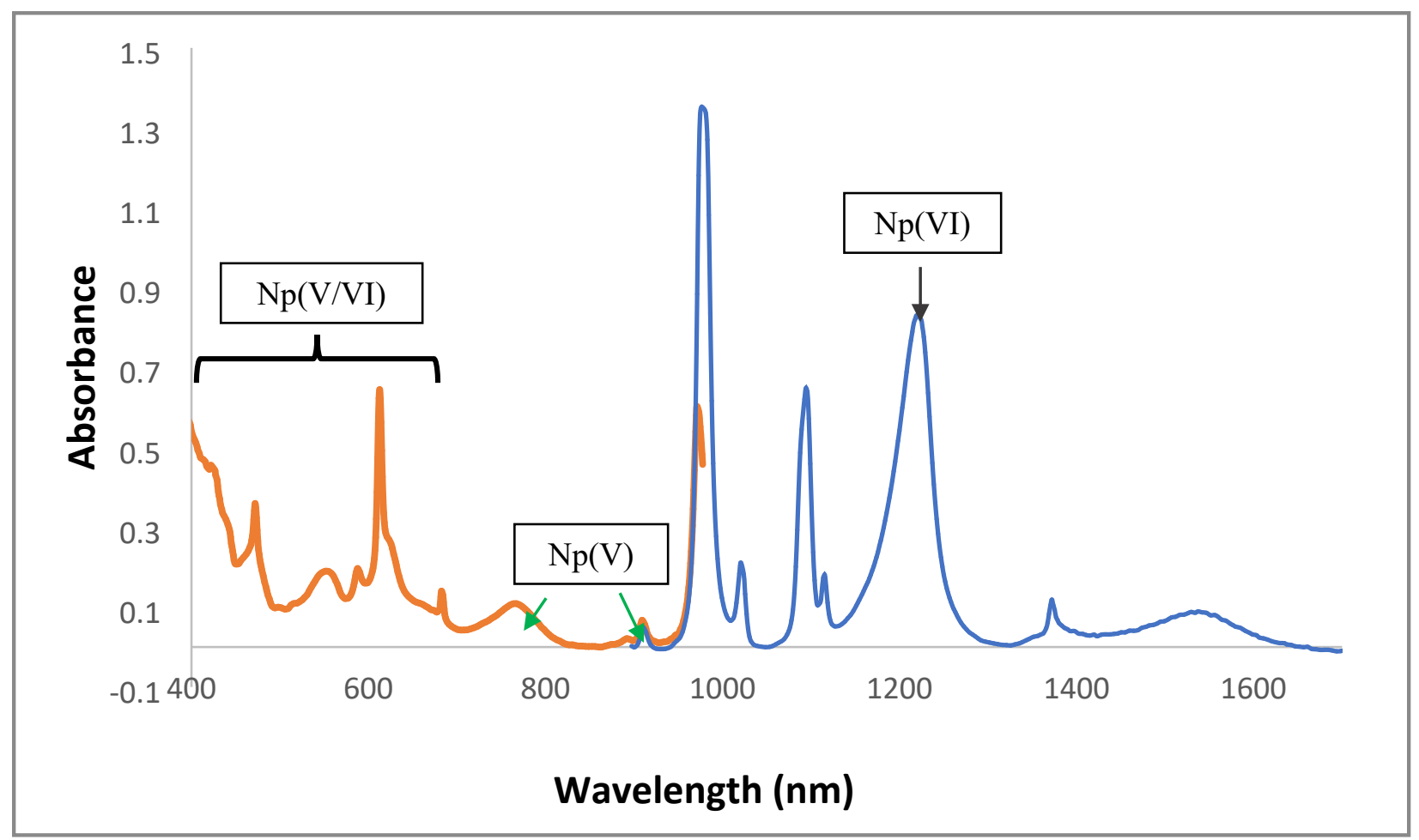

Figure 4.2. Vis (orange) and NIR (blue) absorption spectra of the diluted P5NC9 consolidated sample characterized by the analytical group. Used a $1 \mathrm{~cm}$ optical pathlength cuvette and blanked in water.

A Vis-NIR absorption spectrum was also collected on the P5NC9 sample before dilution using a flow cell with an optical pathlength of $1 \mathrm{~mm}$ (see Figure 4.3). Interesting spectral features were discovered in a solution with a concentration of $\sim 150 \mathrm{~g} \mathrm{~Np} / \mathrm{L}$. When the ratio of $\mathrm{Np}(\mathrm{V}): \mathrm{Np}(\mathrm{VI})$ was approximately $1: 1$, a significant shoulder to the $765 \mathrm{~nm}$ peak shifted to $\sim 790 \mathrm{~nm}$, and a new band appeared near $840 \mathrm{~nm}$. This shift and the presence of a new band cannot be attributed exclusively to $\mathrm{Np}(\mathrm{VI})$ because it does not absorb light in this region of the spectrum at a comparable concentration of $\sim 210 \mathrm{~g} \mathrm{~Np} / \mathrm{L}$ (see Figure 3.15). Additionally, the 1,615 $\mathrm{nm}$ peak appears to have split into two components; the new component appeared at $1605 \mathrm{~nm}$. These new spectral features seem to be dependent on total $\mathrm{Np}$ concentration. 


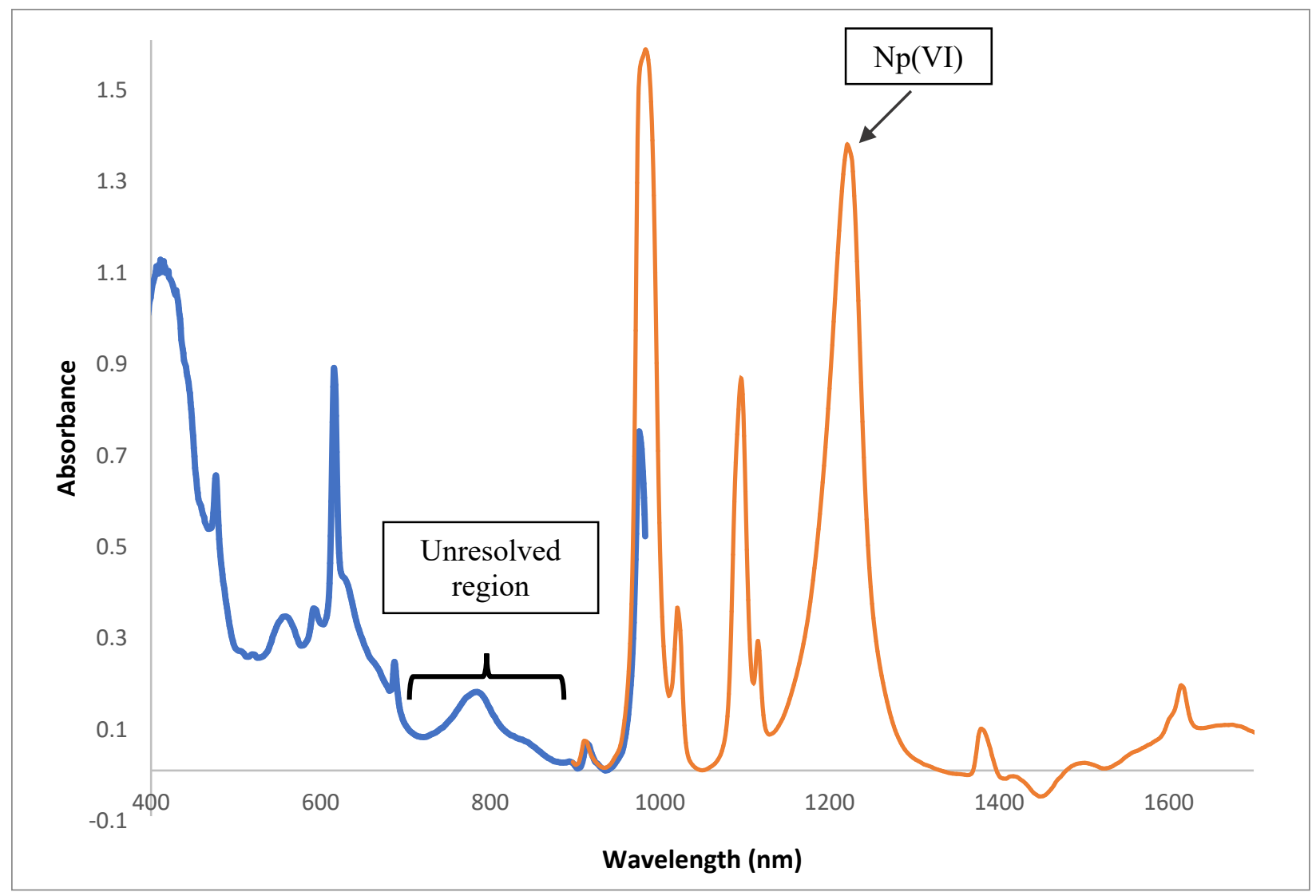

Figure 4.3 Vis (orange) and NIR (blue) absorption spectra of the undiluted P5NC9 consolidated sample. Used a $1 \mathrm{~mm}$ optical pathlength cuvette and blanked in water.

The concentration of $\mathrm{Np}(\mathrm{V})$ could not be determined using the $765 \mathrm{~nm}$ absorption band in this sample since it was distorted. The $1,096 \mathrm{~nm}$ peak was used instead because it appeared to be only slightly affected by the $\mathrm{Np}$ (VI) 1,222 $\mathrm{nm}$ absorption band. A baseline (spline) correction was applied to the $1,050-1,150 \mathrm{~nm}$ region of the spectrum. The $\mathrm{Np}(\mathrm{V})$ concentration was then calculated using an extinction coefficient of 26 for this band and 39 for the $\mathrm{Np}(\mathrm{VI})$ absorption band to arrive at a total $\mathrm{Np}$ concentration of $158 \mathrm{~g} \mathrm{~Np} / \mathrm{L}$ in this sample. The analytical group calculated a total Np concentration of either $154 \mathrm{~g}$ $\mathrm{Np} / \mathrm{L}$ based on the diluted P5NC9 consolidated sample, or $164 \mathrm{~g} \mathrm{~Np} / \mathrm{L}$ based on the material balance or sum of each product bottle. An additional Vis-NIR spectrum was acquired on the consolidated P5NC10 product bottle. The spectral features were very similar to the spectrum shown in Figure 4.3. A concentration of $169 \mathrm{~g} \mathrm{~Np} / \mathrm{L}$ was determined using spectrophotometry. This measurement differed from the analytical group numbers $(\sim 150 \mathrm{~g} \mathrm{~Np} / \mathrm{L}$ by material balance). Overall, the absorption concentrations for mixed $\mathrm{Np}(\mathrm{V} / \mathrm{VI})$ samples generally agreed with the analytical group; however, some work focused on the quantification of $\mathrm{Np}(\mathrm{VI})$ spectral signatures is required before implementation.

A training set comprising different $\mathrm{Np}(\mathrm{V} / \mathrm{VI})$ ratios must therefore be generated at total $\mathrm{Np}$ concentrations between 0.1 and $0.9 \mathrm{M}$. Spectroelectrochemistry is particularly suited for this task (see Section 3.5). Results from the study could pinpoint the concentration when these new $\mathrm{Np}$ spectral features appear and provide stepwise spectral data at nearly every $\mathrm{Np}(\mathrm{V} / \mathrm{VI})$ ratio while maintaining a constant total $\mathrm{Np}$ concentration. This study could also include reaction kinetics of the drift back to mixed-valent thermodynamic equilibria after imposing certain potentials. This work has great potential to be published in a peer-reviewed journal. 
One of the most promising regions of the spectrum for quantitative $\mathrm{Np}(\mathrm{V} / \mathrm{VI})$ measurements at high concentration is the $450-600 \mathrm{~nm}$ region. The molar absorptivity values for $\mathrm{Np}(\mathrm{V})$ and $\mathrm{Np}(\mathrm{VI})$ in this region both tend to fall between 3 and $8 \mathrm{M}^{-1} \cdot \mathrm{cm}^{-1}$. This region could be the most useful MDD solution if a pathlength of $<1 \mathrm{~mm}$ is not possible. At concentration up to $1 \mathrm{M} \mathrm{Np}$, the average absorbance value in a spectrum would be $\sim 0.5 \mathrm{AU}$. Additionally, both $\mathrm{Np}(\mathrm{V})$ and $\mathrm{Np}(\mathrm{VI})$ should have comparable contributions in the region, so neither species would be lost.

\section{SUMMARY AND MAJOR CONCLUSIONS}

\subsection{DISCUSSION}

Rapid quantification of concentrated $\mathrm{Np}$ in $\mathrm{HNO}_{3}$ solutions is necessary to improve $\mathrm{Np}$ processing efficiency, an ongoing process at REDC for the ${ }^{238} \mathrm{Pu}$ Supply Program. This work demonstrated that optical spectroscopy may be used for the timely quantification of $\mathrm{Np}$ and $\mathrm{HNO}_{3}$ concentrations in lab 109 and within the shielded hot cells at REDC without sample dilution or transfer. Accurate quantification of $\mathrm{Np}$ concentration to several significant figures (i.e., $\pm 2 \%$ ) without dilution is essential to maximize the impact of this effort.

Two spectroscopic options, UV-Vis-NIR and Raman spectroscopy, were tested on Np solutions at concentrations relevant to ${ }^{238} \mathrm{Pu}$ processing streams, and both exhibited great potential. Quantifying Np using either technique will be challenging but attainable. Both techniques may be used to complement and cross validate one another or may be used independently. Special attention has been given to UV-Vis-NIR spectrophotometry because it appears to be the most promising option.

UV-Vis-NIR absorption analysis will be the primary focus for continued development work. Transferring UV-Vis-NIR calibration models from the glovebox to the hot cell may be more straightforward than Raman because the spectra are essentially normalized when blanking the spectrometer. Technicians also have more experience with UV-Vis-NIR equipment. Quantification by simple univariate methods is possible with UV-Vis-NIR but less realistic with Raman spectroscopy. The program has also had more success implementing absorption spectrophotometry in the hot cell compared to Raman spectroscopy, and Raman spectroscopy requires laser safety precautions that can be challenging to implement.

Crossover UV-Vis-NIR absorption experiments revealed that molar absorptivity values change at high concentration. This may result from cation-cation interactions that are prevalent above $0.2 \mathrm{M} \mathrm{Np}$ concentrations. The $\mathrm{Np}(\mathrm{V}) 980 \mathrm{~nm}$ band and the $1022 \mathrm{~nm}$ peak are not likely to be used for quantitative analysis in these systems due to complications arising from the formation of $\mathrm{Np}$ cation-cation interactions. Most of the peaks in the rest of the spectrum are useable and follow Beer's law until concentration-dependent fluctuations occur at high $\mathrm{Np}$ concentration. These results indicate that using an extinction coefficient of $\sim 17.6$ for the $\mathrm{Np}(\mathrm{V}) 616 \mathrm{~nm}$ peak, instead of $\sim 22$, would be ideal for quantification at MDD-relevant concentrations using a pathlength of 0.1-1 $\mathrm{mm}$. It may be advantageous to use a 0.5 or $1 \mathrm{~mm}$ pathlength because $\mathrm{Np}(\mathrm{VI})$ is more easily detected and generally constitutes $\sim 4 \%$ of total $\mathrm{Np}$ at elevated $\mathrm{Np}$ concentrations.

\section{$5.2 \quad$ NEXT STEPS}

With a spectral library, univariate Beer's law and/or multivariate analysis (e.g., PLSR) approaches may be used to develop regression models that correlate spectral signatures to $\mathrm{Np}$ concentrations in real time.

Methodology developed in glovebox tests may be further tested on hot cell or lab 109 MDD samples of known pedigree in controlled experiments. Eventually, the methodology could be implemented for routine lab 109 measurements and ultimately in the hot cell. 
A spectral library with various $\mathrm{Np}$ concentrations $(0.4-0.9 \mathrm{M})$ and both $\mathrm{Np}(\mathrm{V} / \mathrm{VI})$ oxidation states in $\mathrm{HNO}_{3}$ concentrations $(0.5-1 \mathrm{M})$, corresponding to specific processing scenarios (e.g., NC and MDD feed adjustments), are being generated in glovebox experiments. An example MDD training set is shown in Table 5.1. The following training set will be generated by dissolving known quantitates of $\mathrm{NpO}_{2}\left(\mathrm{NO}_{3}\right)_{2} \cdot 6 \mathrm{H}_{2} \mathrm{O}$ in volumetric flasks. Masses will be recorded to determine the density of these solutions. Spectroelectrochemical measurements must be taken at each concentration to obtain a complete spectral data set at multiple $\mathrm{Np}(\mathrm{V}) / \mathrm{Np}(\mathrm{VI})$ ratios. Voltammetry measurements in solutions containing 20 $-200 \mathrm{~g} \mathrm{~Np} / \mathrm{L}$ will be performed in the potential range from -0.25 to $1.6 \mathrm{~V}$ (vs. $\mathrm{Ag} / \mathrm{AgCl}$ microelectrode and scan rates of $\left.10-1000 \mathrm{mV} \cdot \mathrm{s}^{-1}\right)$. Scan rates will be varied to determine diffusion coefficients by the Randles-Sevcik equation, and a Nernstian analysis will be used to determine the stoichiometry of electron transfer. Temperature effects $\left(10-50^{\circ} \mathrm{C}\right)$ must also be accounted for. 
Table 5.1. Training set concentration for MDD feed adjustments.

\begin{tabular}{ccc}
\hline Sample & Np (M) & HNO $_{\mathbf{3}}(\mathbf{M})$ \\
\hline 1 & 0.40 & 0.50 \\
\hline 2 & 0.65 & 0.75 \\
\hline 3 & 0.90 & 1.00 \\
\hline 4 & 0.40 & 0.50 \\
\hline 5 & 0.65 & 0.75 \\
\hline 6 & 0.90 & 1.00 \\
\hline 7 & 0.40 & 0.50 \\
\hline 8 & 0.65 & 0.75 \\
\hline 9 & 0.90 & 1.00 \\
\hline
\end{tabular}

The following lists several important items that will be addressed soon.

1. Study the effects of varying $\mathrm{HNO}_{3}$ concentration on the NIR water band region, characterize features using multivariate data analysis, and quantify detection limits.

2. Determine how to correct for instrument drift over time and how consistent the approach is from day to day.

3. Test the performance of the new Cary 6000i spectrophotometer and compare results to the Ocean Insight spectrometers.

4. Establish a validation/verification procedure (i.e., instrument performance checks).

5. Begin discussions about how to standardize the spectrophotometric approach such that it is approved for NMC\&A purposes.

6. Continue investigating the installation of new fiber optic cables in the hot cell. It would be advantageous to have several more pairs of fiber optic cables in the hot cell, and it appears that the periscope port will be the best option moving forward.

7. Consider adding fiber connections to a glovebox in lab 109.

8. Develop a sample introduction system for both hot cell and production glovebox applications.

Testing the new Cary $6000 \mathrm{i}$ spectrophotometer for $\mathrm{Np}$ measurements would also be beneficial. Some preliminary cold tests have already been carried out. The instrument was validated against several absorbance standards (neutral density filters), and the values were in excellent agreement (see Tables 5.2 and 5.3). The same tests were varied out using the FiberMate accessory, fiber optic cables, and a cuvette holder. Unfortunately, the results from this test were not on the same level of accuracy. This finding has been discussed with Agilent personnel and an in-person meeting is being set-up to evaluate this. Another useful feature of the Cary 6000i automatically aligns wavelength position every time it is turned on, which could help correct for instrumental drift over time. The instrument is more sophisticated than the Ocean Insight spectrometers currently being used, but its bulkiness could be a problem for use in a glove box setting or the control room. Testing is necessary to determine whether the increased capability will outweigh the cost of ownership, size, and complexity. 
Table 5.2. UV-Vis Cary neutral density filters.

\begin{tabular}{cccccc}
\hline Reference & $\mathbf{4 4 0} \mathbf{~ n m}$ & $\mathbf{4 6 5} \mathbf{~ n m}$ & $\mathbf{5 4 6 . 1} \mathbf{~ n m}$ & $\mathbf{5 9 0} \mathbf{n m}$ & $\mathbf{6 3 5} \mathbf{~ m}$ \\
\hline 37209 & 3.119 & 2.915 & 2.956 & 2.991 & 2.800 \\
\hline 38652 & 2.642 & 2.501 & 2.566 & 2.683 & 2.526 \\
\hline 37467 & 0.039 & 0.038 & 0.037 & 0.037 & 0.037 \\
\hline Measured & $\mathbf{4 4 0 . 4 1 8}$ & $\mathbf{4 6 5 . 3 1 4}$ & $\mathbf{5 4 6 . 2 2 6}$ & $\mathbf{5 9 0 . 5 7 2}$ & $\mathbf{6 3 4 . 9 1 8}$ \\
\hline D1 & 3.122 & 2.919 & 2.957 & 2.990 & 2.802 \\
\hline 38652 & 2.642 & 2.503 & 2.566 & 2.684 & 2.526 \\
\hline 37467 & 0.040 & 0.039 & 0.038 & 0.038 & 0.038 \\
\hline $\begin{array}{c}\text { Difference } \\
(\%)\end{array}$ & $\mathbf{4 4 0} \mathbf{n m}$ & $\mathbf{4 6 5} \mathbf{~ n m}$ & $\mathbf{5 4 6 . 1} \mathbf{~ n m}$ & $\mathbf{5 9 0} \mathbf{n m}$ & $\mathbf{6 3 5} \mathbf{~ m}$ \\
\hline 37209 & 0.109 & 0.136 & 0.029 & -0.030 & 0.074 \\
\hline 38652 & -0.003 & 0.093 & 0.019 & 0.050 & 0.035 \\
\hline 37467 & 3.391 & 3.402 & 3.144 & 3.699 & 4.005 \\
\hline
\end{tabular}

Table 5.3. UV-Vis-NIR Cary neutral density filter results.

\begin{tabular}{lcccccc}
\hline Reference & $\mathbf{3 6 0} \mathbf{~ n m}$ & $\mathbf{4 6 5} \mathbf{~ n m}$ & $\mathbf{5 4 6 . 1} \mathbf{~ n m}$ & $\mathbf{6 3 5} \mathbf{~ m}$ & $\mathbf{1 , 1 0 0} \mathbf{~ n m}$ & $\mathbf{1 7 , 0 0} \mathbf{~ n m}$ \\
\hline 88683 & 1.553 & 1.597 & 1.597 & 1.580 & 1.519 & 1.481 \\
\hline 73649 & 0.238 & 0.255 & 0.269 & 0.280 & 0.308 & 0.329 \\
\hline Measured & 360.284 & 465.314 & 546.226 & 634.9179688 & $1,100.162$ & 1,700 \\
\hline 88683 & 1.550 & 1.596 & 1.597 & 1.581 & 1.515 & 1.476 \\
\hline 73649 & 0.237 & 0.255 & 0.269 & 0.280 & 0.308 & 0.330 \\
\hline Difference (\%) & $\mathbf{3 6 0} \mathbf{~ n m}$ & $\mathbf{4 6 5} \mathbf{~ n m}$ & $\mathbf{5 4 6 . 1} \mathbf{~ n m}$ & $\mathbf{6 3 5} \mathbf{~ m m}$ & $\mathbf{1 , 1 0 0} \mathbf{~ n m}$ & $\mathbf{1 , 7 0 0} \mathbf{~ n m}$ \\
\hline 88683 & -0.186 & -0.056 & -0.009 & 0.079 & -0.258 & -0.323 \\
\hline 73649 & -0.298 & 0.028 & -0.073 & 0.169 & 0.038 & 0.200 \\
\hline
\end{tabular}

A syringe and flow cell design like the one currently being used for research and development could be used in lab 109. However, the approach is too delicate for a robust, routine operation. Another option could include using a programmable FMI pump (see Figure 5.1) or any small volume FMI pump, which could be used to flow specific volumes of solutions and predefined rates in and out of flow cuvettes that are placed in a cuvette holder. The FMI pump requires electrical power, and this model also requires a USB port for connection to a computer. 


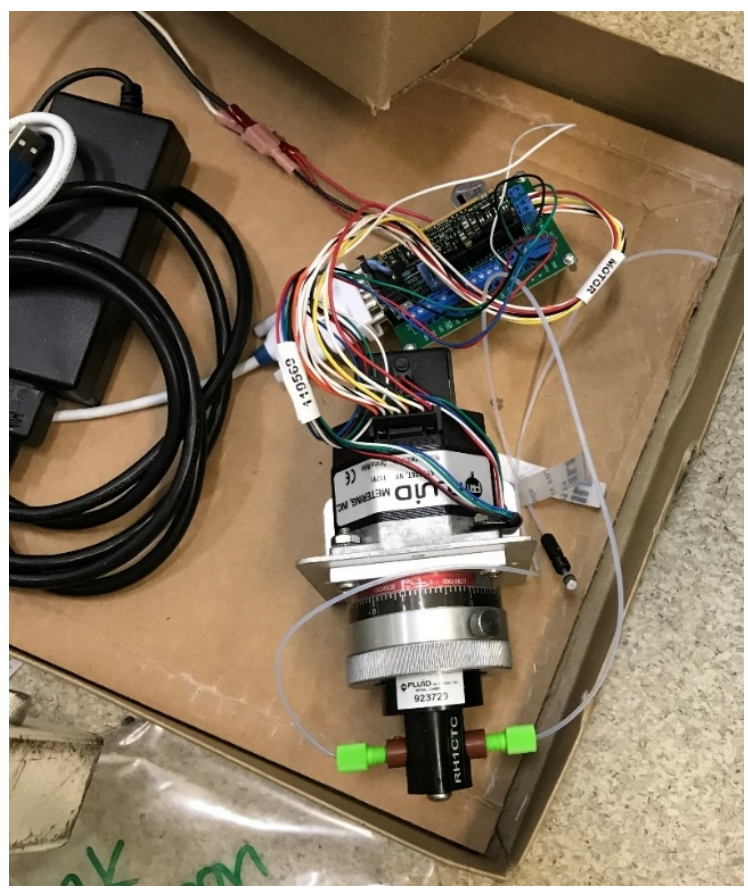

Figure 5.11. Programmable FMI pump.

Another option is shown in Figure 5.2. In this design, a metal syringe is used to bring rinse/blank/sample solution into the cell. Samples could be placed in vacutainers on a tray that can move up and down. The added green portion is designed to hold the entire sample volume so that the solutions do not get caught in the syringe or any hard-to-rinse nooks or crevices. Two in-line Swagelok flow cells were custom made by Spectra Solution Inc. and will be delivered soon. These flow cells have 1/16 in. tubing and a $1.2 \mathrm{~mm}$ optical pathlength. This concept could be applied in both a glovebox and hot cell setting. A stopper still needs to be designed to ensure that the plunger cannot be removed from the syringe. This apparatus could ideally be mounted on a rack in a hot cell cubicle. Other flow cell options are available but do not employ a robust Swagelok design. A syringe could also be used to introduce samples into the cell and expel samples from the cell with other flow cuvettes. 


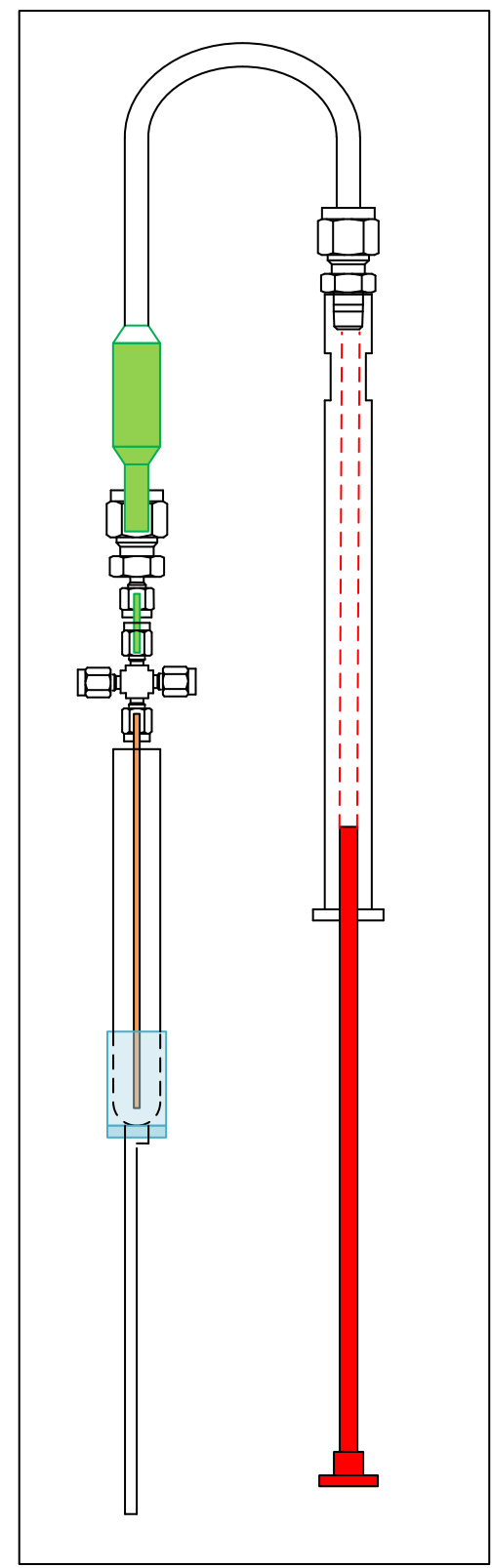

Figure 5.2. Sample introduction system concept for hot cell and glovebox operations.

\subsection{CONCLUSIONS}

Spectrophotometric measurements for quantifying $\mathrm{Np}$ and $\mathrm{HNO}_{3}$ concentration in multiple processing solutions for the ${ }^{238} \mathrm{Pu}$ Supply Program are very promising. The accomplishments outlined in this report clearly demonstrated proof-of-principle and indicate the benefit of continued testing. The findings revealed specific areas for additional testing. Clear steps were outlined to advance this capability in a way that will close the gap between research and development and a robust production-oriented application. 


\section{REFERENCES}

[1] David W. DePaoli, Steven R. Sherman, Jessica A. Hobby, Riley D. Hunley, Jon R. Garrison, Kaara K. Patton, Porter D. Bailey, Frank D. Riley Jr., Chris L. Jensen. 2021. Plutonium-238 Supply Program: Maturity Assessment at 2019 Year End. ORNL/TM-2020/1520. Oak Ridge National Laboratory, Oak Ridge, TN.

[2] Sadergaski, L. R.; Myhre, K. G.; Delmau, L. H.; DePaoli, D. W.; Wham, R. M. 2021. Status of Spectroscopy and Online Monitoring for the Plutonium-238 Supply Program. ORNL/TM2021/1922. Oak Ridge National Laboratory, Oak Ridge, TN.

[3] Sadergaski, L. R.; Steven S. S. S.; Delmau, L. H.; DePaoli, D. W. 2021. Monitoring Radiochemical Processing Streams for the ${ }^{238} \mathrm{Pu}$ Supply Program with Process Pulse II. ORNL/TM-2021/3. Oak Ridge National Laboratory, Oak Ridge, TN.

[4] Ikeda-Ohno, A.; Hennig, C.; Rossberg, A.; Funke, H.; Scheinost, A. C.; Bernhard, G.; Yaita, T. Electrochemical and Complexation Behavior of Neptunium in Aqueous Perchlorate and Nitrate Solutions. Inorg. Chem. 2008, 47, 8294-8305.

[5] Chatterjee, S.; Bryan, S. A.; Casella, A. J.; Peterson, J. M.; Levitskaia, T. G. Mechanisms of Neptunium Redox Reactions in Nitric Acid Solutions. Inorg. Chem. Front. 2017, 4, 581-594.

[6] Sjoblom, R.; Hindman, J. C. Spectrophotometry of Neptunium in Perchloric Acid Solutions. J. Am. Chem. Soc. 1951, 73 (4), 1744-1751.

[7] Freidman, H. A.; Toth, L. M. Absorption Spectra of Np(III), (IV), (V) and (VI) in Nitric Acid Solution. J. Inorg. Nucl. Chem. 1980, 42, 1347-1349.

[8] Chatterjee, S.; Bryan, S. A.; Casella, A. J.; Peterson, J. M.; Levitskaia, T. G. Mechanisms of Neptunium Redox Reactions in nitric acid solutions. Inorg. Chem. Front. 2017, 4, 581-594.

[9] Guillaume, B.; Begun, G. M.; Hahn, R. L. Raman spectrometric studies of "cation-cation" complexes of pentavalent actinides in aqueous perchlorate solutions. Inorg. Chem. 1982, 21 (3), $1159-1166$.

[10] Madic, C.; Guillaume, B.; Morisseau, J. C.; Moulin, J. P. "Cation-Cation" Complexes of Pentavalent Actinides - I. J. Inorg. Nucl. Chem. 1979, 41, 1027-1031.

[11] Auwer, C. D.; Gregoire-Kappenstein, A. C.; Moisy, Ph. Np(V) cation-cation interactions. A new contribution from EXAFS spectroscopy? Radiochim. Acta 2003, 91, 773-776.

[12] Maiwald, M. M.; Sittel, T.; Fellhauer, D.; Skerencak-Frech, A.; Panak, P. J. Thermodynamics of neptunium(V) complexation with sulfate in aqueous solution. J. Chem. Thermodynamics 2018, $116,309-315$.

[13] Ban, Y.; Hakamatsuka, Y.; Tsutsui, N.; Urabe, S.; Hagiya, H. Matsumura, T. Spectroscopic study of $\mathrm{Np}(\mathrm{V})$ oxidation to $\mathrm{Np}(\mathrm{VI})$ in $3 \mathrm{~mol} / \mathrm{dm}^{3}$ nitric acid at elevated temperatures. Radiochim. Acta 2014, 102 (9), 775-780.

[14] Edelstein, N. M. Reanalysis of the Aqueous Spectrum of the Neptunyl(V) $\left[\mathrm{NpO}_{2}^{+}\right]$Ion. J. Phys. Chem. A 2015, 119, 11146-11153.

[15] Matsika, S.; Pitzer, R. M.; Reed, D. T. Intensities in the Spectra of Actinyl Ions. J. Phys. Chem. A. 2000, 104, 11983-11992.

[16] Bryan S. A.; Levitskaia, T. G.; Johnsen, A. M.; Orton, C. R.; Peterson, J. M. Spectroscopic Monitoring of Spent Nuclear Fuel Reprocessing Streams: An Evaluation of Spent Fuel Solutions via Raman, Visible, and Near-Infrared Spectroscopy. Radiochimica Acta 2011, 99 (9), 563-571. 
[17] Luke R. Sadergaski, L. R.; Toney, G. K.; Delmau, L. H.; Myhre, K. G. Chemometrics and Experimental Design for the Quantification of Nitrate Salts in Nitric Acid: Near-Infrared Spectroscopy Absorption Analysis. Appl. Spectrosc. 2021, published online.

[18] Sadergaski, L. R.; David W. D. W.; Myhre, K. G. Monitoring the Caustic Dissolution of Aluminum Alloy in a Radiochemical Hot Cell Using Raman Spectroscopy. Appl. Spectrosc. 2020, 74 (10), 1252-1262.

[19] Steinbach, D. S.; Anderson, C. A.; McGeorge, G; Igne, B. Calibration Transfer of Quantitative Transmission Raman PLS Model: Direct Transfer versus Global Modeling. 2017, 12, 347-356.

[20] Galvao, R. K. H.; Soares, S. F. C.; Martins, M. N.; Pimentel, M. F.; Araujo, M. C. U. Calibration Transfer Employing Univariate Correction and Robust Regression. Anal. Chim. Acta. 2015, 864, $1-8$.

[21] Pelletier, M. J. Quantitative Analysis Using Raman Spectrometry. Appl. Spectrosc. 2003, 57 (1), $20-42$.

[22] Uriarte, L. M.; Bonales, L. J.; Dubessy, J.; Lobato, A.; Baonza, V. G.; Caceres, M. The selfabsorption phenomenon in quantitative Raman spectroscopy and how to correct its effects. Microchem. J. 2018, 139, 134-138.

[23] Casella, A.; Lines, A.; Nelson, G. Bello, J.; Bryan, S. MicroRaman Measurements for Nuclear Fuel Reprocessing applications. Procedia Chem. 2016, 21, 466-472.

[24] Tochiyama, O.; Nakamura, Y.; Hirota, M.; Inoue, Y. Kinetics of Nitrous Acid-Catalyzed Oxidation of Neptunium in Nitric Acid-TBP Extraction System. J. Nucl. Sci. Tech. 1995, 32 (2), 118-124.

[25] Ianoul, A.; Coleman, T.; Asher, S. A. UV Resonance Raman Spectroscopic Detection of Nitrate and Nitrite in Wastewater Treatment processes. Anal. Chem. 2002, 74 (6), 1458-1461.

[26] Segtnan, V. H.; Sasic, S.; Isaksson, T.; Ozaki, Y. Studies on the Structure of Water Using TwoDimensional Near-Infrared Correlation Spectroscopy and Principal Component Analysis. Anal. Chem. 2001. 73(13): 3153-3161.

[27] Chang, K.; Shinzawa, H.; Chung, H. Concentration Determination of Inorganic Acids that Do Not Absorb Near-Infrared (NIR) Radiation through Recognizing Perturbed NIR Water Bands by them and Investigation of Accuracy Dependency on Their Acidities. Microchem. J. 2018, 139, 443-449.

[28] Lin, J.; Brown, C. W. Near-IR Spectroscopic Measurement of Seawater Salinity. Environ. Sci. Technol. 1993, 27 (8), 1611-1615.

[29] Lascola, R.; O’Rourke, P. E.; Kyser, E. A. A Piecewise Local Partial Least Squares (PLS) Method for the Quantitative Analysis of Plutonium Nitrate Solutions. Appl. Spectrosc. 2017, 71(12), 25792594.

[30] Maiwald, M. M.; Sittel, T.; Fellhauer, D.; Skerencak-Frech, A.; Panak, P. J. Thermodynamics of neptunium(V) complexation with sulfate in aqueous solution. J. Chem. Thermodynamics 2018, $116,309-315$.

[31] Topin, B. S.; Aupiais, J.; Baglan, N. Determination of the stability constants of nitrate complexes of $\mathrm{Np}(\mathrm{V})$ and $\mathrm{Pu}(\mathrm{V})$ using CE-ICP-MS. Radiochim. Acta 2010, 98, 71-75.

[32] Owen, A. J. Uses of Derivative Spectroscopy. Application Note by Agilent Technologies. 1995.

[33] Eisenstein, J. C.; Pryce, M. H. L. Interpretation of the Solution Absorption Spectra of the $\left(\mathrm{PuO}_{2}\right)^{+2}$ and $\left(\mathrm{NpO}_{2}\right)^{+}$Ions. J. Res. Natl. Bur. Stand., Sect. A 1966, 70A, 165.

[34] Elgrishi, N.; Rountree, K. J.; McCarthy, B. D.; Rountree, E. S.; Eisenhart, T. T.; Dempsey, J. L. A Practical Beginner's Guide to Cyclic Voltammetry. J. Chem. Educ. 2018, 95 (2), 197-206. 
